\title{
INTERNATIONAL RADIO BROADCASTING AND POST-CONFLICT STATE-BUILDING: THE CASE OF CANADA'S RANA FM
}

\author{
by

\begin{abstract}
David T. Harmes
Bachelor of Applied Arts, Ryerson University, 1995

Master of Arts, Concordia University, 2000
\end{abstract}

\begin{abstract}
A dissertation
presented to Ryerson \& York Universities

in partial fulfillment of the requirements for the degree of

Doctorate of Philosophy

in the Joint Graduate Program in Communication \& Culture

Toronto, Ontario, Canada, 2012
\end{abstract}

(C) David T. Harmes 2012 


\section{- DECLARATION -}

I hereby declare that I am the sole author of this dissertation.

I authorize Ryerson University to lend this dissertation to other institutions or individuals for the purpose of scholarly research.

I further authorize Ryerson University to reproduce this dissertation by photocopying or by other means, in total or in part, at the request of other institutions or individuals for the purpose of scholarly research. 


\title{
- ABSTRACT -
}

\section{INTERNATIONAL RADIO BROADCASTING AND POST-CONFLICT STATE- BUILDING: THE CASE OF CANADA'S RANA FM}

\author{
David T. Harmes \\ Doctorate of Philosophy in the Ryerson \& York Universities \\ Joint Graduate Program in Communication \& Culture \\ Toronto, Ontario, Canada, 2012
}

International Radio Broadcasting (IRB) has been used as a mass communication tool of the state since its inception in the early 1920s. Following its historic use in programs of propaganda, public diplomacy, psychological operations, and international development communication, the practice of IRB can also be found in a number of post-conflict statebuilding operations that are not well documented. Through a case study methodology this dissertation examines the nature of, and motivation for, the use of IRB in post-conflict state-building, as experienced by Canada's Rana FM in contemporary Afghanistan (2006 - 2011). Using primary research from structured interviews with IRB practitioners and personal observation of IRB operations in Bosnia-Herzegovina, Kosovo and Afghanistan, this study draws on information from directing staff, management, producers, on-air presenters, and technical staff; as well as a variety of sources including internal content analyses, opinion polling, and unclassified government documents. Using the strategic communication frameworks of propaganda and development communication, this study found IRBs to function as a form of 'defensive propaganda' that aims to reinforce the institutions of the developing state during the process of democratic reconstruction. IRBs in post-conflict state-building can be seen to function in a surrogate capacity that aims to become a creditable source of news and information, in order to maximize audience share and provide a platform for public discussion. This dissertation presents new empirical information on Canada's IRB in Afghanistan, Rana FM, which operated from January 2007 to July 2011. 
LIST OF FIGURES

p. viii

CHAPTER 1:

\section{INTRODUCTION}

Background p. 1

Aim and Scope of Research p. 2

Definitions if IRB $\quad$ p. 11

Functionalist Approaches to IRB p. 13

A Strategic Communication Approach to IRB p. 16

Methodology p. 19

Organization of Dissertation $\quad$ p. 22

CHAPTER 2:

THE DEBATE OVER POST CONFLICT STATE-BUILDING

Introduction p. 24

Political Order and State-Building Strategies $\quad$ p. 27

Critical Perspectives on State-Building p. 29

Civil Society and Post-Conflict State-Building p. 35

Dialectical Modernization Theory p. 38

A Community-Based Approach p. 40

Democratic Reconstruction Model p. 43

Criticism of Democratic Reconstruction Practice p. 46

$\begin{array}{ll}\text { Summary } & \text { p. } 50\end{array}$

CHAPTER 3:

THE DEBATE OVER INTERNATIONAL RADIO BROADCASTING

Introduction p. 53

History of IRB $\quad$ p. 54

$\begin{array}{ll}\text { Propaganda Theory } & \text { p. } 59\end{array}$

Public Diplomacy p. 69

Development Communication p. 74

Dominant Paradigm of Development Communication Research p. 76

Criticism of the Development Communication Approach p. 82

Strategic Communication and Development $\quad$ p. 85

$\begin{array}{ll}\text { Summary } & \text { p. } 90\end{array}$ 


\section{CHAPTER 4:}

\section{IRB \& STATE-BUILDING IN AFGHANISTAN}

$\begin{array}{lr}\text { Introduction } & \text { p. } 97\end{array}$

$\begin{array}{ll}\text { Afghanistan in Context } & \text { p. } 99\end{array}$

$\begin{array}{ll}\text { State-Building in Afghanistan p. } 103 & \text { p. }\end{array}$

The Battle for Hearts and Minds p. 108

Case Study: Rana FM p. 110

Technical Delivery p. 112

Structure and Organization p. 114

Programming Concept and Design p. 121

News Selection Process p. 126

Broadcast Analysis p. 132

Talk Radio and Call-in Shows p. 133

Summary

p. 135

\section{CHAPTER 5:}

\section{THEORIZING IRB IN AFGHANISTAN AND BEYOND}

Introduction

p. 138

Summary of Theoretical Frameworks

p. 140

Summary of Findings

p. 143

Comparison with other models of IRB

p. 146

Analysis and Conclusions

p. 151

Motivations for Use of IRB

p. 155

Implications of Research

p. 158

Limitations

p. 160

Conclusions

p. 161

Further Research

p. 163

ANNEX A: Pillars of the Afghanistan National Development Strategy p. 165

ANNEX B: United Nations Security Council Resolution 1386

p. 166

ANNEX C: Agreement on Provisional Arrangements in Afghanistan Pending the ReEstablishment of Permanent Government Institutions (Bonn Agreement) p. 168

ANNEX D: General Research Information p. 176

$\begin{array}{ll}\text { ANNEX E: Research Interview Guide p. } 178 & \text { p }\end{array}$

$\begin{array}{ll}\text { REFERENCES } & \text { p. } 179\end{array}$ 


\section{- LIST OF ABBREVIATIONS -}

ACSOR

AFG

ATA

BBC

BBG

CEFCOM

CENTCOM

CEP

CSO

DDR

DRC

DRM

DSB

GIRoA

IC

IRB

IRBs

ISAF

JAM

MERN

MoE

MoP
Afghan Center for Socio-Economic and Opinion Research

Afghanistan

Afghanistan Transitional Administration

British Broadcasting Corporation (UK)

Broadcasting Board of Governors (US)

Canadian Expeditionary Force Command (Canada)

Central Command (US)

Community Empowerment and Local Governance Project

Civil Society Organization

Disarmament, Demobilization \& Reintegration

Democratic Republic of Congo

Democratic Reconstruction Model

Defense Science Board (US)

Government of the Islamic Republic of Afghanistan

International Community

International Radio Broadcasting

International Radio Broadcasters

International Security Assistance Force

Joint Assistance Mission

Middle East Radio Network

Measures of Effectiveness

Measures of Performance 


\begin{tabular}{ll} 
NATO & North Atlantic Treaty Organization \\
NGO & Non-Governmental Organization \\
NWICO & New World Information and Communication Order \\
PSO & Post Conflict Peace Building \\
PWGSC & Peace Support Operations \\
R2P & Public Works and Government Services Canada \\
SACEUR & Responsibility to Protect \\
SRSG & Supreme Allied Command Europe \\
TCN & Special Representative of the Secretary-General \\
UN & Troop Contributing Nation \\
UNAMA & United Nations \\
UNDP & United Nations Assistance Mission in Afghanistan \\
UNESCO & United Nations Development Programme \\
UNTAET & United Nations Educational, Scientific and Cultural Organization \\
UNSCR & United Nations Transitional Administration for East Timor \\
UNGAR & United Nations Security Council Resolution \\
VOA & United Nations General Assembly Resolution \\
WoG & Voice of America \\
\hline Whole of Government
\end{tabular}




\section{- LIST OF FIGURES -}

$\begin{array}{lll}\text { Figure 1. Taxonomy of Theoretical Frameworks } & \text { p. } 3\end{array}$

Figure 2. Strategic Communication Model p. 18

$\begin{array}{ll}\text { Figure 3. Geo-Political Map of Afghanistan } & \text { p. } 98\end{array}$

Figure 4. Ethnic Distribution Map of Afghanistan p. 99

Figure 5. Language Distribution Map of Afghanistan p. 101

$\begin{array}{lll}\text { Figure 6. } & \text { EuTel Satellite Coverage Map } 112\end{array}$

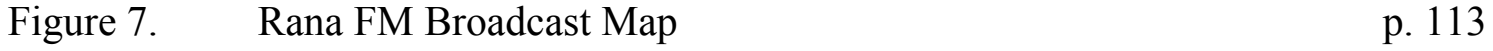

Figure 8. News Balance by Mission Framework p. 130

Figure 9. News Balance by Political Framework p. 130

Figure 10. News Balance by Social Framework p. 131

Figure 11. Word Picture of Rana FM Headlines p. 132

Figure 12. Rana FM Broadcast Map p. 145

Figure 13. Radio Oksigen Broadcast Map (Bosnia-Herzegovina) p. 148

Figure 14. Radio K4 Broadcast Map (Kosovo) p. 149

Figure 15. Radio Free Afghanistan Network Map p. 156

$\begin{array}{lll}\text { Figure 16. Afghanistan Casualty Map } & \text { p. } 157\end{array}$ 


\section{- CHAPTER ONE-}

\section{Introduction}

Since the end of the Cold War, international radio broadcasting (IRB) has been used with increased frequency in programs of post-conflict reconstruction and development (Price 2002). From Bosnia-Herzegovina, to Kosovo, to Afghanistan, IRB has become a regular feature of multi-national state-building operations, and continues to be employed in such

programs today (Canadian Press 2007). Despite the almost 20 years of use in this context, surprisingly little is known about the role of IRB in post-conflict development generally, or that of state-building operations more specifically.

Theorizing the role of IRB in post-conflict state-building is refracted through the larger and separate debates, including those between liberal and critical scholars, over the nature of north-south relations, post-conflict state-building, and the role of international radio broadcasting. In the former cases, liberal scholars view north-south relations and post-conflict state-building in positive-sum, modernist terms, where the north (or west) is seen to be motivated by the values of democracy and human rights promotion (McFaul 2004; Wesley 2008). Critical scholars, in contrast, view north-south relations and postconflict state-building as being motivated by a form of self-interested imperialism which is seen to benefit the north at the expense of the south (Rubin 2006).

Drawing on similar assumptions, liberal theorists of IRB (Price 2002; Heil 2003) have tended to view such media in altruistic terms, with programming that is informed by democratic values and the principles of popular participation. Critical media scholars, on the other hand, have tended to view such uses of IRB as 'propagandistic' in nature (Snow 
\& Taylor 2006; Sussman 2010), or a form of cultural imperialism more broadly (Schiller 1991; Barker 2008). It should be noted here that the term 'propaganda' is a contested one. Critical scholars have tended to use the term propaganda to describe a neutral process for the dissemination of ideas, whereas liberal theorists reserve it for describing adversarial information with a connotation of being inaccurate, incomplete, or 'untrue' information.

Reflecting the rising use of IRB in post-conflict state-building, as set within these broader theoretical debates, the purpose of this dissertation is to examine the nature of, and motivation for, international radio broadcasting in contemporary Afghanistan. In doing so, it argues that IRB in Afghanistan reflects the 'defensive' self-interests of the coalition countries, with democracy promotion being viewed as a means to realize these interests rather than as an end in itself. This is to say, while the democratic reconstruction of Afghanistan may be the model preferred by the coalition countries for reinforcing the Afghan state, it is not the only model available, nor the state-building objective itself. In practical terms, this motivation manifests itself in an approach to broadcasting that can be best characterized as 'defensive propaganda' that works to reinforce the institutions of the developing state during the process of democratic reconstruction

\section{Aim and Scope of Research}

The dissertation begins by reviewing the broader theoretical debates over post-conflict state-building and international radio broadcasting. Viewed in a four-quadrant taxonomy (Figure 1 below), the primary theoretical positions informing this research can be divided into four distinct groups: theories related to state-building and development, and theories related to media and communication, each with their own liberal and critical variants. 


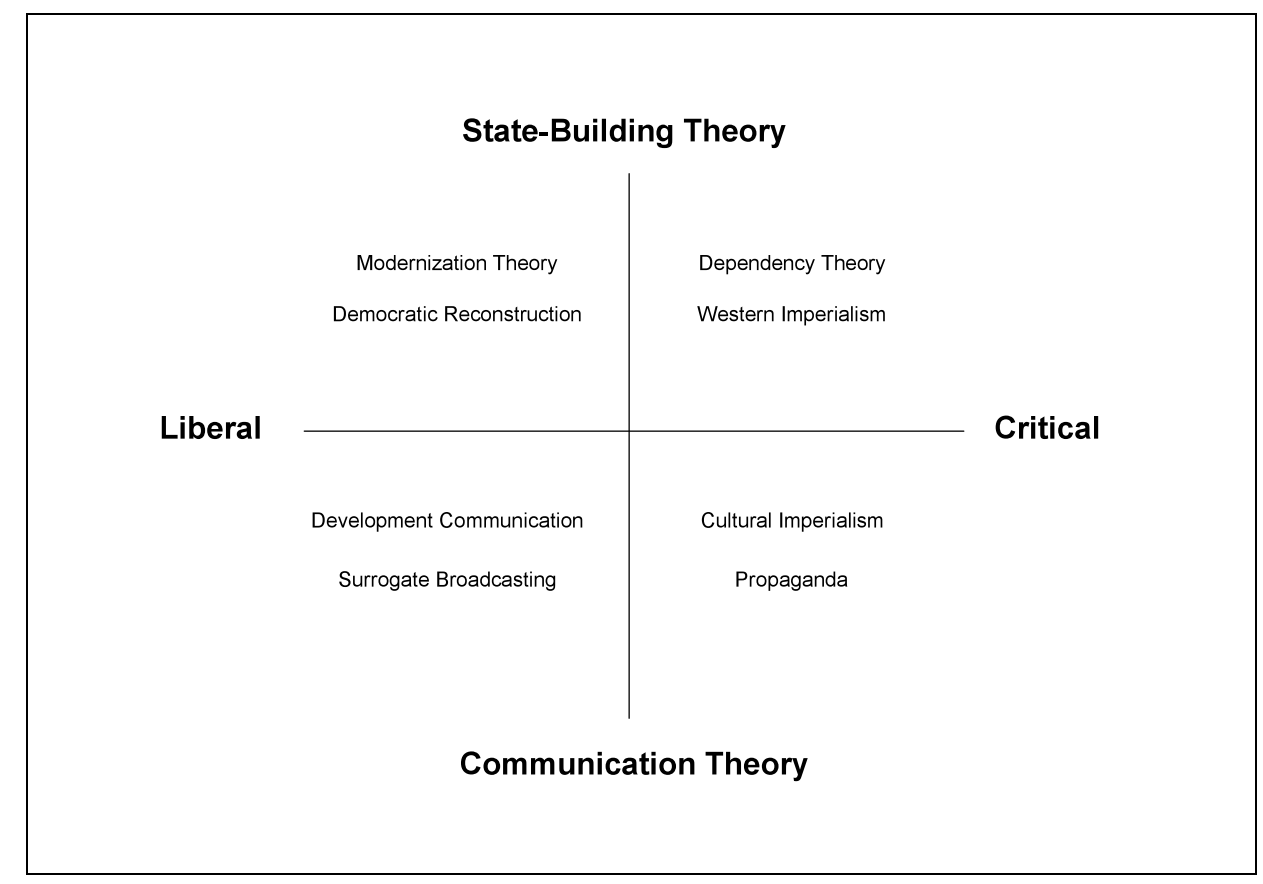

Figure 1. Taxonomy of Theoretical Frameworks (Source: Author)

The liberal approach to state-building is commonly understood as a contemporary form of modernization theory where assumptions about social, political, and economic progress underpin a broader international development agenda, as generally follows the same historical trajectory of development as Western Europe and North America (Suhrke 2007). Following the Second World War, such modernization theories can be seen in the early development strategies of both colonial and post-colonial states where 'national' or 'state' institutions were built to encourage the formation of a national identity supplanting those of local or ethnic origin (Kolsto 2000). Development theorist John Martinussen (1997) described this modernization process as a mutually reinforcing set of sequences that include economic growth, social and political stability, as well as some form of national integration and democratization programs. Such model programs offered little 
distinction between the political systems of Africa, Asia, or Latin America, as any

existing social structures were assumed to go through similar processes of transformation.

He explained that:

It was recognized, though, that considerable differences existed among the developing countries, but these variations were not assigned central importance in theory construction because all systems were expected to undergo a common process of change where the different traditions would be destroyed and replaced by institutions and structures similar to those found in the modern and highly industrialized societies (Martinussen 1997: 168).

While this early body of theory has been criticized as being overly dualistic in contrasting the concepts of 'traditional' and 'undeveloped' with those of 'modern' and 'developed', it nonetheless set the foundations for a generation of development research (Martinussen 1997). By the mid-1970s however, classical modernization theory came under attack for its "value-loaded, positive attitude toward the political systems of the USA and other highly industrialized North-Western societies" (Martinussen 1997: 167); as well as a failure to account for other forms of ethnic or cultural diversity (Connor 1972; McPhail 2009). Following such criticism, this dominant paradigm went through a rhetorical shift from its use of 'modernization' to the emerging concepts of 'democracy promotion' and 'democratic reconstruction' (Barker 2008). Its main contribution however, was to define the four central problems of political development that continue to define the field today: state-building; nation-building; civic participation; and the allocation of resources.

The concept of state-building itself, used in this study, has received considerable attention since the end of the Cold War (Vidal 2003: 1). International interventions such as those seen in Cambodia (1993); Bosnia-Herzegovina (1995); the Democratic Republic of the Congo (1997); East Timor (1998); Kosovo (1999); and Afghanistan (2002) have, at 
different times, occupied the attention of the international community with the objective of stabilizing failed or fragile states as the dominant model for international intervention (Ottaway 2003). While the success of international state-building remains the subject of considerable debate (Sedra 2002, 2004; Whaites 2008), the specific model of 'democratic reconstruction' in use today can be understood as the dominant strategy for post-conflict reconstruction and development since the end of the Cold War (Ottaway 2003).

As codified by Marina Ottaway (2003), the Democratic Reconstruction Model (DRM) is comprised of two central components, security sector reform and democratic development, that are implemented according to a relatively specific timeline that spans approximately ten years. The process begins with a negotiated settlement to the conflict (or some form of accommodation with internationally recognized domestic authorities), followed by a national conference of all major domestic groups to help determine the structure of the political system - with a view to holding national elections within two years. Security sector reform includes: the demobilization of former combatants, the formation of a new national army, constabulary police services, and the development of civilian oversight institutions. Strategies for this 'state-based' type of development range from the basic requirements of developing a national constitution, enactment of electoral law, and multiparty elections; to broader programs that recognize the need to reinforce democratic institutions, help to foster a vibrant civil society, and promote a media system free from political influence (Ottaway 2002; Junne \& Verkoren 2005). In either case, the role of international actors is understood to be temporary in nature. International relations professor Michael Wesley (2008) explains that: "The philosophy of state-building is that external actors will initially supply what are taken to be the crucial attributes of the state 
- coercion, capacity, legitimacy, and capital - with the intention of transferring these attributes of 'stateness' to an indigenous sovereign center of political accountability over time" (Wesley 2008: 374). A philosophy that this dissertation argues should to extend to the information sector, where IRB can work to facilitate state-society relations during the reconstruction and/or development of an indigenous media system.

Critical theorists have nonetheless viewed this process as a form of western imperialism (or neo-colonialism) and articulated such concerns through a number of frameworks including postcolonial and dependency theory. Postcolonial theorists (Fanon 1961; Said 1978), for example, have challenged the material and discursive legacies of colonialism arguing that the structures of colonialism continue to exist through both military domination and the discursive practices of the West to define the condition of non-western societies, including the categories of 'underdeveloped' or 'fragile and failed states' (Nuruzzaman 2009). Dependency theorists (Eisenstadt 1976; Boyd-Barrett 1977; Arrighi 2002) describe the economic aspects of the neo-colonial thesis highlighting structures of domination as a continuance of colonialism, and regard the condition of 'underdevelopment' as a western construct built on the inequities of international trade, as well as the economic modernization processes that have worked to entrench such colonial-era relationships of dependency (Dos Santos 1971). Together these positions view the normative liberal approach to state-building as an 'imperial' or 'neo-imperial' enterprise and reject the modernization thesis as a tool for legitimizing cultural domination.

While the imperial thesis has merit at the level of critical theory, it offers little to enhance our understanding of how IRBs function as a component of post-conflict state- 
building. Professor of International Political Economy, Robert Cox, has highlighted the need to understand whether "the aim of the user is to maintain the existing social order, or change it" (Cox 1995: 31). In doing so, he explains that "problem-solving theory is concerned with specific reforms aimed at the maintenance of existing structures; whereas critical theory is concerned with exploring the potential for structural change" (Ibid, p. 32). In the case state-building, where the primary goal is to reinforce the state system, the concern is clearly with the maintenance of existing structures, and in this study how IRB specifically is being used to facilitate it. This is not to say that critical theory is incorrect, but rather that it engages the object of state-building at a different level of analysis. While the Democratic Reconstruction Model (DRM) is an example of problem-solving theory designed to maintain the existing social order (i.e. the international state system), critical theory (in the form of post-colonialism for example) is constructed as an aid to change it. Thus, for the analysis of IRB in post-conflict state-building we inevitability begin in the realm of liberal modernization theory, as it is here where IRB is being increasingly used to support such interventions.

Notwithstanding these distinctions, critics of the DRM (Sedra 2002; Hohe 2005; Suhrke 2007; McPhail 2009) have argued that such models have failed to recognize the pre-existing indigenous structures of power (such as tribal, clan or religious, for example) and would be greatly improved by incorporating bottom-up, community-based strategies, where indigenous structures of power are modified and/or reformed (to include women for example) in order to build local capacity while still pursuing the national development objectives of the state (Hohe 2005). Underlying this practice is a 'liberal institutionalist' conception of the state, which takes for granted the supremacy of the nation-state as the 
dominant actor in international affairs (Dunne 2001), and is generally predominant in issues of international security, conflict, and cooperation (Lamy 2001). The context of democratic reconstruction also provides a useful setting for the analysis of IRB, in that it contains a consistent normative framework for the articulation of objectives, a timeline by which different activities are to be conducted (such as the development of a national constitution and multi-party elections), and a structure for the examination of directed strategic communication programs.

Set within this context, the dominant approach to theorizing IRB can be found in the literature on 'propaganda' and 'development communication'. In terms of the former, international broadcasting has been theorized as a strategic-level tool for use in programs of international communication, such as ideological warfare, political development, and post-conflict state-building. This approach tends to view the purpose and nature of IRB as somewhat variable, depending on the specific context for its use, and the institutional location within which the IRB resides. That is to say, IRB may be used in programs of institutional propaganda, but it may also be used for a more genuine 'quest for dialogue' (Zollner 2006) depending on the particular interests at play. Despite this variation, the practice of IRB has been shaped by theories of propaganda (and public diplomacy) that have collectively worked to shape the structures, techniques and procedures of IRB, as well as the audiences sought for targeting and influence. Here, the term 'propaganda' is used by communication scholars (see for example: Price 2002; Taylor 2003; Snow \& Taylor 2009) as a neutral term for a systematic type of directed communication, similar to the way strategic communication is used by liberal theorists below. 
Development communication approaches have tended to theorize the role of media in development more broadly, emphasizing longer-term structural approaches to help bring about social change. Early theorists such as Daniel Lerner (1958) and Wilber Schramm (1964) argued for the expansion of mass media structures, technologies, and information content, to help facilitate transitions to modern capitalist democracies. In addition to fostering a common understanding of public events, and a sense of national self awareness (Ellul 1965; Anderson 1991), media development was understood to help set the conditions for other forms of social, cultural, political and economic development (Schramm 1964). In this way, development communication theory can be understood in the same context as state-building theory where institutional structures are developed for the longer-term development of the nation-state. Taken together, liberal theories of media and development can be understood to view IRB as a 'functional' or 'strategic' enabler for social change, and are explained in greater detail below.

Critical theorists have challenged the altruistic underpinnings of this approach, arguing instead that such forms of international communication are 'propagandistic' in nature, operating in the interests of Western capital, and may also represent longer-term practices of cultural imperialism (Schiller 1976). Proponents of this approach (such as: Herman \& Chomsky 1988; Schiller 1989; McChesney 2000; McNally 2002; Hackett \& Carroll 2006; Barker 2008; and Sussman 2010) reject the rhetorical shift of propaganda and modernization, and tend to view both IRB and development communication as the informational components of broader neo-liberal activities. In this way, critical media theory reflects the broader neo-imperialist thesis, in both its discursive (Hardt \& Negri 
2000) and material (Rubin 2006) variants, where post-conflict societies are seen to be propagandized through both direct and structural forms of propaganda.

The distinction between 'direct' and 'structural' propaganda is understood here as between a deliberate, centrally controlled communication activity (direct), versus a more unintentional, decentralized process (or set of processes) that collectively work to shape public opinion in accordance with a broader ideological framework (such as liberalism or nationalism). In relation to international development, propaganda studies generally view the 'exporting state' as the primary object of analysis (see for example Price 2002; Taylor 2003, 2009), whereas frameworks of development communication use the 'developing state' as the primary object of analysis (see for example Suhrke 2007; Barker 2008). Both approaches however, use the nation-state as the primary unit of analysis; aim to measure effects; and as a result, provide questions applicable to the study of IRB in contemporary Afghanistan.

Collectively, these theoretical approaches provide a framework for assessing the nature of IRB in contemporary Afghanistan. Detailed in chapters two and three, the study of state-building, propaganda, and development communication theory address questions of media 'content' and 'structure' for application in the specific context of post-conflict state-building in Afghanistan. More specifically, they provide a theoretical framework for understanding the nature of IRB practice, in order to determine the broader motivation for its use. Does it for example, "promote freedom and democracy through the dissemination accurate, reliable, and creditable information" (Gedda 2002: 55) as described by the U.S. Broadcasting Board of Governors, or is it simply propaganda in the service of a broader western interest? Does it promote a broader sense of national (Ellul 1965) or ideological 
(Hardt \& Negri 2000) community? Is it a form of public sphere 'dialogue' (Zollner 2006) or a diversion from the realities of life in Afghanistan?

Despite being situated within the broader context of post-conflict state-building, this dissertation is a study in the practice of IRB (as a question of communication theory) and not an assessment of the broader practice of post-conflict state-building. As such, it is hypothesized that the contemporary practice of IRB in Afghanistan constitutes a form of 'defensive propaganda' that works to reinforce the national institutions of the developing state during the process of democratic reconstruction. This is achieved primarily through a model of IRB known as 'surrogate broadcasting' that aims to engage local populations with information concerning the security, governance, and development activities of their own society.

\section{Definitions of IRB}

The history of IRB is filled with examples of individual state broadcasters being used in directed programs of propaganda, public diplomacy, psychological warfare, and political development, since its inception in the early 1920s (Mattelart 1994). While the practice of IRB began with the development of early broadcasting technologies, it didn't flourish until after the Second World War and the widespread adoption of radio receivers in the decolonizing areas of the 'Third World' where influence was increasingly being sought in the ideological conflicts of the Cold War (Mytton \& Forrester 1988: 457). Today, it is estimated that there are over 100 IRBs in operation, ranging from the well established global broadcasters, such as the BBC World Service, Deutsche Welle, Voice of America, Radio Free Europe, and Vatican Radio; to the many other regional IRBs representing a 
wide variety of state, non-state, religious, and other non-specific political interests. Although the term IRB refers to all types of radio broadcasting intentionally aimed at a foreign audience, the study of IRB itself has been concerned primarily with its use by nation-states for the purposes of propaganda, public diplomacy, and psychological warfare.

U.S. communication professor Monroe Price (2002) describes the concept of international radio broadcasting as an "elegant term for a complex combination of statesponsored news, information, and entertainment directed at a population outside the sponsoring states boundaries" (Price 2002: 200). The McCormick Tribute Foundation (2007) took this definition a step further, marking the delineation between the 'public diplomacy' and 'surrogate' roles played by U.S. international broadcasters. The key to success during the Cold War, they wrote: "was our [U.S.] understanding of two distinct aspects of our communications policy: public diplomacy - telling the world our story; and surrogate broadcasting - giving other countries the opportunity to openly discuss themselves" (McCormick Tribute Foundation 2007: 4). Although the notion of "giving others the opportunity..." may be somewhat ideological and paternalistic in nature, the concept of 'surrogate broadcasting' itself implies a model of IRB that emphasizes the delivery of specific forms of media content, over the development of any sustainable broadcast capability. That is to say, the motivation for such activities would appear to be more short-term in nature than any overt interest in the long-term development of media structures. While recognizing the limitations of such terminology, it nonetheless serves as a useful descriptive category of IRB that is understood widely amongst both researchers and practitioners alike. 


\section{Functionalist Approaches to IRB}

Having outlined the explanatory approaches concerning the motivation for IRB in postconflict state-building, this section explains how IRB is theorized within communication studies more specifically. That is to say, the way in which IRB has been studied reflects a functionalist approach to mass communication research where 'how-to' type questions have dominated the debate. As a defined category of analysis international broadcasting has largely been theorized from a 'functionalist' or 'structural-functionalist' perspective (see for example: Lasswell 1934, 1948; Cowan-Shulman 1990; Price 2002; Heil 2003; O’Keeffe \& Oliver 2010). Critical media theorists (such as: Nichols 1984; Alexandre 1987; Snow \& Taylor 2006) have also engaged the subject of IRB, but have tended to focus more on the normative assumptions as to 'why' such activities are conducted, as well as the political context that gives rise to their use. Both perspectives have focused their analysis on the structural aspects of such communication, highlighting the role of institutions and their ability to shape information environments.

Functionalist theory is an approach to communication research that views mass media as performing a number of functions in society, such as providing information, indicating relations of power, maintaining a commonality of values, or reducing social tensions. Communication Professor Dennis McQuail (1994) has summarized the five basic functions of media in society. The first three functions were identified by Harold Lasswell (1948) as: (1) surveillance of the environment; (2) correlation of the parts of society, and (3) transmission of the cultural heritage; which were later supplemented by: (4) entertainment (Write 1960), and (5) mobilization (Mendelssohn 1966). According to this taxonomy, all IRBs could be expected to perform the following functions: 
- Information: provide information about event and conditions in society; indicate relations of power; and facilitate innovation, adaptation and progress.

- Correlation: explaining, interpreting, and commenting on the meaning of events; providing support for established authority and social norms; consensus building; establishing orders of priority and signalling relative status.

- Continuity: expressing the dominant culture and recognizing sub-cultures; forging and maintaining a commonality of values.

- Entertainment: providing amusement, diversion, and the means of relaxation; reducing social tension.

- Mobilization: campaigning for societal objectives in political and/or economic development, as well as military affairs, and religious activity.

Critical approaches to the study of IRB have focused their critiques on the underlying structures of the communication technologies (Ellul 1965), government communication strategy (Alexandre 1987; Snow \& Taylor 2006), as well as the underlying politicaleconomic interests that are seen to benefit from such communicative activities (Herman \& Chomsky 1988; Mosco 1996). While important questions in and of themselves, they collectively form a macro-level analysis which tends to omit any evaluation of how such individual broadcast organizations work to achieve defined communication objectives. When viewed in the context of international state-building, any political and economic interests are assumed to coincide with those of the sponsoring state, and as a result, are less relevant to questions concerning the specific function of IRB, as they are to broader questions concerning the motivation for such activities.

While not addressing IRB specifically, normative theories for the role of media in early state-building projects can be located in the post-Second World War frameworks of ‘development communication' - where mass communication strategies were used to help 
set the conditions for other forms of national development (Schramm 1964). Following the Second World War, when the attention of the West turned toward 'modernizing' the newly independent states emerging from Colonialism, development theorists such as Daniel Lerner (1958), Walter Rostow (1960), Everett Rogers (1962), Lucien Pye (1963), and Wilbur Schramm (1964) all began exploring topics in the emerging field of mass communication research. In doing so, they argued for the expansion of mass media structures (Lerner 1958; Schramm 1964), and technologies (Rogers 1962) in order to help facilitate a transition to modern capitalist democracies. In addition to fostering a national community of 'shared experience' (Anderson 1991), mass media were understood to help 'set the conditions' for other forms of social, political, and economic development, by providing basic information and a platform for public debate (Schramm 1964). Although the modernization thesis had been criticized for its 'top-down' approach to development (Sedra 2002), neglect of internal relations (Wesley 2008), and perpetuation of the social, economic, and discursive structures of colonialism (McPhail 2009) it nonetheless became the 'dominant paradigm' for development communication research and continues to be used today.

In either case, IRB can be seen to function as part of larger programs of strategic communication that work to help shape information environments in support of broader foreign policy goals. U.S. Communication Professor Umaru Bah (2008) for example, has argued that: "development communication research in the United States was not only influenced by U.S. Cold War propaganda objectives, it was in essence a manifest U.S. anti-Soviet foreign policy strategy" (Bah 2008: 183). Here, Professor Bah highlights one of the central aspects of the development communication critique: that, when viewed 
from a strategic perspective, it was simply the application of mass communication and propaganda research to the emerging post-war strategy of international development that resulted in the doctrine of development communication. Despite such criticism however, the dominant paradigm of development communication remains in use today, and as Bah observed, this is largely because "the locus of power remains in the West, whose interests are well served by the paradigm" (Bah 2008: 193).

\section{A Strategic Communication Approach to IRB}

The framework of strategic communication itself is an example of the dominant paradigm in use today. Frequently used by practitioners in the related areas of public affairs, public relations, public diplomacy, and international radio broadcasting (Romarheim 2005), the strategic communication (or StratCom) framework helps to explain the role of IRB in its various contexts of directed communication programs.

Defined by a set of 'core instruments' the concept of strategic communication is used by practitioners to understand: attitudes and cultures; engage in a dialogue of ideas; and influence attitudes and behaviour in programs of foreign relations (U.S. DSB 2004: 11). The various institutions involved in such work, including departments of foreign affairs or state, defence, and development, generally use different terminology to describe their communicative activities (such as: public diplomacy, information operations, etc.), but share a common understanding of the stages and process of directed communication programs. Such communication programs have the advantage of viewing communicative activities within their actual context, which in the case of state-building may be a highly contested information environment where multiple actors can be seen to compete for the 
attention and support of both media (Wolfsfeld 1997), and the wider population (Nissen 2007). An explicit strategic communication approach to the practice of IRB can be seen in the U.S. Broadcasting Board of Governors' Strategic Communication Model (Figure 2) below. Used widely in IRB planning, this model consists of five categories for assessing the objectives, information market, program development, message delivery, and related metrics used in such programs, and helps to explain the motivation for any such IRB use.

The identification of objectives aims to explain the broadly articulated 'mission objectives' in order to help establish a common operating picture for the various actors involved. In the case of IRB, these are generally articulated by the directing or funding organization and are usually made public in the form of published mission statements.

Analysis of the 'strategic context' and related 'media markets' helps to establish the overall structure of an IRB in relation to the broader ethno-linguistic communities and works to define 'target audiences' within the political boundaries of broadcast regulation. The structuring of such 'information communities' will have significant implications for the longer-term goals of political development and state-building operations. Strategies of communication that are oriented toward political communities (such as the nation-state) may have the effect of consolidating populations under a particular ideology, within the geographical area, but can also serve to alienate minority ethno-linguistic communities residing within the same political space. On the other hand, strategies that are oriented toward ethno-linguistic communities may achieve higher levels of social integration, but work against the development objectives of state-building operations. The orientation of IRB towards either of these communities constitutes one of the greatest structural factors in determining how IRB will be used to support state-building operations. 


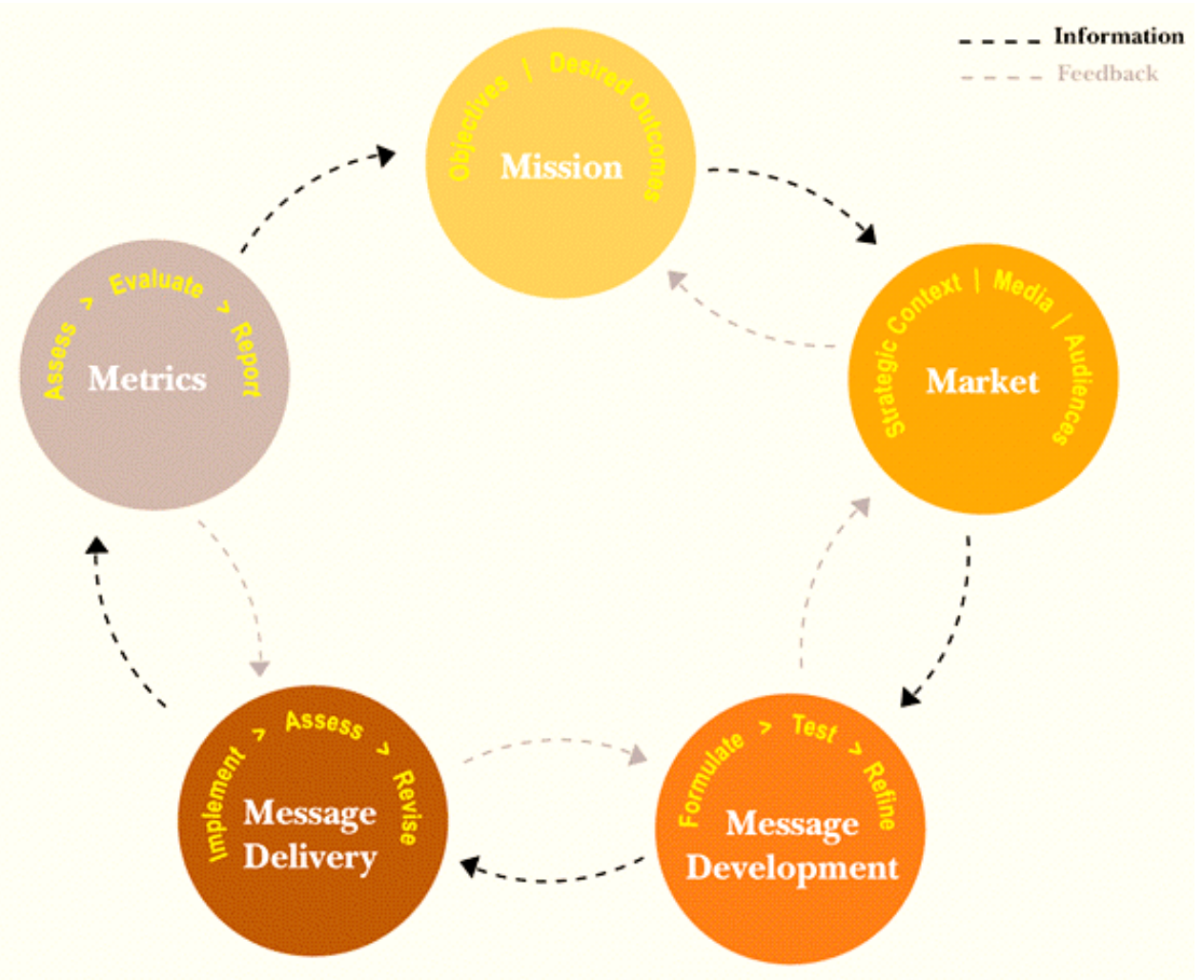

Figure 2. Strategic Communication Model (Source: Broadcasting Board of Governors, 2008)

Questions surrounding the use of appropriate communication technologies in the 'message delivery' stage begin with the communicative behaviours of the audience, and the dominant media of communication already in place (and may also account for other forms of communication used in audience feedback, marketing, and/or any supporting materials used in educational programming). Message delivery here refers to the overall format adopted (i.e. talk, music, news, etc.), as well as the specific content used therein. Radio content for example, can be further broken down into the four main categories of: news, talk, commercial-type 'spots' (which may include public service announcements, commercials, or commercial-like messaging), and music. Interestingly, while the music component is frequently the largest proportion of broadcast content, it tends to be least 
studied aspect of IRB content. This is unusual given the significant role music plays in attracting audiences in the first place, but also understandable in the cases of institutional analyses, where the primary concern has been with media function over the analysis of any effects.

The measurement of effects constitutes one of the great debates in the analysis of media generally and strategic communication more specifically. No agreement exists on what effects are possible and /or achievable, or the time-frames required for such change to occur. Effects measurement is often divided into short, medium, and long-term time horizons, where metrics such as: the awareness of political issues, attitudes toward them, and behavioural change, can be observed. Effects on individual opinions and behaviours are measured through standardized opinion polling where change can be seen over time; as well as community indicators including: voter turnout and preference, local market conditions and price fluctuations, as well as incidents of political violence (Macnamara 2003; List 2006). Although no agreement exists on the measurement of effects, the desire to do so has long been understood as a characteristic common to all forms of propaganda (Ellul 1965).

\section{Methodology}

The analysis of IRB (see for example: Cowan-Shulman 1990; Heil 2003; Zollner 2006;

O'Keeffe \& Oliver 2010) has generally followed an institutional approach that centres on the individual broadcast organization (such as the Voice of America, Radio Free Europe, Radio Liberty, the BBC World Service, or Vatican Radio). This approach has served to focus analytical attention on the underlying broadcast objectives; institutional structures 
and organization; programming and content (especially focused on news); audience size and composition; and any observable effects on individual and group behaviour. These methods of institutional research can be seen to follow the functionalist theories of early mass communication research that developed out of the state-sponsored programs in the U.S. where the research agenda was framed by the ideological conflicts of the Cold War (Hardt 1992; Park \& Pooley 2008). Others have examined IRB as a tool of international relations (Price 2002; Snow \& Taylor 2010) and study these models comparatively, but tend to focus more on the relative power of states to communicate internationally, than the functioning of any singular broadcast institution.

In order to assess the 'defensive propaganda' hypothesis, this dissertation adopts a case study research design that incorporates primary research from structured interviews (Burnham, Gilland, Grant \& Layton-Henery 2004: 205) and participant observation (Ibid 222), as well as a variety of quantitative data sources including: internal content analyses, opinion polling ${ }^{1}$, and unclassified government documents. In doing so, it aims to develop a comprehensive picture of Canada's international broadcasting efforts to Afghanistan, in a format suitable for comparative analysis in future research. The case of Canada's Rana FM was selected for its role in the Afghanistan state-building mission where, since 2007 it has been broadcasting a modernist 'democratic perspective' to the southern population belt in Kandahar province. Use of this particular case also helps to define the contours of 'post-conflict state-building' as a post-Cold War phenomenon, where the dominance of the nation-state as the prevailing form of political organization, has come into question (Appadurai 2002; Price 2002; Saul 2005).

\footnotetext{
${ }^{1}$ Data from this opinion polling was subsequently classified by the Department of National Defence and does not appear in this report.
} 
The research interviews were conducted between May 2008 and December 2009 using a strategic communication framework to guide discussions so that the information collected could be accurately compared with existing case study research. Based on this framework, an interview guide (at Annex D) was used to structure these discussions into five categories that included: (1) broadcast purpose and objectives; (2) audiences and information environments; (3) content and programming; (4) technique and technology; and (5) any metrics and / or analysis used. In accordance with the research protocols of the Ryerson University Research Ethics Board no deception or incomplete disclosure was used in this study. These interviews provided the basis for understanding the broader processes of broadcast planning, development, and day-to-day operations, as practiced throughout the IRB in question (i.e. Rana $F M$ ), as well as the foundation for confirming the representative nature of the case study selected. In doing so, these interviews worked to develop a comprehensive understanding of IRB operations as practiced within western democratic countries (i.e. NATO).

The practice of IRB in state-building operations is often set within a context of violent conflict where the identity of journalists and on-air presenters is withheld from public disclosure (generally through the use of pseudonyms) to help protect their identity. Accordingly, the disclosure of actual identities, including the linking of pseudonyms to identities, could constitute a risk to participants and, as a result, are not used in this study. No information indentifying the participants is presented in this report. In addition to the safety concerns, this was done for the very practical reason that the subjects sought are generally government employees or contractors that, as a rule, are authorized to speak publicly about what they do, but generally require higher authorization to sign anything 
that may be perceived as a legally-binding document. As a result, consent was recorded verbally at the start of each interview following the research protocols of the Ryerson University Research Ethics Board.

In terms of the participant observation, my involvement with the Canadian Forces (CF), and five-year employment with Rana FM, has been invaluable to understanding the practice of IRB. Daily interaction with journalists, on-air presenters, broadcast managers and directing staff, about the day-to-day operations of IRB in Afghanistan (and a variety of similar situations around the world) provided me with a comprehensive understanding of the inter-workings of Rana FM, as well as the conduct of IRB more generally. As an Officer in the Canadian Forces I was employed as the Chief Analyst for radio broadcast operations between May 2006 and March 2011, and was responsible for the coordination of market analysis and audience research. While participation in this type of operational research has provided me with an 'insiders' view of IRB practice, the questions addressed in this dissertation are more strategic in nature and do not rely on any previously gathered materials. This, in turn, has provided me with the separation necessary for the conduct of independent research. No classified materials are used in this report.

\section{Organization of the Dissertation}

This dissertation is organized into five chapters. Chapter One has introduced the central problematic, scope of dissertation research, theoretical frameworks and method of study. Chapter Two outlines the theoretical debates over post-conflict state-building to establish more precisely what IRB needs to be doing in order to help facilitate the other aspects of state development. Chapter Three examines the debate over IRB, including its traditional 
role in programs of propaganda and public diplomacy, and the theoretical frameworks of development communication as a normative theory for the use of media in development. Chapter Four examines the case of Rana FM, Canada's IRB in Afghanistan, to illustrate what IRB is doing as part of a specific multi-national state-building operation. Chapter Five then concludes the dissertation with an analysis of IRB in state-building operations, including a comparative assessment with others models in use today, in order to reflect back on the theoretical frameworks presented. These chapters are followed by a number of annexes containing related source documents followed by the dissertation references. This report itself is organized and formatted in accordance with the 2009 style guide of the American Psychological Association. 


\section{The Debate Over Post-Conflict State-Building}

Post-conflict state-building can be understood as a process of institutional development which aims to set the conditions for long-term national development (Coyne 2005) and is closely related to the development concept of 'capacity building' (Martinussen 1997). It is characterised by the development of state institutions, such as a national government, postal service, a judiciary, a national army, and police forces; and differs from 'nationbuilding' in the results it seeks to achieve (Coyne 2005). In fact, one of the challenges frequently encountered in discussions on state-building is that the terminology is used interchangeably with nation-building, peace-building, and post-conflict reconstruction. American political scientist and Executive Director of Global Policy Forum, James A. Paul (2001) provides a succinct definition of the two entities:

'States' govern a territory with boundaries. They have laws, taxes, officials, currencies, postal service, police and (usually) armies. They wage war, negotiate treaties, put people in prison and regulate life in thousands of ways... 'Nations' by contrast are groups of people claiming common bonds like language, culture and historical identity (Paul 2001: 1).

State-building therefore, is seen by liberal theorists as the development process used to establish (or reinforce) the basic institutions of state, in order to stabilize post-conflict environments and help foster a durable peace in failed or failing states (Ottaway 2003:

314). Critical theorists have challenged the normative basis of such activities, viewing it instead as a form of western imperialism, designed to serve the interests of international capital at the expense of local interests (Rubin 2006). As such, the aim of this chapter to 
outline the basic theoretical approaches to state-building, as well as the dominant model in use today, in order to help define the context of contemporary state-building in which IRB is being examined.

International Development Professor John Martinussen (1997) has described the structure of development theory as having three distinct analytical components: (1) a development concept (or central objective); (2) an underlying development theory; and (3) the development strategy used; that are useful to help understand the terminological differences encountered within the state-building literature. An example of this, taken from Afghanistan, would see the central concept as modernization; the theory as statebuilding; and the strategy as one of 'democratic reconstruction' that works to incorporate security, governance, and development objectives (Ottaway 2003). Other related theories of modernization have included technological transfers (Rogers 1962) and national media development (Lerner 1958; Schramm 1964) as alternatives to (or sometimes in parallel with) other forms of institutional development, in the longer processes of nation-building or political modernization.

Nation-building, as a development concept itself, aims to consolidate populations within a specified geographic area into a cohesive political entity; whereas state-building aims to build the infrastructure that makes such consolidation possible (Coyne 2005). If nation-building is understood as the long-term development objective, then state-building could be seen as one of the strategies used to get there. Both activities are understood as components of 'political development' (where structural factors are involved) and have been informed by such theory since the Second World War (Martinussen 1997). Statebuilding also differs from theories of post-conflict reconstruction in that the former may 
occur prior to the establishment of the post-conflict conditions (i.e. the cessation of hostilities) normally associated with such forms of international development (Krause \& Jutersonke 2005). A common distinction that can be observed in contemporary statebuilding practice is in the range of actors participating in the process. State-building operations tend to be led by donor nations and/or international agencies (such as NATO or the United Nations), whereas much of the work surrounding post-conflict development is NGO / civil-society-led. Whereas post-conflict development aims to facilitate longterm solutions that help to prevent any relapse into violent conflict, the primary aim of state-building is to prevent state-failure and collapse. Although much can be made of the differences between the various development objectives, many of the core activities involved in such practices remain the same.

Post-conflict state-building therefore, can be understood as the full set of activities designed and conducted by a wide range of international actors for the explicit purpose of stabilizing a nation-state following conflict or disaster in order to prevent state-failure and collapse. While opinions differ on the specific objectives (Ottaway 2003; Coyne 2005), as well as the strategies used to get there (Sedra 2002; Vidal 2003; Whaites 2008), a number of core activities can be identified that remain consistent across all contemporary state-building operations. Although commonly referred to as simply the 'security' and 'development' components of such missions, nine core sectors can been identified: (1) national security; (2) rule of law; (3) local governance; (4) state institutions; (5) financial system and tax structure; (6) infrastructure development; (7) media sector development; (8) health and education; and (9) economic development-type activities (Junne \& Verkoren 2005). 
In the execution of these activities, post-conflict state-building can be understood to follow two theoretical approaches to state development that are commonly referred to as 'top-down' or 'bottom-up' models. Top-down models are often characterized by an emphasis on national-level processes, such as electoral or security sector reform, whereas bottom-up models tend to emphasize community consultation or popular participation in their approach to state-building. However, both approaches include variants that work to blur such distinctions. What follows next is an outline of the different theories considered in relation to such international state-building efforts, including critical perspectives on the concept itself, followed by a review of the more specific models and strategies in use today. These positions are then followed by a review of internal debates on the practice of state-building, before summarizing its contemporary use as the contextual framework for the analysis of IRB.

\section{Political Order and State-Building Strategies}

A persistent problem that is frequently underestimated by both development researchers and practitioners is the issue of security (Martinussen 1997; Salomons 205). Threats of physical violence to individuals, communities, and the state itself, provide a significant challenge to theories of development, and serve to limit the range of options available to development practitioners. Under conditions of sustained physical violence, Martinussen (1997) explains that "governments have been forced to give a very high priority to the reinforcement of state security... to the detriment of both development initiatives and promotion of public participation in political decision making” (Martinussen 1997: 277). Political order and state-building strategies, therefore, are programs designed to address 
such security challenges, and are based on the sequenced construction of state institutions and government agencies, in what has been referred to as: 'The Three-Dimensional State' (Chai-Anan 1991) - that is to say: security, governance, and development.

Following Daniel Lerner's (1958) 'revolution of rising expectations' - where the beginning of a development process was seen to create expectations beyond what would be achieved - U.S. political scientist Samuel Huntington (1968) argued that the authority of the central government, via the military and police, had to be consolidated throughout the state prior to the expansion of other forms of socio-economic development, in order to mitigate political instability and prevent uprisings and/or rebellion (Huntington 1968). Although widely criticized by development researchers for his conception of military-led development (Randall \& Theobald 1985), the basic strategy of security-sector reform as a pre-cursor to other forms of socio-economic, political and cultural development remains in use today - particularly where interventions occur prior to the cessation of hostilities. Carnegie Endowment senior associate Marina Ottaway (2002) has codified this approach in its current form as the 'democratic reconstruction model' (see below) where securitysector reform and democratic development are pursued in sequence, and according to a specific timeline that assumes both finite political will (Ottaway 2002) and limited resources (Ignatieff 2002). What these state-building strategies have in common with the top-down modernization theories, Martinussen has explained, "is the notion of the state, and above all the bureaucracy, as the central and most important political institution in the development process" (Martinussen 1997: 175) - a point of contention in the context of post-conflict states, where day-to-day governance and capacity-building are pursued both concurrently and through a wide variety of actors. 


\section{Critical Perspectives on State-Building}

Critical perspectives on state-building are largely concerned with the legitimacy of such interventions, and their impact on structural relations of power. Theorists (such as Brittan 2002; Boyd-Barrett 2003; Chomsky 2003) reject the normative liberal approach to postconflict reconstruction and argue that international state-building works to facilitate the interests of free-market capital, and perpetuate the exploitive conditions of colonization. In this sense, state-building operations have been seen as an ideological activity referred to as 'western imperialism' or 'liberal-imperialism' (Brittan 2002), that have privileged western democracies and reinforced the dominance of liberal-democratic ideology over any pre-existing forms of development (Centre for Public Integrity 2003). In this sense, critical scholars have taken exception to the development concept of modernization, and its related strategies of post-conflict reconstruction (Suhrke 2007) and international statebuilding (Rubin 2006). The primary exceptions can be seen in their understanding of the state formation processes, state-society relationships, and the challenges of developing a postcolonial national identity within the material and discursive legacies of colonialism.

In looking at the processes of state formation, Rubin (2006) reminds us that at its most basic configuration, "state formation consists of the interdependent mobilization by a sovereign of three types of resources: coercion, capital and legitimacy" (Rubin 2006: 178). Coercion is the ability to exercise sovereignty over a given territory, capital refers to the revenue required to fund state functions, and legitimacy relates to the mechanisms by which the state claims to exercise power on behalf of the nation. During the formation of states in Europe, Rubin observed, "rulers struggled and negotiated with subjects who became citizens to extract resources [in order] to wage war against external threats. In the 
postcolonial world rulers struggled and negotiated with external powers [in order] to gain aid or capital to protect themselves from domestic threats" (Rubin 2006: 178). Although this 'inverse' process of state formation acquired the necessary elements of coercion and capital, it lacked the legitimacy necessary to govern as governments derived their power from foreign sources over civic participation. Legitimacy of the state-society relationship is further compounded by differences in the source of knowledge and social authority in non-state-based societies. That is to say, there is an epistemological distinction between the different forms of social organization and authority within tribal and religious-based societies where legitimate forms of authority may derive from alternate criteria (such as birth line, age, religious knowledge / experience, etc.).

Development theorist John Martinussen (1997) echoes this inverse relationship witnessed in postcolonial state formation, but attributes it not to the accumulation of state capital, but rather to larger social processes of national ideology and cultural affiliation. In the European situation, he wrote: "The population in each of the nation-states sensed some kind of common identity and a common sense of belonging, prior to the formation of territorially defined states" (Martinussen 1997: 320). In the postcolonial states of the developing world, the process was reversed. States were formed by external powers with little regard for the ethno-linguistic configurations of existing populations - resulting in what has been termed 'state-nations' (Ibid). In doing so, the central development task of postcolonial states became the consolidation of populations within the boundaries of the state (i.e. nation-building) and not the development of state institutions. This ideology came to be seen as one of 'state-nationalism' (Stavenhagen 1990) or 'civic nationalism' (Ignatieff 2003) which stand in contrast to the ethnic nationalisms rooted in civil society. 
Martinussen goes on to argue that the lack of congruence between nation and state found in many postcolonial countries has impacted negatively on other forms of development “...by diverting resources from development efforts to conflicts between states and their people, or to border disputes between states" (Martinussen 1997: 321).

The specific state-society relationship then can be taken as a key variable in the formation of stable, congruent nation-states. From the early Westphalian model of statebuilding (around congruent national populations), to the postcolonial model of national development (within a politically defined territory), the understanding of different statesociety relationships forms a key distinction from the modernization paradigm. By way of classification, Martinussen (1997) describes four different categories of state-society relationships. The first category are states with a high degree of congruence between the nation and state, where the "legitimacy of the state is solidly grounded in the perceptions of the majority of the population as belonging to exactly the political community which is governed by the concerned state" (Martinussen 1997: 321). The new state of Kosovo is a case in point, where the Albanian population separated from Serbia (1999) in a process of national self-determination supported by international intervention. The second category is where large ethnic communities co-exist within the same territory. Bosnia-Herzegovina is a good example of this where Bosnian-Muslim and Serb communities have co-existed since the enactment of the Dayton Peace Accord in 1995. The third category of relations is where large parts of the population perceive the state as "a distant and alien institution" (Ibid). Afghanistan is a good example of this where a weak central government has little interaction with populations outside of the major cities. The fourth category, unique to 
the Arab world, inverts the concept of a multiethnic state and instead perceives the nation to be comprised of numerous individual states.

In the case of Afghanistan, questions have been raised as to whose interests are actually being served by the current international state-building project (Rubin 2006); the wisdom of adopting a western dominated 'modernization' approach to reconstruction and development (Suhrke 2007); as well as a lack of any broad-based political consensus involving the full range of oppositional groups (Nuruzzaman 2009). Beginning with the question of interests, Rubin (2006) highlights a long-term view of international relations indicating that: "For centuries stronger powers have intervened along their peripheries to establish politically acceptable forms of order" (Rubin 2006: 177). In doing so, he argues that state-building is simply the contemporary version of a long-standing international security task - the stabilization of the periphery by great powers, which he argues, "must now be carried out in a globe governed by a regime of universal juridical sovereignty of the nation state" (Rubin 2006: 176). In doing so, he describes the long evolution of 'great power' international relations from the early doctrines of colonization and imperialism, to contemporary practices of peace-building, post-conflict reconstruction, and stabilization (or humanitarian) operations. To this end, Rubin (2006) notes that: "The central fact of the environment in the past half-century has been the replacement of global juridical imperialism by global juridical national sovereignty" (p. 176). This, he suggests, has led to the current system of UN authorized missions providing international legitimacy for interventions by powerful western states in areas perceived to be a threat to international peace and security. Interestingly, he notes that UN "operational doctrine requires that the transition lead to adoption of a constitution providing for at least the appearance of liberal 
democracy, with election constituting the principal benchmark" (Rubin 2006: 184).

Although the initial motivation for such interventions may rest with the 'great powers', he concludes, negotiation among the various actors within the international system can lead to a convergence of practice that serves the interests of all parties involved (Rubin 2006: 184). A perspective, this dissertation argues, is reflected in the operation of IRB supporting such interventions.

On the issue of using western-based reconstruction doctrine, Astri Suhrke (2007) has suggested that "the conflation of post-war reconstruction with a broader agenda for development and modernization has brought out a wide range of tensions associated with social change” (p. 1291). Specifically, the 'liberal peace' doctrine of reconstruction and development represents radical change in places like Afghanistan "that escaped European colonial conquest [and have] always been more shaped by influences from Asia and the Middle East than form the West" (Suhrke 2007: 1293)². Seen within its historical context, this model of democratic reconstruction has been viewed within Afghanistan as the latest attempt by foreign powers to colonize the region. The main difference, Suhrke notes, is the role of third party external agents. She explained: "While foreign assistance places significant know-how, capital and, often, military force behind the reconstruction effort, it does not provide legitimacy beyond the utilitarian functions associated with the return of peace and the start-up of reconstruction" (Suhrke 2007: 1294). This 'legitimacy gap' can be seen to manifest in processes that go beyond reconstruction and into development activities where foreign influence is seen to "undermine traditional values and the role of religion in society" (Suhrke 2007: 1296).

\footnotetext{
${ }^{2}$ Despite 'escaping colonial conquest' Afghanistan is nonetheless considered to be a postcolonial state as its political boundaries were defined by the intersection of the British (India), Russian, and Persian Empires through a process know as 'negative sovereignty' or the space in-between (Suhrke 2007).
} 
Mohammed Nuruzzaman (2009) echoes such concerns over the importation of Western models, arguing that the problem of post-conflict state-building can be better explained by understanding conflict dynamics and unequal economic relationships than any lack of institutional capacity or bureaucratic efficiently. Factional struggles over access to state power and resources constitute the single greatest challenge to the postconflict reconciliation process. In cases where the reconstruction process is preceded by a formal peace agreement (such as Bosnia-Herzegovina) such challenges may be shifted to the political arena. In cases where conflict moves directly to reconstruction without such an all-party agreement (as seen in Afghanistan and Iraq) politically marginalized groups have little incentive to participate in such processes. Having been specifically excluded form the political process, the Taliban in Afghanistan provide a case in point, where they are left with few alternatives to armed conflict for contesting state power. In light of such concerns, Nuruzzaman (2009) maintains that "a collective sense of national identity and loyalty to the state is a pre-requisite for success of state-building activities" (Nuruzzaman 2009: 289). Without a basic commitment to the concept of a unified state, he suggests, state-building activities will lack the legitimacy necessary for success.

Taken together, critical perspectives on post-conflict state-building highlight the concerns associated with modernization theory and its role in legitimatizing neo-colonial activities. In doing so, however, a number of key assumptions are made with regard to the nature of the actors involved. First is that capitalist democratic states tend to be viewed as monolithic actors with pre-determined interests, rather than sites of contested opinion or terrains of struggle themselves. A question frequently asked here is whether the invasion if Iraq (2003) would have occurred regardless of the U.S. administration in power? 
Second is that the purpose and nature of state-building is understood to be the same regardless of the particular context or composition of actors involved. Were there no differences in the rational for intervention between Bosnia-Herzegovina, Kosovo, Afghanistan or Libya? Is the conduct of these missions the same regardless of the dominant international agencies (i.e. UN, NATO, etc.) involved? While critical theory raises important questions related to the purpose and conduct of such interventions, it overlooks democratic governments and international institutions as sites of contested terrain and would benefit from a more nuanced view of state-building.

\section{Civil Society and Post-Conflict State-Building}

Defined as the "uncoerced collective action around shared interests, purposes and values" (LSE 2009), civil society marks the terrain between the state, family and market, where a wide variety of NGOs, community groups, business associations, and social movements participate in the ongoing development of society. Harpviken et al. (2002) have suggested that the relative strength of a country's civil society organizations (CSOs) "is thought to have major implications for political stability, economic productivity, and human wellbring more generally" (Harpviken et al. 2002). Almond and Verba (1989) argue that the political element of many CSOs facilitates better awareness, a more informed citizenry, and greater participation in established political process (Almond \& Verba 1989). CSOs are thought to be vital to democracy as a mechanism to build social capital and develop a sense of shared values, which can help to bind society through shared interests (Putnam et al. 1994). In relation to state-building, it is widely assumed that CSOs play a political 
role through close interaction with the state (Kamali 2001), and through the provision of public welfare services (UNDP 2002).

Although widely considered in relation to democracy promotion and democratic development practices, civil society organizations have been criticized for their own lack of democratic representation (Zaleski 2006); comprised of a limited demographic that is biased toward global north (Pithouse 2005); and part of a neo-liberal (Zaleski 2006) or neo-colonial (Sen 2010) strategy that propagates liberal values in the interests of free market capital, which some see as linked to the Washington Consensus ${ }^{3}$ on international development (Zaleski 2006). In Branding Democracy: US Regime Change in Post-Soviet Eastern Europe, for example, Gerald Sussman (2010) examines the wide variety of CSOs involved in democracy promotion activities in Central and Eastern Europe following the collapse of the Soviet Union. Through a framework of 'structural propaganda' he argues that the institutional transplant of political democracy constitutes a 'soft imperialism' that "negates the organic and evolving basis of democracy... which must arise from the longterm struggles of a people within their own defined spaces of identity" (Sussman 2010: xvi). While the necessity of "long-term struggle" is a value judgement not supported by empirical evidence, the direct transplantation of such minimalist forms of democracy have been widely recognized as ideological activities designed in support of the global expansion of liberal democracy (Sussman 2010).

Within post-conflict environments, such perceptions of bias can lead CSOs to being perceived as party to the conflict, and may severely limit their scope of activities, range of physical movement, and function within any state-building process. Security

\footnotetext{
${ }^{3}$ The Washington Consensus was a standardized set of development principles used by Washington-based institutions such as the IMF and World Bank in the decade following the end of the Cold War. It has since been replaced by the Seoul Development Consensus (2010) as the G20's framework for development.
} 
concerns within Afghanistan for example, have limited the ability of CSOs to influence development beyond the major urban centers (Caan \& Worden 2007) and privileged a model of state-society relations that "prioritizes service delivery of over the deliberative role of civil society" (Howell \& Lind 2009: 719). This latter point helps demonstrate an interesting paradox in the composition of Afghanistan civil society. CSOs throughout the countryside are comprised largely of traditional community structures (known as Jirgas or Shuras) which emphasize the more deliberative function of CSOs, whereas the growth of a 'civil sector' to help accommodate the distribution of international aid has taken on a more specific apolitical service delivery model (Howell \& Lind 2009). The implications of this for Afghan state-building suggest that a greater emphasis ought to be placed on a bottom-up 'dialectical' approach to modernization (discussed below) where indigenous social structures can play a greater role in rebuilding of Afghan civil society. Discussing this point, Howell and Lind (2009) explain that:

In recent years, some donors have widened their gaze to the so-called 'traditional' and religious institutions... [signifying] a growing realization among donors that they have overemphasized NGOs in their strategies and programming at the expense of understanding the much broader and varied associational landscape in Afghanistan, a problem that is seen in other aid contexts, as well (Howell \& Lind 2009: 731).

While this deepening of cultural awareness among donor countries is an encouraging sign for the better incorporation of Afghan civil society in the state-building process, it seems to parallel larger trends in the overall approach. In sum, the post-conflict development of civil society organizations can be seen to occur in tandem with other social, political and economic development activities, and serves to both reinforce, and be reinforced by, the use of IRB in such environments. 


\section{Dialectical Modernization Theory}

An alternate approach to the top-down models of state-building came in response to the perceived value-bias of classical modernization theory and instead viewed the concepts of 'tradition' and 'modernity' as dialectical social phenomena that work to influence one another through a process of social change where "the result is not simply modernization but numerous different processes of change" (Martinussen 1997: 172). In contrast to the narrow focus of classical modernization theory on the political and economic aspects of development, the dialectical approach is more concerned with the broader range of statesociety interactions (Martinussen 1997) and human security needs (Krause \& Jutersonke 2005). While India is frequently cited (Rudolph \& Rudolph 1967) as an example of this theory in practice (for its use of the caste system in modern political institutions), there are also recent examples of its use in Afghanistan and East Timor.

In Afghanistan the incorporation of 'Jirgas' into state decision-making provides a good example. A Jirga, such as the (generally) annual Loya Jirga or 'grand assembly' in Afghanistan, is an assembly of tribal elders which makes decisions by consensus and are considered to be 'socially-binding' by the tribal code Pashtunwali (Rahman 1995). They have been used for centuries to help resolve disputes and discuss issues of significance throughout the Pashtun tribal belt of contemporary Afghanistan and Pakistan, and have since been incorporated nationally into the Afghan political system where other minority populations also have been included. A Jirga is generally called on an as-needed basis before decisions need to be taken. The July 13, 2002 Loya Jirga, for example, appointed Hamid Karzai as President of the Afghanistan Transitional Administration (ATA), which governed the country until elections could be held in 2005. In June 2010, a Loya Jirga, 
"chosen to reflect Afghan tribes, politics and geography" met to discuss the government's plan to achieve peace with the Taliban (Reuters 2010). By incorporating such Jirgas into modern government decision-making, both systems were altered in the process creating a hybrid of tribal and modern decision-making practice.

While the national-level Loya Jirgas get international media attention, local Jirgas occur frequently with little notice. Research associate Mark Sedra (2002) has advocated a bottom-up, community-based strategy in Afghanistan based on the Shura system - the Islamic religious version of the Pashtun tribal Jirga system - in order to help build local capacity while providing basic services for the population (Sedra 2002: 2). Noting that its traditional form excludes women, Sedra (2002) argued that:

With the necessary reforms, the Shura could be molded into a broad-based inclusive structure of governance, instrumental in identifying community needs, planning development programs, and implanting them across ethnic lines (p. 2).

The logic here, being that the modification of traditional decision-making forms has a better chance of acceptance and participation than do democratic systems foreign to the local populous. People may vote in national elections, yet still expect to participate in community decision-making processes.

Although not widely considered in the contemporary practice of state-building, dialectical modernization theory has nonetheless provided a sound normative framework for the incorporation of culture into contemporary models of political development, and can nonetheless be seen to influence local level governance and decision-making at the community level. 


\section{A Community-Based Approach}

If dialectical modernization theory is understood as an attempt to incorporate indigenous social structures into national-level governance, then the community-based approach can be seen as an inverse application of the same philosophy. At its core, a community-based approach aims to incorporate national-level state-building objectives, such as democratic governance and infrastructure development, into community-level decision-making practices. While state-building efforts by the international community have traditionally focused on national-level institution building, community-based approaches have been attempted in both Indonesia and East Timor (Hohe 2005: 63), as well as some parts of Afghanistan (ISAF 2009). In discussing the relative novelty of this approach, Hohe (2005) observed that: "While decentralization and devolution have become the main international objectives to enhance good governance in developing countries, they are not yet commonly integrated in state-building after conflict" (Hohe 2005: 59).

As experienced in East Timor, Hohe (2005) described the process of 'developing local governance' (following its independence from Indonesia in 2002) as “a program intended to enable villagers to make their own development choices" (Hohe 2005: 63). Following the withdrawal of Indonesia, and the near total elimination of East Timor's official administration (Hohe 2005: 59), the Asian Development Bank, various UN agencies, and the World Bank began a Joint Assistance Mission (JAM) with the aim of rebuilding the administrative structures, while encouraging reconciliation of the warring parties and a strengthening of civil society (Joint Assistance Mission 1999). In doing so, the Community Empowerment and Local Governance Project (CEP) was established to "ensure that communities have an effective vehicle for participating in and guiding the 
rebuilding of their nation" (Joint Assistance Mission 1999: 12). This project, Hohe notes, was a successor to a similar World Bank project in Indonesia, of which East Timor was a part, enabling the financial resources to be made available for the beginning of the United Nations deployment - UNTAET (Hohe 2005: 63).

The creation of 'community development councils' for the 13 sub-districts of East Timor were intended to bring forward development ideas from the grassroots level, while providing the legal framework "to receive and disperse funds" from the UN / World Bank program (Hohe 2005:64). At the same time, the program was intended to modify the local power structures by introducing a "democratic sense of equality" (Hohe 2005: 64). Local members of the community, 18 years and older and not a traditional or local leader, could run for council. Although the exclusion of traditional and local leaders from the councils was intended to create a de facto separation of powers at the local level (i.e. village chief as executive; community development council as quasi-legislative body; and a council of elders as a quasi-judicial body), people expected such positions to be filled according to their traditional indigenous power structure (Hohe 2005). "The discrepancy between the modern way of selecting administration staff and the local ideas about legitimate leaders in these positions led to the rejection of personnel by local populations" (Hohe 2005: 61). As in other programs of democratic development (i.e. Afghanistan; Iraq), non-eligibility of the traditional powers has been seen as an attempt to undermine the authority of local leadership, and not a true expression of democracy.

Although the use of development funds to support local governance initiatives can be seen as a step in the right direction, a number of important issues were raised along the way. The assumption of a 'power vacuum' following the Indonesian withdrawal opened 
the doors to a social engineering approach that promoted democracy at the expense of aid delivery and economic development (Hohe 2005: 70). Because candidates for the central positions were traditionally selected by village elders, the development councils had "no important meaning for the inside community" (Hohe 2005: 67). In times of social and/or political crisis, traditional structures of power are frequently relied upon, as they provide a commonly understood basis for social order. As Hohe noted: "Indigenous structures are often prevailing and [already] have the trust of the population" (Hohe 2005: 70). Another challenge of the social engineering approach was seen with the incorporation of women into the community development councils. Although the communities had little trouble electing $50 \%$ women, traditional gender roles prevented them from participating fully as equal partners in the process. As Hohe has observed: "During the CEP village meetings, female council members were mostly taking care of food and drinks for the people who attended" (Hohe 2005: 68).

An additional challenge to implementing a community-based approach relates to the disparate interests of the various development organizations involved. In the case of East Timor, Hohe observed that the idea of a bottom-up approach was not appreciated by the international NGO staff. She wrote that "international agencies arrived with their own concepts and strategies of how to conduct development and were not willing to use creations of other organizations" (Hohe 2005: 65). UNTAET, for example, delayed formalizing the councils as they were understood to be "not in favor of decentralizing their power" (Hohe 2005: 64), illustrating a form of competition experienced among the various international development organizations. 


\section{Democratic Reconstruction Model}

The Democratic Reconstruction Model (DRM) has become the primary formula around which donor countries and international organizations seek to rebuild societies emerging from conflict in the post-Cold War era (Ottaway 2002; Call \& Cook 2003). It was largely defined during the four-year United Nations mission in Cambodia (1991 - 1995) where "the UN set out to demobilize soldiers, de-mine the countryside, exercise political control of the country's pending democratic elections, and foster a culture of human rights and accountability" (Call \& Cook 2003: 233). Carnegie Endowment Senior Associate Marina Ottaway (2003) has described it as "a well-intentioned response to a growing problem: the need for international intervention in post-conflict countries to stabilize the situation and prevent the recurrence of conflict" (Ottaway 2003: 314). This model, she observed, "is based on the assumption that democratic [political] systems provide mechanisms for reconciliation and are the best guarantors of lasting peace" (Ibid).

Early examples of the model witnessed a relatively straight forward approach to security sector reform, including the disarmament, demobilization, and reintegration (DDR) of former combatants, and the development of a new national army and civilian police force; to a model of political reform that included the structuring of a democratic political system, registration of voters, and the holding of multi-party elections within a reasonable period of time, that suited both the internal conditions of the country and the desire of the international community to establish a timetable for withdrawal (Ottaway 2003: 316). In some cases, where a culture of democracy already existed, this process worked rather well. In others, where there was no experience with democratic processes, it took considerably longer. In both situations, implementation of the DRM occurred with 
mixed results: Angola relapsed back into conflict following national elections; Cambodia modified the electoral process (after the fact) to facilitate a power-sharing arrangement; and Mozambique delayed their national elections to ensure demobilization was complete (Ottaway 2003: 316).

Despite these early setbacks, the DRM has been applied on numerous occasions and as a result, has been refined along the way. As the model exists today, it is comprised of two central components: security sector reform, and democratic development; that are both implemented according to a timetable set by the international community. Security sector reform includes the demobilization of former combatants, the formation of a new national army, constabulary police services, and the development of civilian oversight institutions. Democratic development programs have evolved from the basic components such as: the structuring of a democratic system, development and approval of a national constitution, the enactment of electoral law, and multiparty elections; to a much broader program that recognizes the need to reinforce and strengthen democratic institutions and to help foster a vibrant civil society, including the development of an independent media system. The process begins with a negotiated settlement to the conflict followed by a national conference of major domestic groups (to determine the structure of the political system) and elections within two years (Ottaway 2002: 22). Recent examples of this can be seen in Cambodia, Bosnia-Herzegovina, and Afghanistan, where developments since 2001 suggest a strict adherence to the model. Selections from $B B C$ News, 'Afghanistan Timeline' (7 May 2010) illustrate this point well:

20015 December - Afghan groups agree deal in Bonn for interim government. 200122 December - Pashtun royalist Hamid Karzai is sworn in as head of a 30member interim power-sharing government. 
2002 June - Loya Jirga, or grand council, elects Hamid Karzai as interim head of state. Karzai picks members of his administration which is to serve until 2004. 2002 December - President Karzai and Pakistani, Turkmen leaders sign deal to build gas pipeline through Afghanistan, carrying Turkmen gas to Pakistan.

2003 August - NATO takes control of security in Kabul, its first-ever operational commitment outside Europe.

2004 January - Grand assembly (Loya Jirga) adopts a new constitution which provides for strong presidency.

2004 November - Presidential elections: Hamid Karzai is declared the winner with $55 \%$ of the vote.

2005 September - First parliamentary and provincial elections in more than 30 years.

2006 February - International donors meeting in London pledge more than \$10bn $(£ 5.7 \mathrm{bn})$ in reconstruction aid over five years.

2006 October - NATO assumes responsibility for security across the whole of Afghanistan, taking command in the east from a US-led coalition force.

2008 November - Taliban militants reject an offer of peace talks from President Karzai, saying there can be no negotiations until foreign troops leave Afghanistan. 2008 December - President Karzai and new Pakistani President Asif Ali Zardari agree to form joint strategy to fight militants operating in their border regions. 2009 March - President Barack Obama unveils a new US strategy for Afghanistan and Pakistan to combat what he calls an increasingly perilous situation.

2009 August - Presidential and provincial elections are held, but are marred by widespread Taliban attacks, patchy turnout and claims of serious fraud.

2009 November - Hamid Karzai is sworn in for a second term as president.

2010 June - Loya Jirga reported that they "had reached a broad consensus that there was no alternative to seeking peace with the Taliban" (Reuters 2010).

While the story of Afghanistan is far from over, it is nonetheless still possible to observe the application of the DRM, where questions concerning both the appropriateness and effectiveness of the model have been raised (Ignatieff 2002; Sedra 2002; Ottaway 2002, 2003). In fact, one of the most frequent observations concerning its use has been the question of resources. As Ottaway (2002) wrote: "This model is enormously expensive, requiring major commitments of money and personnel on the part of the international community... [and it] has only been implemented seriously in the case of Bosnia where the international community has made an open-ended commitment of money and power to see the job through to the end" (Ottaway 2002: 22). If one considers the current list of 
state-building operations: Bosnia-Herzegovina, Kosovo, Afghanistan, Sierra Leone, the DRC and Burundi; the issue she maintains is not one of political will. "The resources are just not available" (Ottaway 2002: 24) - A criticism which led Michael Ignatieff (2002) to label the Afghan mission as 'Nation-Building Lite'. In doing so, a normative argument has been advanced for limiting the objectives of political development to the shorter-term state-building activities where the objective, Ottaway (2002) suggested, is "not to impose common identities on deeply divided peoples, but to organize states that can administer their territories and allow people to live together despite differences" (Ottaway 2002: 2).

\section{Criticism of Democratic Reconstruction Practice}

Criticism of democratic reconstruction practice can be grouped into four main categories related to the questions addressed. First, are questions concerning the overall legitimacy of state-building operations discussed above (Heiberg 1994; Hoffmann 1996) as well as concerns over where, and under what circumstances, international interventions ought to occur (ICISS 2001). Second, are debates over the specific mission objectives. What is possible? What is achievable? Who has the capacity to take-on what activities? The third relates to the particular strategy adopted. Top-down? Bottom-up? Security first? Etc. And fourth, are concerns over the effectiveness of the particular strategy adopted.

Discussions over where and under what circumstances such interventions are to occur are both characterized by arguments over the criteria for international intervention, such as the 'Responsibility to Protect' (R2P) doctrine which views state sovereignty as a moral responsibility. In short, the R2P doctrine has three components that: (1) hold states responsible for the protection of their populations (against genocide, war crimes, crimes 
against humanity or ethnic cleansing); (2) charges the international community with the responsibility to assist the failing state by building its capacity to protect; and (3) charges the international community with the responsibility to intervene, both diplomatically and militarily if the failing state in either unwilling or unable to do so (ICISS 2001). Although criticised for its reliance on the UN Security Council to authorize interventions, the R2P doctrine has nonetheless provided a normative framework for international humanitarian intervention (UNGAR 63/308), and was invoked in response to the 2010 Libyan uprising (UNSCR 1973).

Stemming from this debate is the criticism related to the particular state-building objectives pursued during such operations. Krause \& Jutersonke (2005) remind us that the challenges associated with state-building operations represent "a profound rupture in the domestic process of state-building... attempting to redistribute political, economic or social power, and reshape the institutional terrain on which political competition occurs" (p. 449). The post-genocide reorganization of administrative districts in Rwanda provides a case in point. In the months following the international intervention, Rwanda's political landscape was reoriented from ethnically constituted political districts to geographical entities reflecting the North, South, East, West and capital areas of the country (National Post 2008). Nonetheless, the level of political re-organization or 'social engineering' that is sought during state-building operations remains the subject of considerable debate (Ottaway 2002; Hohe 2005; Krause \& Jutersonke 2005). At one end of the spectrum, concern over resources calls for a 'minimalist approach' to state-building where the least amount of intervention necessary to stabilize a country is advocated. At the other end, concerns over the pre-conflict political conditions that may have contributed toward state 
failure and collapse remain an ongoing development concern. As a way to bridge the gap between security and development, the UNDP (1994) began advocating the concept of 'human security' as a set of criteria aimed at unifying post-conflict reconstruction and development efforts. Krause \& Jutersonke (2005) explained that:

[Human security] meant adopting a bottom-up or local approach to security that focused on the relationship between states and their populations, and that moved away from equating the security of a state or regime with the economic, political and social well-being of its citizens (Krause \& Jutersonke 2005: 457).

The 'human security' or 'population centric' frameworks are increasingly referred to as the 'new paradigm' in international development, contrasting such bottom-up, people centered approaches, with the top-down, state-centered focus of modernization theory.

With a tentative understanding of what is expected to work, and what objectives ought to be sought, the third significant area of criticism is over the strategy used to get there. State-building is expensive and requires substantial commitments of time, money, and personnel from member states of the international community that are not uniformly available to all missions (Ottaway 2002). Debate surrounding the structure, organization, and particular strategy adopted, center on the issue of resources and who (donor nations, development organizations, military alliances, etc.) have the capacity to operationalize such plans or parts thereof. In addition to the physical context, or circumstances on the ground, the strategy adopted will in large part reflect the capacities of the organizations involved, and not simply the established doctrine of state-building. Situations of extreme violence and insecurity, for example, will necessitate a military-led process that, by virtue of capacity, tends to privileges a 'security first' strategy (Salomons 2005). While the case for security prior to any form of substantial development has merit, it tends to ignore the 
longer-term role of unequal resource distribution in fuelling conflict. Top-down strategies can be seen to follow sectoral collaboration (i.e. security, governance, education, health, media development, etc.) where different organizations take national-level responsibility for different sectors; whereas bottom-up approaches will tend to reflect collaboration of organizations with similar capacity that take responsibility for all sectors within a single geographic area.

Finally, are empirical debates over the effectiveness of such operations, including the criteria for measuring success, and the appropriate timeframes for such measurement (Krause \& Jutersonke 2005). In 2005 for example, United Nations Special Representative of the Secretary-General (SRSG) Jacques-Paul Klein remarked that: "it is necessary to recognize that the track record of $\mathrm{PCPB}$ is mixed, and perhaps even negative on balance" (Quoted in Krause \& Jutersonke 2005: 448). To be sure, countries including Afghanistan, Somalia, Liberia, Angola, Haiti, and Cambodia were noted for their high rates of armed violence, limited structures for domestic governance, and questionable respect for human rights and the rule of law. Only Bosnia-Herzegovina and Mozambique have been considered 'possible successes' in the post-Cold War era (Ibid). One of the challenges in quantifying these projects is that there is little agreement on what 'success' looks like, or the timeframes required for state-building efforts to show demonstrable effects. The Human Security Centre (2005) for example, has argued that although the success rate of PCPB remains around $30 \%$, the cumulative effect of repeated efforts "guarantees eventual success in breaking the vicious cycle of endemic conflicts, and in setting states on a path of sustainable security, development and state-building" (Quoted in Krause \& Jutersonke 2005: 449). While such repeated efforts may be costly in both human and 
financial terms, they reflect a general intolerance felt be the international community to let conflicts run their natural course (Ottaway 2002) of which the March 2011 Libyan intervention serves as a case in point.

\section{Summary}

Overall then, post-conflict state-building operations can be understood as the full range of activities conducted by international actors, with internal cooperation, to help stabilize conflict areas and foster a durable peace in failed and failing states (Ottaway 2003: 314). Such operations will include some form of peacekeeping or peacemaking by international military forces; security sector reform that includes the disarmament of combatants and the development of a national army; as well as some form of democratic development that will generally include the drafting of a new constitution, registration of voters, and multiparty elections within a fixed period of time (Ottaway 2003: 316). Examples of such operations include: Cambodia (1993); Bosnia-Herzegovina (1995); Democratic Republic of the Congo (1997); East Timor (1998); Kosovo (1999); and Afghanistan (2002).

Throughout this time, the dominant approach to state-building has taken the form of 'democratic reconstruction' where a variety of security, governance, and development objectives have been pursued according to a standardized model with specific timelines established by the international community. This dominant model is characterized by a 'top-down' centralized approach to state-building where civil society participation is, for the most part, limited to participation in a pre-determined democratic process. The DRM has been criticised for under-valuing existing socio-cultural factors in reconstruction and development planning, and strategy development. An alternate approach, emphasizing a 
'bottom-up' methodology, where strategy is developed from the existing socio-cultural factors up, was also discussed. The emphasis here is placed on greater civic participation during all aspects of the reconstruction and development process. While both approaches recognize the security and development components of the state-building enterprise, they invert the relative priority, as the 'top-down' / 'bottom-up' dichotomy suggests. Although these are relatively distinct categories in theory, such approaches may merge, shift, or be combined in practice. An example of this has become evident in the revised strategy for Afghanistan where a greater emphasis has been placed on local level governance and the indigenous tribal structures of social organization (ISAF 2009). The significance of this to IRB in state-building suggests that mechanisms for popular participation are required from the outset of any reconstruction process, and that platforms for both vertical and horizontal communication ought to be established in order to help facilitate the necessary state-society relations throughout any development process.

Overall, we may conclude that the practice of state-building (as practiced today) is a top-down process of neo-liberal institutional development that proceeds according to a model of democratic reconstruction. Although such state-building theory has evolved over time to incorporate more socio-cultural factors into the development of strategy, its implementation remains somewhat fragmented. This suggests that a full accounting of the existing socio-cultural (and informational) structures is significant to the development of a state-building strategy, as well as to the overall objectives themselves. If state-building objectives are to be consensually determined, and articulated amongst the population, a mechanism for two-way communication will be required. 
While the specific role of IRB will be dependent upon the overall state-building objectives, two basic requirements can be observed. One is the transmission of relevant information from the state to the population; the other is the transmission of information from the population to the state. As explained in the next chapter, media theory related to such an approach mirrors the top-down / bottom-up strategies of state-building, and will influence the communication structure accordingly. The role of IRB as a force multiplier in state-building operations requires that the informational components of the different security, governance, and development sectors be fully and accurately communicated to the population for consideration. Conversely, in order to 'build from the people up' a platform for community participation needs to be established that allows for individual and community feedback on such issues. 


\section{- CHAPTER THREE -}

\section{The Debate Over International Radio Broadcasting}

International radio broadcasting (IRB) has a long history in the service of ideological conflicts where the support of local populations has been seen as vital to the outcome of such efforts. From its early war-time development, to the bi-polar conflicts of the Cold War, IRB has been used as a tool in various programs of strategic communication since its inception in the early 1920s. Underlying much of its use, the practice of IRB has been informed by theories of propaganda, public diplomacy, and development communication that have worked to shape the organization of IRB, including the objectives, content, and overall structure of the broadcast communities that have worked collectively to facilitate the broader political objectives of the sponsoring state.

In order to situate the study of IRB within post-conflict state-building, this chapter examines the evolution of IRB, and its theoretical underpinnings, to demonstrate its longstanding use in strategic communication programs of propaganda and public diplomacy since the Second World War. This chapter begins with a brief review of the history and definitions of IRB, followed by an examination of its theoretical roots in both propaganda and public diplomacy. It then turns to the alternate theoretical framework of development communication in order to highlight the unique circumstances facing IRB in post-conflict development, before assessing both approaches as strategic communication enablers for use in political development. The chapter concludes with a summary of questions for the analysis of IRB practice in contemporary post-conflict state-building. 


\section{History and Definitions}

The literature on 'international broadcasting' reveals a general focus on such activities as propagandistic tools of the Cold War (Alexandre 1987; Cowan-Shulman 1990), that have continued to serve the strategic communication (Snow \& Taylor 2006) and foreign policy objectives of the exporting state (Price 2002; O’Keeffe \& Oliver 2010). While said to be working at the "crossroads of journalism and diplomacy" (Heil 2003), many IRBs began their service in strategies of propaganda during the Second World War, and continued thereafter as tools of strategic communication in the ideological conflict of the Cold War, and more recently in the so-called 'Global War on Terror' (O'Keeffe \& Oliver 2010). Independent scholar Holly Cowan-Shulman (1990) for example, documented the origins of a 'journalistic strategy' in wartime propaganda doctrine, as the 'agitprop' drama-aspropaganda used in Europe at the beginning of the war lost favor following America's entry into the conflict. She explained that:

Between 1942 and 1944 the forms in which the Voice of America cast its propaganda moved from agitation to factual news reporting, a shift necessitated by the increasing American emphasis on Allied military victory (Cowan-Shulman 1990: 6).

This journalistic approach to IRB, she explained, became necessary with the American strategy to communicate directly with the populations of occupied Europe, rather than directing messages towards their adversary. Other national governments, including the UK, Germany, and Russia, were also using IRB to propagate a variety of messages to a variety of audiences in pursuit of their own specific national interest during the war (Price 2002). For its part, Canada's International Service began in 1945, broadcasting six hours a day to Western Europe, in English, French and German (Finnie 1996). Although it was 
initially designed to keep Canadians serving in Europe informed, psychological warfare against Germany was said to be a priority during the remaining months of the war (Hall 1997; Canadian Broadcasting Corporation 2010). Organized under the Department of External Affairs, the station added several new language services in Western Europe, before shifting its focus toward the Soviet Union in the 1960s (Siegel 1997; Olechowska 2007).

When the Second World War ended, and the attention of the West turned toward the East, governments and international radio broadcasters alike began restructuring their strategic communication assets to facilitate the new 'public diplomacy' strategies being designed for the ideological struggle of the Cold War (Taylor 2009). With the post-war development of communication research as a defined discipline of study (Cmiel 1996), the term propaganda increasingly took on negative connotations (in North America ${ }^{4}$ ) and became reserved for describing adversary information only. Nonetheless, the objective journalism strategy adopted was being refined in contrast to the so-called 'battering-ram' direct-message tactics used by the Soviet Union (White 1952).

Following the propaganda campaigns of the Second World War, independent researcher Ralph White (1952) argued that a new resistance to international propaganda had emerged that was forcing western broadcasters to "cultivate the highest standards of journalism" simply to attract the desired audiences in the increasingly competitive media environments of post-war Europe (White 1952: 540). Monroe Price (2002) later noted how the journalistic concept of 'balance' was well suited to this mission, as it was both

\footnotetext{
${ }^{4}$ In a recent survey of public diplomacy broadcasters, O'Keeffe and Oliver (2010) have noted that the Chinese government still uses the Mandarin word for propaganda to describe its own activities, but in recognition of the sensitivities surrounding the practice of propaganda, has stopped using the word in foreign languages (p. 7).
} 
"journalistically praiseworthy and important as a means of validating the propaganda enterprise" (Price 2002: 4). With greater access to the audiences of war-time propaganda, however, White's analysis began to shift thinking from the earlier top-down approaches of functionalist theory, toward a greater emphasis on audience behaviors and their media consumption practices - a precursor to the 'limited effects' theories emerging at the time (see for example Katz \& Lazarsfeld 1955).

In Voice of America: A History (2003), former VOA deputy director Alan Heil provides another view of the 'objective journalism' model of international broadcasting as it was used for public diplomacy during the Cold War. Through a history of VOA's epochal events, Heil describes many of the institutional struggles (including political intrusions, reorganizations, budget cuts, and leadership purges) to argue that: "America's Voice can continue to enhance national prestige in an increasingly dangerous world, promote the national interests, and foster cultural ties with others if it keeps its covenant with listeners 'to tell it straight"' (Heil 2003: 4). In doing so, he emphasizes the notion of 'creditability' suggesting that efforts to 'propagandize' the service will inevitability have negative effects, such as the loss of audience share. Underlying this case, Heil views the VOA as no different from commercial media institutions, advocating a liberal-pluralist 'watchdog' role that others have referred to as 'ideological propaganda' for its role in supporting nationalist, free-market objectives (Ellul 1965; Herman \& Chomsky 1988). While a useful account of VOA's history, Heil's anecdotal methodology provides a poor framework for evaluating the effectiveness of such communication efforts, leaving only a normative argument for the objective journalism model of IRB. 
In the decade following the Cold War a lot of thinking changed. Diplomatic strategies for international relations began to explore theories of 'soft power' (Nye 2004); international broadcast regulation became rapidly de/re-regulated (McChesney 2000); and changes in information technology (i.e. satellite, internet, and digital audio) increased the number of both state and non-state actors operating in the new areas of geo-political interest (Djerejian 2003; Sussman 2010). Strategic communication resources of the U.S. began to shift away from Eastern Europe, first toward Africa and Asia, and then later to include the so-called 'Arab and Muslim World' (Djerejian 2003). Large ethno-linguistic communities, that cross-cut the political boundaries of the nation-state, were increasingly recognized by a wide variety of state, market, and civil-society organizations (Appadurai 2002). Institutional change in the U.S. (Nawawy 2006; Snow \& Taylor 2006) resulted in all non-military U.S. broadcasting organized under the Broadcasting Board of Governors (BBG) within the Department of State. Numerous other religious, international, and nongovernmental organizations (such as: the Arab League, Hezbollah, or the United Nations Integrated Regional Information Network) began broadcasting to communicate messages in one form or another; and commercial enterprises such as Al Jazeera began to challenge the hegemony of western global broadcasters such as CNN and the BBC World Service.

As these changes occurred, the model of objective journalism adopted to counter enemy propaganda during the Cold War increasingly came into question. Concerns over the effectiveness of IRB to reach new audiences dominated the debate, as market-based principles of commercial broadcasters were increasingly applied to strategies of IRB. In 2002, George Gedda, the U.S. State Department correspondent for the Associated Press, documented this shift in a case study of VOA's Middle East Radio Network (MERN), 
and its Arabic-branded station Radio Sawa. In it he described the Broadcasting Board of Governors' 2002 - 2007 strategic plan, Marrying the Mission to the Market, as a strategy designed to "promote freedom and democracy through the dissemination of accurate, reliable and creditable information" (Gedda 2002: 55). While similar in objectives to the early models of objective journalism, what distinguished this new approach to IRB from previous strategies, was a greater reliance on market research principles to help account for what was "already available in the marketplace and what has the best chance of delivering the largest possible target audience to get the message across" (Gedda 2002: 54).

This new 'commercial model' of IRB, with its news and information embedded within programs of popular music, can be seen as similar to the way in which commercial broadcasters operate in North America - delivering targeted audiences to advertisers in a 'free lunch' type of format (Smythe 1981). While this commercial approach (designed to maximize audience share) may prove to be successful in attaining more 'youth' listeners, questions concerning its ability to achieve the state's strategic communication objectives remain unresolved. Communication Professor Mohammed el-Nawawy (2006) examined multi-year opinion research data on Arab-youth perceptions toward the U.S., and argued that attitudes toward U.S. foreign policy may have actually worsened since their exposure to Radio Sawa (Nawawy 2006: 200). For theories of mass communication, this reinforces the need for a methodological framework that accounts for the complexity of audience reception, and the ability of IRBs to communicate strategic messages to their designated audiences. 
Overall, IRB can be understood as a strategic communication tool of the state that is used for the promotion of foreign policy generally, as well as programs to help initiate and support transitions to more stable and democratic societies (Price 2002). In times of conflict, IRB is increasingly coordinated with military strategy and used in programs of post-conflict reconstruction and development. Understood as a soft power tool of foreign policy, IRB is operationalized within larger programs of propaganda or public diplomacy, where the commercial models designed to maximize audience share work to disseminate news that is accurate, objective, and reliable. Although the effectiveness of IRB remains the dominant question in debates over its use, such use by nation-states has been seen to increase exponentially since the end of the Cold War (O'Keeffe \& Oliver 2010), and can be seen in current programs of public diplomacy, democracy promotion, and democratic reconstruction.

\section{Propaganda Theory}

Underlying the practice of IRB have been theories of propaganda and public diplomacy that have worked to shape its institutional development and use in programs of strategic communication. Although the origins of propaganda practice, to intentionally disseminate information for the purpose of persuasion, dates back to the $17^{\text {th }}$ century Reformation and its use by the Catholic Church to help stem the tide of Protestantism (Jowett \& O'Donnell 2005), much of the literature concerning its practice has focused on the period of 'modern propaganda' that followed the First World War and the widespread dissemination of mass communication technologies (Cmiel 1996). Following the Industrial Revolution and the transition of many western countries to capitalist economies, technological developments 
in both transportation and communication made possible the mechanized spreading of ideas to mass audiences. The development of inexpensive newspapers, steam trains, railway networks, photography, the telegraph, telephone and underwater cable, set the technological conditions for mass communication and the wide-spread dissemination of ideas to mass audiences (Mattelart 1994).

Much of the literature on propaganda concerns itself with the period from 1917 to 1991 in what can generally be understood as the age of 'modern propaganda'. This period is characterized by the salience of the nation-state as the dominant international actor, its corresponding use of mass media as a tool of foreign policy, and the bi-polar framework of international conflict informing much of the research on mass communication (see for example Ellul 1965; Mattelart 1994; Taylor 2003; Jowett \& O'Donnell 2005). The early study of propaganda began with questions regarding its methods and effectiveness, but has since shifted to a more critical examination of the broader structures and functions of communication in society. With the outbreak of WWI, and Germany's use of air-dropped leaflets in the United Kingdom, the principles of both advertising and public relations (as codified by Ivy Lee's 1904 'Declaration of Principles') were put to use in the 'national interest' with the formation of the Committee for Public Information in the U.S. (1917) and the Ministry of Information and (related) Department of Enemy Propaganda in the U.K. (1918). Although the Allied countries were somewhat late in the war developing this institutional capability, interest in the effectiveness of propaganda was institutionally set, and effects-based research into the formation of public opinion flourished after the war (Cowan-Shulman 1990). 
In 1922, journalist and political commentator, Walter Lippmann argued in Public Opinion that participatory democracy was no longer achievable in complex industrial societies and that 'specialists' (such as public relations practitioners or 'councils') were required to help "crystallize public opinion" and "manufacture consent" for executive action in modern democracies (Lippmann 1922). He argued that people's behaviour was based less on any "direct and certain knowledge" of events, than on the "pictures in our heads" created by modern media. For Lippmann, propaganda was simply an effort to "alter the pictures to which men respond" (Lippmann 1922: 11). Further, he argued that the ability to manipulate public opinion rests not only on the persuasive power of mass media (particularly cinema in this case), but on the ability to restrict the public's access to events. "Without some form of censorship" Lippmann wrote, "propaganda in the strict sense of the word is impossible" (Quoted in Stuart 1996: 152). From the standpoint of mass communication theory, this particular insight has had a lasting impact and can be seen in current models of psychological operations and information warfare where the concept of 'information interdiction' (including physical destruction) has been the subject of considerable debate (Miller 2003).

Through an analysis of First World War propaganda, U.S. Professor of Political Science Harold Lasswell (1934) identified the five components of successful propaganda programs, and as a result, argued for a type of institutional coordination that links policy development with propaganda activities (Lasswell 1934). Although a novel concept at the time, this level of coordination is now considered one of the central principles of strategic communication planning and can be seen in contemporary practice (see for example: U.S. DSB 2004). Lasswell's most enduring contribution to the field of mass communication 
can be seen in theory with his development of the "Who says what, in which channel, to whom, with what effect" model of mass communication (Quoted in Fisk 1990: 30). While a seemingly simple conception of the mass communication process, it nonetheless raised the question of 'effect' in the analysis of propaganda, shifting the analytic emphasis from the production of content, toward both communicative structures and audience reception, in the overall assessment of propaganda activities.

In a detailed study of propaganda technique, Garth Jowett and Victoria O’Donnell (1999) examined the institutionalization of propaganda practice and in so doing identified international radio broadcasting as the medium possessing substantial capacity to bypass the traditional socializing institutions of state, church, school, and family. They explained that: "radio has become the major medium of full scale international 'white propaganda' in which the source of the message is clear and the audience knows and often eagerly expects to hear different political viewpoints" (Jowett \& O’Donnell 1999: 129). The authors are careful not to overstate the impact of IRB but do highlight the reaction of many state governments whose populations were subject to such activities. Here, they explained that: "many governments in the recent past were concerned enough about the provision of alternate news sources to resort to highly costly jamming of signals" (Jowett \& O’Donnell 1999: 138). Of additional interest to understanding the role of IRB in statebuilding, is their prediction on the future of the practice. In 1999 they wrote that:

International radio broadcasts have at times been a potent force in shaping the world of propaganda in the $20^{\text {th }}$ century, and they are likely to remain so in the foreseeable future... [although] the battle for the 'hearts and minds' of listeners will not be the epic battles of the past between Communism and capitalism, but probably on a larger world scale between conflicting cultures of the industrialized advanced countries and the less advantaged Third World countries (Jowett \& O’Donnell 1999: 138). 
Although not yet on a world scale, examples of supra-national broadcasting, such as the United States' Arabic-language broadcaster Radio Sawa, are now broadcasting to entire 'language regions' of the world, reflecting changes in the geo-political landscape since the end of the Cold War. While reflecting changes in the current political environment, this model of 'public diplomacy broadcasting' has a long history in international affairs. From the early models of 'empire broadcasting' (including Radio Moscow 1923; Vatican Radio 1931; and the BBC Empire Service 1932) to the public diplomacy broadcasters of today (such as the Voice of America, BBC World Service, China Radio International, or Radio Canada International), nation-states have sought to influence and inform foreign populations for essentially ideological reasons of national interest (Taylor 2003). While these may also include information for the purposes of business, tourism or immigration, IRB is generally considered to be an instrument of foreign policy able to shape the media space of another society, including the opinions of its population and political leadership (Price 2002; O’Keeffe \& Oliver 2010).

In writing a history of propaganda since the Second World War, British Professor of international communication Phillip Taylor (2003) has examined the effectiveness of various propaganda campaigns to highlight the importance of 'frames' and 'credibility' in the successful propagation of ideas. In terms of frames he describes the structure of postwar American thought as one represented as "a struggle between the free world and the slave world" that established the framework (or master narrative) for U.S. Cold War ideological discourse (Taylor 2003: 252). This narrative, he argued, was reinforced and refined into a "stark confrontation" by the Truman Doctrine of 1948, which emphasized modernization and state-building activities in order to stabilize conflict areas and prevent 
the spread of communism (Merrill 2006). Throughout these campaigns, Taylor shows how credibility became the central issue in the ideological "battles for competing truths" (Taylor 2003: 322). Propaganda activities, he argues, were understood to be less about being right as they were about being credible. With the post-war expansion of IRB into the contested areas of Eastern Europe, credibility became the operational focus of Cold War propaganda efforts, as reflected in the United States' Smith-Mundt Act (1948) that institutionalized this practice. By creating a legal mandate for the Voice of America, the act codified the practice of providing accurate, objective, and comprehensive information about the United States and its policies. A similar sentiment can be seen in the Voice of America mandate itself, that aims to "present the policies of the United States clearly and effectively, and also present responsible discussions and opinion on these policies" (U.S. Public Law 94-350).

Critical research on the utility of propaganda crystallized in the 1960s with the work of Jacques Ellul in Propaganda: The Formation of Men's Attitudes. As a professor of law and sociology, Ellul takes a much wider view, arguing that propaganda is more accurately characterized as a sociological phenomenon resulting from the 'atomizing' effects of mass media technologies and the related disassociation of individuals from other forms of social organization including family, tribe, church, or village (Ellul 1965: vi). For Ellul, the "concern for effectiveness" is the central characteristic common to all practices of modern propaganda, regardless of difference in political regime, marking an ontological shift from earlier theories anchored in the 'East-West' political frameworks of the Cold War. Through a comparative analysis of state propaganda, Ellul describes 'national self-awareness' as the one effect common to all practices of modern propaganda 
regardless of the political ideology or method used (Ellul 1965: ix). Here, the effects of propaganda on perceptions, attitudes and behaviours are no longer perceived as 'shortterm' or 'direct', but rather as long-term or 'structural' in the formation of opinion, and can be seen in the development communication strategies adopted following the Second World War (Bah 2008). While Ellul's analysis has served to broaden our understanding of propaganda effects in national development, it has also worked to reinforce the nationstate as the primary unit of analysis in propaganda studies, dominating such research for over a generation.

U.S. Professors Edward Herman and Noam Chomsky (1988) developed a further critique of propaganda practice in modern industrialized societies in The Manufacture of Consent: The Political Economy of the Mass Media. In doing so, they conceptualized the problem as one of commercial interests that systematically work to set the news agenda for democratic participation. They explained that:

In short, the major media - particularly, the elite media that set the agenda that others generally follow - are corporations 'selling' privileged audiences to other businesses. It would hardly come as a surprise if the picture of the world they present reflected the perspectives and interests of the sellers, the buyers, and the product (Chomsky 1989: 8).

Propaganda is understood here as the result of media behaviour, institutionally structured to serve the interests of capital, while at the same time working to reinforce the ideology of advanced capitalist democracies. Through a methodology of 'paired examples', the authors have identified numerous historical inconsistencies between U.S. foreign policy and American public opinion, to demonstrate the dysfunctional 'watchdog' role of mass media in American society. Applying the propaganda model to explain media behaviour, 
Herman \& Chomsky (1988) have shown how the dominant media in the United States have worked to systematically filter out dissenting opinion, thereby helping to frame the boundaries of public debate. Although the propaganda model has been criticized for excessive determinism (Schlesinger 1989), and a tendency to minimize journalistic agency (Hallin 1994), it has nonetheless served to highlight some of the limitations of commercial media organizations to provide the information necessary for democratic participation.

In Branding Democracy (2010), Gerald Sussman uses a propaganda framework in order to help explain Western 'democracy promotion' efforts in the post-Soviet states of Eastern Europe. In doing so, he describes the policies and techniques of U.S. government institutions, and non-government organizations, that have been used in support of foreign policy objectives to help engineer elections and elect pro-Western leaders in the so-called 'colour revolutions' in Eastern Europe (Sussman 2010: xix). Although not directly related to state-building activities, the promotion of democracy can be seen as a related activity to the larger processes of democratic reconstruction and development, particularly as it relates to the manufacture of domestic support for such activities.

Two additional streams of literature that see a propagandistic function of mass media came in response to the economic globalization and neo-liberal restructuring of the 1980s (Garnham 1990; Golding \& Murdock 1991; Bagdikian 1992; McChesney 2000), as well as the renewed emphasis on state power since 2001 (Price 2002; Harmes 2004, Ralston Saul 2005; Snow \& Taylor 2006). Of significance here to questions of political development is the shifting nature of power between the state and the market; and the institutional mechanisms by which state power is exercised internationally. Collectively, 
this literature has worked to reinforce the nation-state, and its corresponding institutions, as the primary actors in shaping public opinion within democratic societies. Questions concerning the role of mass media, and the political and economic interests they serve, are supported by macro- and institutional-level analyses that indicate patterns of media behaviour consistent with the economic logic of capital accumulation. Media content has been understood to reflect elite interests, framed in ways that work to help reinforce the dominant ideology and consolidate national power. Audiences here are critiqued as being 'atomized individuals' with little agency in the construction of meaning, and as a result, media effects are more often assumed than assessed empirically (for example: Chomsky 1989; Bagdikian 1992; McChesney 2000).

Throughout these arguments certain aspects of the supporting evidence reoccurs with frequency. The role of institutions such as: the Committee on Public Information (CPI), the Voice of America (VOA), the BBC World Service (BBC), the Broadcasting Board of Governors (BBG), have informed much of the debate. Content was generally regarded as news and information until after the Cold War when new political strategies, institutions, and information technologies broadened conceptual and creative thinking (Sussman 2010). Audiences have generally been viewed by such theorists as atomized, passive recipients, with little agency in the construction of meaning; whose 'effects' have been measured through voting and public opinion polling. Collectively there is a strong case made for a nation-state's use of propaganda in the maintenance of national unity and projection of state power, but less so for elite classes to determine the strategic interests of the populace. While the usefulness of propaganda as a value-free concept may have passed, the use of its 'tactics, techniques and procedures' in contemporary programs of 
strategic communication is alive and well. The central characteristics of: disseminating information for the purpose of persuasion, and; concern for the analysis of effects, can be seen in the current debates over public diplomacy and strategic communication.

Overall, the central debates concerning propaganda theory can be understood as: definitional, moral, legal, and empirical. The definitional debates over what exactly propaganda is, who conducts it, and how and where it occurs, have largely settled around Ellul's criteria of "anyone concerned with effects" and generally reflects the approach of institutional political-economy, situating power in the institutions of state and market (see for example: Taylor 2003). Normative questions concerning the legality and morality of propaganda practice are far from resolved (Price 2002). Critical scholars have raised a number of important questions concerning the structure and content of media in liberal democracies, and the 'propagandizing effect' they are thought to have on structures of individual thought and the boundaries of political debate. Empirical questions concerning the effectiveness of propaganda have evolved, from analyzing direct short-term effects on individuals (Lasswell 1948; Shannon \& Weaver 1949) to a greater concern over longerterm structural effects, such as national self-awareness (Ellul 1965) or the naturalization of elite interests (Herman \& Chomsky 1988; Schiller 1989; McChesney 2000; McNally 2002; Hackett \& Carroll 2006).

The difference between content and structure in propaganda analysis forms an important distinction worth highlighting as it underscores one of the major fault-lines in the debate. Propaganda as content, as a product for the dissemination of ideas, involves the manipulation of symbols and is generally characterized by the omission of opposing viewpoints. As forms of media, film, posters and individual radio or television programs 
fall into this category. The information contained within such content is often empirically true, but not necessarily a complete version of events. Propaganda in this category has been regularly identified as such, and as a result, criticized for its manipulative intentions (White 1952). Propaganda as a larger process for the dissemination of ideas relies on the design of information structures in order to help frame debates where dissenting opinions may be encountered and at times encouraged (Zollner 2006). Information structures, such as national-level publications or broadcasters, will tend to view information (regardless of expressed opinion) through a 'national' frame, thereby encouraging a process of national self-awareness (Ellul 1965) or the perception of a larger imagined community (Anderson 1991). Propaganda in this view is ontologically distinct from the 'propaganda as content' version, requiring different methods of analysis. When it comes to the assessment of IRB, both content and structure must be accounted for in determining its role and effectiveness regardless of the context.

\section{Public Diplomacy}

Following the declining use of the term 'propaganda' to describe the activities of western governments (Sussman 2010: xviii), the phrase 'public diplomacy' emerged in the 1960s to describe a similar set of activities (Zollner 2006; Cull 2009). Although the basic tenets of public diplomacy can be seen in early theories of public relations (Lee 1904, Bernays 1928) and propaganda (Lasswell 1934), its use as a defined strategy for communication did not begin until the 1980s. In 1987 for example, Laurien Alexandre described public diplomacy as "the relatively new and rather innocuous sounding term used by Reagan officials to describe the very old practice of propaganda" (Alexandre 1987: 30). What the 
doctrine of public diplomacy shares with the earlier theories of propaganda is now well documented (Snow \& Taylor 2006; Zollner 2006); with both activities displaying similar objectives, organizational structures, information products, categories of audience, and debate over effects. What is new however, is an increased emphasis on 'listening' to the opinions and perspectives of the people a state is seeking to influence, as well as a desire to build longer-term relationships with both individuals and civil-society organizations what some have now referred to as characteristics of 'the new public diplomacy' (Potter 2002; Djerejian 2003; Nye 2010; O'Keeffe \& Oliver 2010). It is important to point out however, that this so-called 'quest for dialogue' may be used as an influence strategy in and of itself, or as Zollner (2006) argued, "there is a need to look closer at who benefits from the application of such discourse" (Zollner 2006: 168-9), raising questions of power in the analysis of two-way communication.

Traditional public diplomacy is commonly defined as "a government's process of communicating with foreign publics in an attempt to bring about understanding for its nation's ideas and ideals, its institutions and cultures, as well as its national goals and current policies" (Dutta-Bergman 2006: 103). Or as the "effort by the government of one nation to influence the public or elite opinion of another nation" (Potter 2002: 3). 'New' public diplomacy shifts the emphasis from 'influencing' foreign publics toward a process that encourages 'mutual understanding' (Snow 2009: 8). In a survey of definitions, Hans Tuch (1990) observed that the one characteristic common to almost all definitions was that for public diplomacy to exist, it must be projected outside a country's borders by an official body (Tuch 1990). While this has usually been the purview of departments of state or foreign affairs, public diplomacy activities are increasingly being conducted by 
western military forces (Armstrong 2010) and non-governmental organizations (Snow 2009) in more permissive security environments.

Programs of public diplomacy are constructed to differ from earlier linear models of propaganda in that they emphasize feedback and dialogue over the traditional one-way methods of mass communication; or as communications professor Nancy Snow (2009) observed: “...public diplomacy philosophies, strategies and tactics are shifting from oneway informational diplomatic objectives to two-way interactive public exchanges" (Snow 2009: 10). Joseph Nye (2010) has recently described the practice of public diplomacy as consisting of 'three dimensions' that work toward the same goal: short-term media communications, mid-term strategic communication, and the development of long-term relationships (Nye 2010). Here, Nye has identified the important 'temporal' distinctions that characterize different public diplomacy activities, and their anticipated effects.

Public diplomacy activities generally include student, cultural and international visitor-exchange programs; government video teleconferencing with foreign journalists; funding for non-governmental organizations; international broadcasting; and increasingly the assistance and coordination of private sector resources (Nye 2004). Although public diplomacy uses a wide variety of enablers to achieve its policy objectives, international radio broadcasting is by far the most contentious aspect of such programs and occupies a central position in the debates over strategy (Alexandre 1987; Gedda 2002; Djerejian 2003; Dutta-Bergman 2006; Nawawy 2006; O’Keeffe \& Oliver 2010). In a survey of public diplomacy-type IRBs, O'Keeffe and Oliver (2010) identified the five dominant objectives of PD broadcasting: 
(1) to provide credible alternative sources of information and ideas, particularly to nations which may have insufficient resources to support robust independent media; (2) to access and influence the overseas-residing diaspora; (3) to preserve non-English languages; (4) to counter Western and English-language media, cultural, or political dominance; and (5) to project a country's culture, ideas, values and expertise (O'Keeffe \& Oliver 2010: 14).

As a communication strategy of nation-states, public diplomacy programs have generally viewed mass media as a tool for the promotion of national interests and largely reflect the assumptions held by the functionalist theories of mass communication (see $\mathrm{p}$. 12 above). Critical scholars have linked historical surges in public diplomacy activity to the ideological conflicts of the Cold War (Alexandre 1987; Snow \& Taylor 2006, 2009), and the Global War on Terror (Dutta-Bergman 2006; Zollner 2006), citing an increase in organizational growth and spending. ${ }^{5}$ Its use as a tool of foreign policy has witnessed an expansion in many regional power centers (including the U.S., U.K., Germany, Russia, and China) as well as 'middle powers' including Australia and Canada (Hall 1997).

A recent example of this can be seen in the Canada's (2005) International Policy Statement, A Role of Pride and Influence in the World, where the expansion of a public diplomacy program "to promote Canadian culture, innovation, education and business opportunities" is listed as one of the government's foreign policy initiatives (Government of Canada 2005: 29). Despite this public diplomacy goal however, Canada's approach to international broadcasting is said to be unique among the G8 countries. "It's very limited investment in international broadcasting is matched by its very limited interest in using it to promote the country or to advance its foreign policy objectives" (O’Keeffe \& Oliver 2010: 13).

\footnotetext{
5 In May 2010, BBC News reported that South Korea had resumed 'propaganda operations' against North Korea amid a crisis in relations [over the sinking of a South Korean warship] ( $B B C$ News 2010).
} 
In a review of Canada's public diplomacy efforts in Afghanistan, LieutenantColonel Christian Lemay (2009) identified some of the challenges to coordinating the country's new 'Whole of Government' (WoG) approach to international state-building operations. Whereas the processes of post-conflict reconstruction and counter-insurgency operations used to be separate activities he noted, they have now become "two sides of the same coin" (Lemay 2009: 35). Accordingly, Lemay suggests that the coordination of different Canadian government agencies, between both each other and their multinational counterparts, remains one of the main challenges to any such interagency, multinational approach to public diplomacy - that has recently become the norm in multinational statebuilding operations. Lemay explained that:

One of the major difficulties [in Afghanistan] was the synchronization and convergence of politico-military operations, public affairs activities, intelligence operations, psychological operations and effects-based operations, including theatre-wide interagency effects, within a common communication strategy (Lemay 2009: 35).

Where such coordination remains as a challenge to Canada's whole of government public diplomacy, the aim of reinforcing the fledgling government of Afghanistan may prove to be a unifying factor, helping to facilitate the synchronization of information strategy with short, medium and long-term state-building objectives being distilled into an overarching communication strategy. While such synchronization may be occurring among Canada's disparate government agencies, it appears to be taking place on the military's terms, in an approach described as a "militarized communication strategy" (Mazepa 2011: 309).

Overall, public diplomacy can be understood as a process by which nation-states engage with foreign publics in order to influence and inform the attitudes and behaviours 
within the target society. It differs from traditional forms of propaganda in its emphasis on two-way communication but retains many of the same strategies and tactics. Although public diplomacy programs use a wide variety of activities and enablers, its practice can be understood to follow the three dimensions of short-term media communication; midterm strategic communication; and the longer-term development of lasting relationships (Nye 2010). While the use of IRB in post-conflict state-building is concerned primarily with the first, it may also work to set the conditions for the later two; by establishing the structure of the broadcast community, and helping to developing supporting networks of practitioners.

\section{Development Communication}

An alternate framework for examining the role of IRB in post-conflict state-building can be found in the post-Second World War literature on development communication where the object of analysis shifts from the exporting state to that of the developing state. After the Second World War, international development institutions such as the World Bank (1944), International Monetary Fund (1944), and the United Nations (1945) were created to help coordinate the post-war reconstruction of Germany and Japan, and help develop the newly independent states emerging from colonialism. The objectives were twofold: help to improve the lives of the inhabitants living in the peripheral regions of the world (McPhail 2009); and help modernize the underdeveloped areas of the world into liberaldemocratic nation-states (Schramm 1964). This later objective was considered to be part of a larger U.S. strategy (known as the Truman Doctrine) to help prevent the spread of communism, and may be more accurately described here as 'strategic development'. The 
role of communication in such directed programs has been described as: "the process of intervening in a systematic or strategic manner with either media (print, radio, telephony, video, and the Internet), or education (training, literacy, schooling) for the purpose of positive social change" (McPhail 2009: 3).

In the early post-war years, 'national development' was seen as the objective to transition societies from other forms of social organization including family, tribe, clan, or religion; that today is now referred to as 'nation-building' or 'state-building' (Ottaway 2002; Ignatieff 2003; Sedra 2004; Fukuyama 2006). Theories of communication related to the consolidation of the nation-state are often categorized according to the effects one anticipates. Following McCormack (1961) and Carey (1969), Dennis McQuail (1994) has explained that: "for theory formulation much depends on whether one takes a positive or negative view of the different outcomes" (McQuail 1994: 71). Liberal media theorists (see for example: Lerner 1958; Rogers 1962; Pye 1963; Schramm 1964) supporting the consolidation of the nation-state, conceptualize media from an institutional perspective and theorize an explicit role for mass media in strategies of national development. The theorists in this category tend to view 'media' as institutions that play an active role in the construction of national identity, and tend to locate power in the political and economic institutions of the state, downplaying the role of human cultural activity in the formation of identity.

Critical theories (see for example: Tomlinson 1991; Mattelart 1994; Appadurai 2002) by contrast, take a much wider view of mass communication that tends to include a variety of commercial and cultural products, as well as the distributive functions of trade and human migration (Appadurai 2002). This group of theorists tends to conceptualize 
communication from a macro perspective that views 'media' as playing a role in social transformation more broadly, but generally does not address the subject of state-building directly. Theorists in this category tend to locate power within cultural factors such as language and ethnicity, as well as the media which work to expresses them, challenging the national political communities of the state. Media in this context are understood to be 'transnational' in character, working to either consolidate ethno-linguistic populations, or fragment national communities, depending on the perspective taken or level of analysis used. While this macro perspective is helpful toward understanding the broader cultural context into which IRBs operate, it is less relevant to the present discussion concerning the nature of IRB in post-conflict state-building.

\section{Dominant Paradigm of Development Communication Research}

Frameworks of development communication have helped to explain the use of media in programs of political development where communication technologies have been found to help 'set the conditions' for additional forms of development (Schramm 1964). Since the turn of the last century and the challenges of the Great Depression, an assortment of different communication technologies have been used by western states for the explicit purpose of social, political, and economic development, domestically and in programs of international development (McPhail 2009). Domestic programs that were designed to support agricultural assistance and literacy training in Europe, Canada, and the United States, helped millions of people with crop production and skills training that served to help modernize their economies after the Second World War (McPhail 2009). Eastern Canada's Antigonish Movement provides an early example of such a program 
that was designed to support "farmers, miners, and fishermen" throughout the Atlantic region (McPhail 2009: 12). Through the use of home-based study clubs, supported by a variety of printed materials, the program is estimated to have trained 'several thousand' people domestically and over 5000 ‘community leaders' worldwide (McKenna 2009).

Following the Second World War, when U.S. foreign policy became focused on stopping the spread of communism, attention turned toward modernizing underdeveloped areas of the world that would come to be known as the 'Third World' (Samarajiwa 1987: 5). Institutional development theorists such as Daniel Lerner (1958), Walter Rostow (1960), Everett Rogers (1962), Lucien Pye (1963), and Wilbur Schramm (1964) were all exploring topics in the emerging field of mass communication research ${ }^{6}$, where issues of political development topped the research agenda of the U.S. government. They argued for the expansion of mass media structures (Lerner 1958; Schramm 1964), technologies, and content (Rogers 1962) to help facilitate a transition to modern capitalist democracies. In addition to fostering a common understanding of public events, and a sense of shared experience, mass media were understood to set the conditions for other forms of social, cultural, political and economic development (Schramm 1964). The modernization thesis has been criticized for its 'top-down', centralized approach to development, neglect of internal relations, and perpetuation of the social and economic structures of colonialism, but nonetheless became the dominant paradigm of development communication research and continues to be used today (see for example: BBC World Service Trust 2003).

\footnotetext{
${ }^{6}$ Critical scholars tend to view the category of 'mass communication research' as a sub-section of the wider field of 'communication studies' and do not equate this post-war period with the origins of the discipline. For a detailed discussion on the history of communication research, see Park \& Pooley (Eds.). (2008). The History of Media and Communication Research: Contested Memories. New York: Peter Lang.
} 
The dominant paradigm of development communication theory has emphasized a transfer of technology (Rogers 1962) to the Third World, in order to encourage literacy and help create a 'climate for modernization' that would facilitate economic development and a transition to modern capitalist democracy (Lerner 1958, Schramm 1964). In terms of development theory, these early models were understood as part of a larger strategy to "substitute nationalism for the alternative models of socialism on offer from the Soviet Union" (Mosco 1996: 121). Mass media in this context was understood to be national in character and capable of conferring status upon individuals (such as modernist political leaders), reinforcing social norms of thought and behavior (McQuail 1994), and assisting in the education and training of the population. As a result, the development of a modern media system was understood as necessary to set the conditions for other forms of social, political, and economic development (Schramm 1964). In a 2009 survey of this literature, McPhail explained that: "Development communication, particularly radio, was viewed as being central to improving the economic and social lot of the poor" in areas of the Third World (McPhail 2009: 6).

Reflecting the broader currents in development theory, the central debate within development communication is characterized by the same 'top-down' versus 'bottom-up' dichotomous approach to development planning and communication projects. Top-down approaches are generally characterized by objectives set outside of the target population, reflecting the interests of the initiating organization more so than those of the people and/or communities involved. Early programs of 'national development' for example, sought to dislodge attachment from local tribe, clan, or ethnic identities, in favour of a type of civic-nationalism that aimed to consolidate populations within the nation-state 
(Schramm 1964). In doing so, national-level strategies have been used to help develop common information markets, through infrastructure development and regulation, that in turn, has worked to set the conditions for national participation. Contextual variables, such as the size and shape of the country, literacy rates, mobility and participation of the population, as well as disposable income (Lerner 2001) have all factored in to the specific model adopted.

Top-down approaches were used widely in Africa and Asia after the Second World War when the dominant paradigm of development communication theory guided the activities of many donor-countries, foundations, and the development organizations implementing such projects. Following the Cold War and the deregulation of the 1990s, national strategies shifted toward neo-liberal versions, privatizing national broadcasters (Alhassan 2005), and effectively confining national governments to the regulation sector of the communication industries (Price 2002). A recent example of this approach can be seen in the BBC World Service Trust's (2003) reconstruction and development program for the broadcast media in Iraq, where the establishment of a: "technically proficient, editorially independent and impartial" national broadcaster was seen as the best approach to help facilitate a process of democratization (BBC World Service Trust 2003: 1). In describing the rationale for this approach, the $\mathrm{BBC}$ report cites the diverse ethnic and religious make-up of the country and the inability of the Coalition Provisional Authority (CPA) to "convince Iraqis of its good intentions and to engage them in a discussion on the future of their country" (Ibid).

Bottom-up approaches to development communication are characterized by a greater emphasis on the maintenance of existing, indigenous communication structures 
and community participation in both the planning and execution of development projects. Community-based programs of media development have sought to use communication technology for the coordination and articulation of community interests, frequently citing participation as the objective itself. In doing so, bottom-up, community-based strategies have tended to focus on issues of social development (such as literacy, sexual health, family planning, etc.) and media production more than any overt political or economic goals. Cultural factors such as language and literacy, communicative behaviours, and access to communication technologies appropriate to the community, are among the contextual variables identified in bottom-up approaches. Although in use since the early 1900s, bottom-up approaches to international development rose to prominence in reaction to the dominant paradigm critique (discussed below) of the late-1970s. Two of the most commonly used bottom-up approaches, of note to the examination of IRB, are known as 'participatory communication' and 'education-entertainment' or simply 'edutainment'.

Participatory communication is an approach that "implies the right to participation in the planning and production of media content" (Quarry 2006: 2) and differs from topdown versions in that they actively seek community participation in both the planning and development stages of the communication program. Participatory communication emphasises a horizontal exchange of information over vertical models of knowledge dissemination. McPhail (2009) has described three separate rationales for the use of a participatory approach: (1) native populations possess relevant information regarding their own circumstances; (2) native populations have a human right to contribute to the formation of their own advancement; and (3) inclusion of native populations helps to draw greater support for development programs, that in turn, will help to facilitate the 
achievement of common goals (McPhail 2009: 28). While often discussed in theory, the implementation of participatory models has proven to be a greater challenge in practice. Development communication practitioner Wendy Quarry (2006) has examined the gap between the 'rhetoric of participation' and the actual implementation of such programs to suggest that while there may be great interest on the part of decision-makers for programs of participatory communication, there are few initiatives designed that will actually foster participation (Quarry 2006: 3). A critique that was echoed in an assessment of Germany's public diplomacy programs, where the enthusiasm for community 'dialogue' was seen to be more of an 'institutional ideology' than any true form for public participation (Zollner 2006).

'Edutainment' is another approach to development communication that seeks to use the entertainment function of mass media (including radio, film, television, music, and live theatre) to educate a specified audience in programs designed to foster 'positive social development' (Singhhal \& Rogers 1999, 2003; McPhail 2009). It is characterized by fictional or dramatic programs ranging from children's media to adult education, and is increasingly used for the promotion of heath-related issues (McPhail 2009: 34). In this way, edutainment can be understood as similar to the practice of social marketing where the goal of influencing attitudes and behaviours supersedes any desired participation from the target audience (Andreasen 1995). While generally considered a bottom-up approach for addressing local development concerns, the practice of edutainment itself has much in common with some of the early programs of propaganda and can also be observed in topdown programs of political development. A recent example of this approach can be seen in the Canadian International Development Agency’s financial support (Cdn \$400,511) 
for dramatic television programming in Afghanistan, that while designed to educate the population on the roles and duties of the Afghan National Police, has also been described as: "a propaganda campaign to transform the image of the notorious Afghan National Police in the hearts and minds of the country's television viewers" (Woods 2010).

\section{Criticism of the Development Communication Approach}

Criticism of the modernization thesis in general, and of the dominant paradigm of development communication specifically, grew during the mid-1970s in the forms of 'dependency theory' (Eisenstadt 1976; Boyd-Barrett 1977) and 'cultural imperialism' (Schiller 1976; Fejes 1980; Boyd-Barrett 1982; McPhail 1987; Mattelart 1994). As a concept of international political economy, dependency theory has helped to explain the condition of 'underdevelopment' through a macro-level critique on the inequities of international trade, and the economic modernization processes that have worked to entrench colonial-era relationships of dependency. Theotonio Dos Santos (1971) for example, describes this relationship as "a situation in which the economy of a certain group of countries is conditioned by the development and expansion of another economy, to which their own is subjected" (Dos Santos 1971: 226). Essentially, it explains an international division of labor where developed countries use the inexpensive raw materials from underdeveloped countries to manufacture 'value-added' products for commercial distribution back to the same countries, thereby preventing underdeveloped countries from developing a domestic manufacturing capacity - resulting in a structural relationship of dependence. 
Cultural imperialism is the communication-specific critique of the modernization paradigm that began with the work of Herbert Schiller (1976) in the mid-1970s, and rose to prominence with the United Nations Educational, Scientific and Cultural Organization (UNESCO) debates on a New World Information and Communication Order (NWICO). Schiller (1979) explained that:

The concept of cultural imperialism today [1979] best describes the sum of the processes by which a society is brought into the modern world system and how its dominating stratum is attracted, pressured, forced, and sometimes bribed into shaping social institutions to correspond to, or even promote, the values and structures of the dominating center of the system. The public media are the foremost example of operating enterprises that are used in the penetrative process. (Schiller 1979: 9-10).

The 'processes' Schiller describes here, are similar in concept to the forms of ideological propaganda Ellul (1965) speaks about in western societies, where the structures of media information are thought to condition structures of individual thought. Although theories of cultural imperialism have been criticized for neglecting audience agency (Ang 1985), assuming media play a central role in cultural development (Tomlinson 1991), as well as lacking explanatory or predictive power (White 2001), the critique was nonetheless influential enough to split the NWICO debates, eventually resulting in the United States' (1985) and United Kingdom's (1986) withdrawal of support form UNESCO (McPhail 2009). Following the technological and regulatory changes of the 1990s, the framework of cultural imperialism lost prominence to the systems-based theories surrounding the globalization of culture, and is less relevant to development communication today than it was in the 1970s (White 2001). 
Additional critiques of the dominant paradigm began to question the philosophical and intellectual roots of Lerner's model (Shaw 2003). Samarajiwa (1987) for example, examined the relationship between Lerner's (1958) foundational text, The Passing of Traditional Society, and his research on U.S. military propaganda during the Cold War. Shaw (2003) identifies a number of theoretical similarities to the sociological models of ethnic assimilation developed by Chicago School sociologists in the 1920s. And more recently, U.S. Communications Professor Umaru Bah (2008) took the case a step further arguing that: "development communication research in the United States was not only influenced by U.S. Cold War propaganda objectives, it was in essence a manifest U.S. anti-Soviet foreign policy strategy" (Bah 2008: 183). Here, Professor Bah highlights one of the central aspects of the development communication critique; that when viewed from a strategic perspective, it was simply the application of mass communication research to the emerging post-war strategy of international development that resulted in the theory of development communication.

Despite this large volume of criticism, much of the theory and practice of development communication continues to be conceptualized from within the dominant paradigm (Schramm \& Lerner 1976; Fair 1989) while shifting its emphasis from national state-run programs to a greater use of market-based (Alhassan 2005) and/or community (Fraser \& Estrada 2001) approaches. In a survey of this research, Fair has observed that: "The impact of the debate has not been to radically alter the way scholars carry out their research. Rather, it seems the field has continued on the tradition of the modernization paradigm" (Fair 1989: 144 in McPhail 2009: 9). When viewed in terms of the current political constructs (i.e. failed, failing, weak, or collapsed-states) mass media continue to 
be conceptualized by governments from a 'nationalist' or 'realist' perspective where both state and market strategies are considered necessary to provide information, facilitate state-society relations, and integrate populations within the geo-political boundaries of the nation-state.

\section{Strategic Communication and Development}

If propaganda research and development communication can be understood as two sides of the same theoretical coin, one focused on content, and the other striving to develop the communicative structures necessary for democratic participation in underdeveloped areas of the world, then the concept of strategic communication is perhaps the framework best suited for understanding how both unfold in practice. In a recent review of U.S. strategic communication policy, for example, the U.S. Defense Science Board (DSB) Task Force on Strategic Communication (2004) defined strategic communication as:

.... a variety of instruments used by governments for generations to understand global attitudes and cultures, engage in a dialogue of ideas between people and institutions, advise policymakers, diplomats, and military leaders on the public implications of policy choices, and influence attitudes and behavior through communication strategies (U.S. Defense Science Board 2004: 11).

As a dedicated program of foreign relations, strategic communication is understood to help shape political environments in order to facilitate political, economic, and military objectives (Ibid). According to the DSB, strategic communication is comprised of four 'core instruments' including: public diplomacy, public affairs, international broadcasting, and information operations (U.S. Defense Science Board 2004: 12). In this view, public diplomacy is understood to "influence attitudes and mobilize publics in ways that support 
policies and interests", and relies on a variety of activities including: scholarships, youth exchanges, embassy press briefings, foreign language websites, and broadcast interviews with ambassadors and military commanders (Ibid). Public Affairs is designed to 'inform and influence' domestic populations by providing information and briefings to domestic media organizations, but employ similar "tools and methods" as public diplomacy (Ibid) and propaganda (Taylor 2003). International Broadcasting is defined here as the activities "funded by governments to transmit news, information, public affairs programs, and entertainment to global audiences via AM / FM and shortwave radio, satellite television, and web-based systems" (U.S. Defense Science Board 2004: 12). The Voice of America, Radio Free Europe, Radio Liberty, Radio/TV Marti (Cuba), Radio Sawa, and Al Hurra television are noted examples. Information Operations are described as military activities "that use selected information and indicators to influence the attitudes and behaviours of foreign governments, organizations, groups, and individuals in support of military and national security objectives" (U.S. Defense Science Board 2004: 13). Operating by the principles of 'centralized planning' and 'de-centralized execution', the different enablers can be understood to be conducting similar communication activities tailored to a variety of different audiences, both foreign and domestic.

Collectively, the instruments (or enablers) of strategic communication can be seen to follow the history and trajectory of mass communication theory, from propaganda and public diplomacy to development communication, and continue to reflect such theoretical frameworks. It is important to recall that others (Samarajiwa 1987; Bah 2008) have made the case that development communication itself was a result of mass communication and

\footnotetext{
${ }^{7}$ The BBG's StratCom Model (p. 18 above) is an example of such 'tools' used for the conduct of strategic communication.
} 
propaganda research that sought to apply media development as a component of strategic communication policy for the Cold War, and other periods of ideological conflict (Snow \& Taylor 2006). Nonetheless, with a collective focus on observable 'effects' set prior to the communication process, strategic communication instruments (including programs of development communication) can be seen to hold the same assumptions as functionalist theory concerning the role of media in society, and can be categorized in the same way. In this view, media is understood to be instrumental for the five functions of: providing information; correlating socio-political-economic components of society; continuity of culture over time; entertainment; and mobilization of the population in support of broader processes of social transformation and development (McQuail 1994). Underlying this last point is an assumption that views all communication as taking place within a competitive information environment where popular support is something to be competed for between two or more parties.

A perspective that helps us to understand the use of strategic communication in competitive information environments stems from political scientist Gadi Wolfsfeld's (1997) 'political contest model'. Although Wolfsfeld's model explains competition over news media access in contested political environments, it is useful to help understand the use of strategic communication in the contested political environments of state-building operations where competition over the population's 'hearts and minds' is understood to be critical for success (Nissen 2007). In defining this model, Wolfsfeld has outlined the contest over 'access' and 'meaning' that work to set the political agenda and frame issues in terms favourable to the initiating party. Where advantages over media access generally go to state authorities, the framing of issues in culturally-specific ways (which resonate 
with the local population) generally do not, levelling the field within the information domain. Discussing the case of Afghanistan, Thomas Nissen (2007) of the Royal Danish Defence College explained this cultural dynamic. He wrote that:

The Taliban's rhetorical strategy is simple... They use metaphors such as 'crusaders' and 'infidels' etc. to describe ISAF, and this resonates well with the Afghan population; the Taliban understand their local audiences, their culture and their situation much better than ISAF does, and they legitimise their actions and propaganda claims with reference to The Koran and Islam in a way that ISAF is precluded from doing (Nissen 2007: 6).

Whereas the propaganda / public diplomacy perspective of strategic communication can be seen to emphasize the adversarial aspects of the information environment, the use of strategic communication by development practitioners tends to shifts the focus toward a more collaborative approach, emphasizing greater audience participation, downplaying any such competition for audience attention.

In a 2005 World Bank report, entitled Strategic Communication for Rural Development, strategic communication is viewed as a process for facilitating dialogue between governments and their constituents, highlighting the importance of state-society relations in reconstruction and development processes. In doing so, it offers the following definition:

Strategic communication is a comprehensive and holistic concept. It includes all the activities needed for identifying and assessing critical issues, designing and implementing appropriate strategies, and monitoring and evaluating the results. It is an active and empowering solicitation of the stakeholders' perspective, ensuring that mechanisms are in place for a two-way flow of information (Santucci 2005: 4). 
Here, the core elements of assessment, design, implementation, and evaluation can be observed within the larger philosophy of 'stakeholder empowerment' that has become increasingly common amongst development practitioners.

UNICEF for example, describes the use of strategic communication as occurring within a 'new development paradigm' that emphasis 'results-oriented communication' within a larger framework of human rights. While the overall objectives may be seen as different from those of national development or state-building, the communicative tools used to achieve such aims are the same. In their 2005 report on Strategic Communication for Behavior and Social Change in South Asia, UNICEF explained that:

Communication is increasingly understood as an enabler of individual and social level change to achieve established development goals. Communication in the new development paradigm is much more than merely writing press releases or producing radio jingles, T-Shirts, posters or pamphlets. It is a concerted strategy derived from and intrinsically linked to larger development goals (UNICEF 2005: 2).

While all strategic communication can be seen as linked to larger development goals, it is interesting to recall here the similar shift from propaganda to public diplomacy (or what has been termed 'the new public diplomacy') with its greater emphasis on a coordinated strategy and audience participation.

A final example here is taken from the German non-governmental development organization GTZ. In their 2006 report entitled Strategic Communication for Sustainable Development, GTZ defines such directed communication in similar terms. They explain that:

Communication aims at structural changes achieved through co-operative efforts of individuals or groups, usually in a geographically defined community. Gains and changes in knowledge, attitudes and practices are part of this process. Related 
targets are therefore defined from the very outset of a project within the context of a vision and concept of sustainable development (GTZ 2006: 18).

Overall, the framework of strategic communication can be understood as one that serves a variety of short, medium, and long-term objectives, which emphasises 'target' markets and audiences over geographically defined areas (such as community or nation-state). In contrast to the propaganda and development communication frameworks, it views both activities as tactics toward the larger goals social, political and economic development. In doing so, strategic communication uses a wide variety of information enablers including public affairs, public diplomacy, information operations, and IRB which together help set the conditions for the larger development objectives.

\section{Summary}

Taken as a whole, it can be seen that the use of international broadcasting in propaganda and public diplomacy programs has gone through four distinct historical periods shaped by geo-political conflict, changes in technology, and their subsequent effects on thinking about the projection of state power. First, was the wartime period or 'development stage' where international broadcasting capabilities were institutionalized into both Church and state strategies of propaganda. This early theory was largely concerned with content, and the decision-making power to shape it. Little was known about their audiences, and the effectiveness of broadcast information was largely assumed. The strategy of 'objective journalism' was adopted during the Second World War to help counter the perceived falsehoods of enemy propaganda, elements of which can be seen in use today. 
Second was the Cold War period, where wartime international broadcasters, such as the Voice of America, BBC World Service, Radio France International, and Deutsche Welle, were re-focused in the bi-polar conflict. Seemingly content with the models in use, theorists became increasingly concerned with measuring effectiveness. Audiences behind the Iron Curtain were inaccessible to researchers and effects were largely extrapolated from audience feedback (including defections) leading to questions of sample-bias. For the most part, effects were again assumed. In the 1980s, critical positions emerged that questioned the practice of propaganda (and increasingly public diplomacy) as well as both the political and ideological motivations behind the model of objective journalism (Nicholes 1984; Alexandre 1987). Although a number of interesting questions were raised concerning the motivation for, and effectiveness of IRB, the model of objective journalism became the dominant form of IRB until the end of the Cold War.

Third then, was the decade between the end of the Cold War and September $11^{\text {th }}$, 2001. Changes in the geo-political climate, new communication technologies, and the addition of many non-state actors to the practice of international broadcasting, led to new strategies and conceptions of audience. Although the broadcast de-regulation of the 1990s led to a substantial worldwide expansion of international broadcasting activity ${ }^{8}$, its study became part of (and often substituted for) the governing theories of public diplomacy (see for example: Alexandre 1987; Dutta-Bergman 2006). Nonetheless, new conceptions of non-state audiences began to intersect with the political boundaries of the state, creating communities of language and interest that challenged the hegemony of the nation-state as the dominant audience grouping (Price 2002). Indian professor of anthropology Arjun

\footnotetext{
${ }^{8}$ Despite the expansion of international broadcast activities in the 1990s, Radio Canada International experienced substantial budget cuts and discontinued six of its 13 language services following the end of the Cold War (Olechowska 2007).
} 
Appadurai (2002) for example, has argued that the combination of electronic media and human migration has created 'communities of sentiment' which go beyond the national 'imagined communities' (Anderson 1991) of traditional mass media to form transnational groupings that may work to challenge the "monopoly of autonomous nation-states over the project of modernization" (Appadurai 2002: 179).

Fourth, is the period from 2001 to present-day where international broadcasting continues to be theorized from within strategies of propaganda, public diplomacy, and strategic-level communication policy designed to manage information more generally (Miller 2003). Categorical distinctions between domestic and international audiences have become increasingly problematic as both people and media products have been seen to migrate with increased frequency (Appadurai 2002). Models of 'objective journalism' are still in use but now also combine and compete with those of a 'commercial-style' for younger segments of the audience. Effects are still largely assumed, but now understood to be multifaceted and more context contingent. Critical theorists have begun questioning the strategies of 'information dominance' (Miller 2003), and the return of a 'propaganda state' (Snow \& Taylor 2006) in broader programs of public diplomacy.

Throughout these positions a number of common characteristics can be identified that help to identify the model of international broadcasting as currently practiced. First, is that regardless of the specific format adopted (agitative, journalistic, or commercial), all international broadcasters seek to promote a particular set of ideas and can therefore be understood as a form of ideological propaganda, in ways similar to the categorization of western news organizations as forms of ideological propaganda (Ellul 1965; Herman \& Chomsky 1988). Second, we can see that the strategic direction (where they operate) is 
determined largely by the geo-political context, whereas the operational strategy (how they operate) is determined by the cultural context in which they function. That is to say, the specific model of IRB adopted is dependant on the cultural norms and communicative behaviors of the target audience with which communication is sought. Third, is that the vast majority of international broadcasters adhere to the model of 'objective journalism' for news and information; although the more recent 'commercial-style' models in use today have witnessed a declining proportion of their content dedicated to such activities. Fourth, is that audiences are becoming increasingly fragmented in direct relation to the levels of media competition and technological capacity experienced within any particular society. In this context of heightened competition, the perception of creditability is now understood to be a decisive factor in the ability of IRBs to gain audience acceptance and the related market-share.

Outstanding issues in the debate stem largely from the measurement of effects. No agreement exists on what effects are possible, achievable, and importantly the timeframes required for such change to occur. This has led to increased concern over not just 'how' such activities are conducted, but also ‘why' such activities are conducted. While critical scholars have raised such questions, their critiques have focused on the activities of governments (and their messages) more than the broadcast organizations themselves. This debate can be seen as shifting from the study of IRB to the institutional structures of strategic communication that work to define such activities (including public diplomacy programs). While such a shift in emphasis has already begun, the empirical evidence used to debate these issues has remained focused on the broadcast organization itself, ignoring the other public communication enablers in the evaluation of program effectiveness. 
Nonetheless, in the current debate over IRB (see for example: Alexandre 1987; Cowan-Shulman 1990; Gedda 2002; Price 2002; Dutta-Burgman 2006; Nawawy 2006; Snow \& Taylor 2006; McCormick 2007), two categories can be identified that relate to the overall purpose of the broadcaster: 'public diplomacy' broadcasting; and 'surrogate' broadcasting. Public diplomacy broadcasters (such as: the BBC World Service, the Voice of America, Deutsche Welle, or Radio Canada International) are all characterized by mandates which aim to promote national information and perspectives to various parts of the world in order to help promote national interests, maintain contact with expatriate communities, and help to counter false or misleading information about government policy (Price 2002). Radio Canada International's mandate for example, is "to increase awareness of Canadian values, as well as its social, economic, and cultural activities, to specific geographic areas as determined in consultation with the government of Canada" (Radio Canada International, 2007). Surrogate broadcasters, such as Radio Free Europe, Radio Liberty, Radio Free Asia, Radio Sawa, and the Afghan case study - Rana FMpresented below, operate in specific regions of the world where access to information is considered to be limited for any number of reasons including: authoritarian control, underdevelopment, battle-damage, etc. While similar in style and format to the public diplomacy broadcasters, surrogate broadcasting is defined by its focus on the information needs of the domestic populations. That is to say, its goals are to inform local populations about the issues and events affecting their own society, provide assistance to indigenous radio stations, and train indigenous journalists and broadcasters in the western traditions of objective / liberal journalism (Price 2002). Much like the role of training military and 
police personnel in the security sector, the training of journalists is a key indicator in the evaluation of IRB's contribution to media development. ${ }^{9}$

In the area of development communication, two distinct theoretical paradigms can be observed since the Second World War. The first, known as the 'dominant paradigm' is characterized by a top-down, centralized approach to media development that can be seen historically in programs of 'national' or 'state' development. With a greater focus on the establishment of media structures and dissemination of technology, this perspective has sought to 'set the conditions' for political and economic modernization by reinforcing a national community through the promotion of state institutions. Used widely in nationbuilding strategies following the Second World War, the dominant paradigm can be seen today in programs of political development where state-building is understood to be the primary objective. The second, or alternate paradigm, is characterized by a bottom-up, decentralized approach, which is focused on issues of 'human' or 'social development'. Developed in response to the dominant paradigm, this alternate approach is populationcentric, operating at the community level where issues of literacy, health education, and family planning tend to dominate such work.

In light of this distinction, a strategic communication perspective is presented for the examination of IRB in state-building operations where both top-down and bottom-up approaches may be in use. Frequently used by practitioners themselves, the framework of strategic communication shifts the analytical focus to the overall development objectives while accounting for both content and structure in the analysis of directed communication strategy. By viewing propaganda and media development as different tactics in a broader

\footnotetext{
${ }^{9}$ At the level of critical theory, the replication of Western models through such knowledge transfers may also serve as an indicator of the cultural imperialism thesis. See for example: Mattelart 1994.
} 
theory of modernization, strategic communication frameworks are able to help bridge the gap between content and structure, where effects are understood to transpire across short, medium, and long-term timeframes.

In order to assess the motivation for, and nature of, IRB in contemporary Afghanistan, its practice can be evaluated against the strategic communication frameworks of propaganda and development communication. Specifically, does it promote democratic reconstruction through the dissemination accurate, reliable, and creditable information? Does it work to reinforce a broader sense of national or ideological community? Does it work to provide a platform for public discussion and facilitate state-society relations? In addressing these questions, this dissertation examines the case of Rana FM in contemporary Afghanistan through the lens of such communication frameworks in order to reflect on the underlying assumptions concerning the nature of IRB in state-building and motivations for its use in programs post-conflict intervention. 


\section{- CHAPTER FOUR -}

\section{IRB and State-Building in Afghanistan}

The study of IRB in post-conflict state-building is well illustrated by the case of Canada's Rana FM. Broadcasting from Kingston, Ontario, Canada to Kandahar, Afghanistan it was established by the Canadian Forces (CF) in 2006 in order to better communicate with the populations of Kandahar province. Designed to support Canada's state-building mission, this surrogate-type broadcaster has oscillated between military PSYOPS and democratic development-type functions throughout the evolution of recent conflict in Afghanistan. In doing so, Rana FM provides an interesting case for the assessment of IRB in post-conflict state-building, where inter-agency priorities come together as part of Canada's 'Whole of Government' (WoG) approach. Using a case study approach, this chapter aims to develop the hypothesis that the practice of IRB in post-conflict state-building constitutes a form of 'defensive propaganda' that works to reinforce the national institutions of the developing state.

This study of IRB begins with background information on the context for IRB in Afghanistan, and a review of the specific state-building objectives, before examining the information strategy adopted and the role of Canada's Rana FM in the development of a modern democratic state. The first section includes a brief description of the specific geopolitical, military, economic, social-cultural, and informational factors that are relevant to the current conflict, in order to establish the background necessary for understanding the station's evolution. The second section highlights elements of the state-building strategy, with a focus on comparing the security and informational components of the mission, in 
order to draw attention to the tasks one ought to expect from a surrogate broadcaster. The third section then examines the information strategy used by ISAF in counter-insurgency operations, before considering the specific structure and functions of Rana FM, in section four. This section includes a full accounting of its programming, content, audiences, and technical means of broadcast delivery, in order to assess how such IRBs have worked to operationalize the state-building strategy in practice. This chapter then concludes with a summary of broadcast activities, linking the communication objectives and strategy with IRB practice, as well as a brief comparison of Rana FM to other models of IRB, in order to highlight the similarities of such models being used in contemporary state-building.

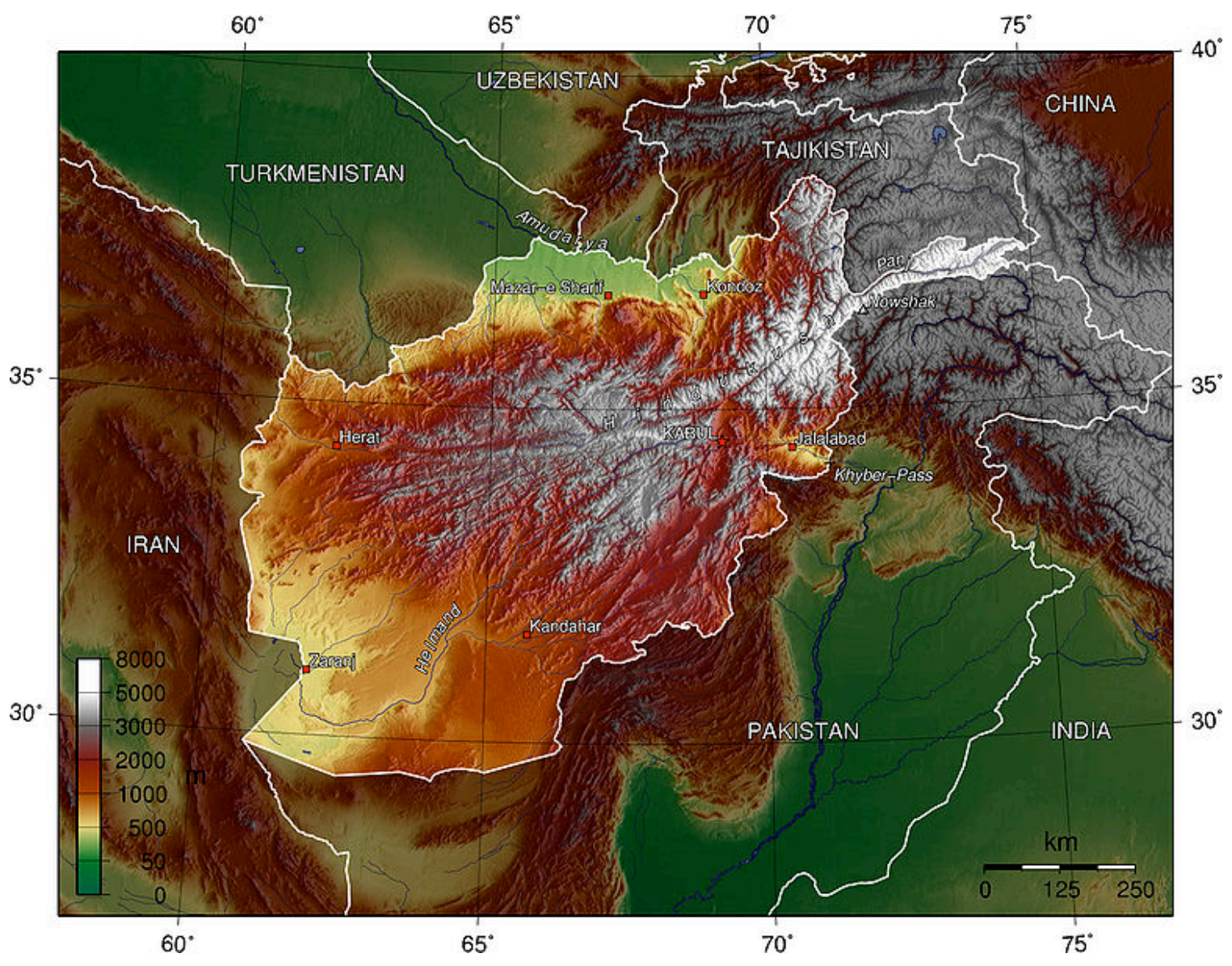

Figure 3. Geo-Political Map of Afghanistan (Source: Wikimedia Commons) 


\section{Afghanistan in Context}

Afghanistan is a landlocked country in South-Western Asia bordered by Pakistan and China to the East, Iran to the West, and the Central Asian Republics to the North. It is centered on the Hindu Kush Mountains in the North-East with large desert plains to the South-West; forming natural boundaries with Iran and South-East Pakistan. The eastern border with Pakistan, also known as the Durand Line, divides the traditional lands of the ethnic Pashtun people between Afghanistan and Pakistan, and remains the single largest challenge to the territorial integrity of the state. Figure 3 (above) and figure 4 (below) illustrate the geo-political and ethnic make-up of the country respectively.

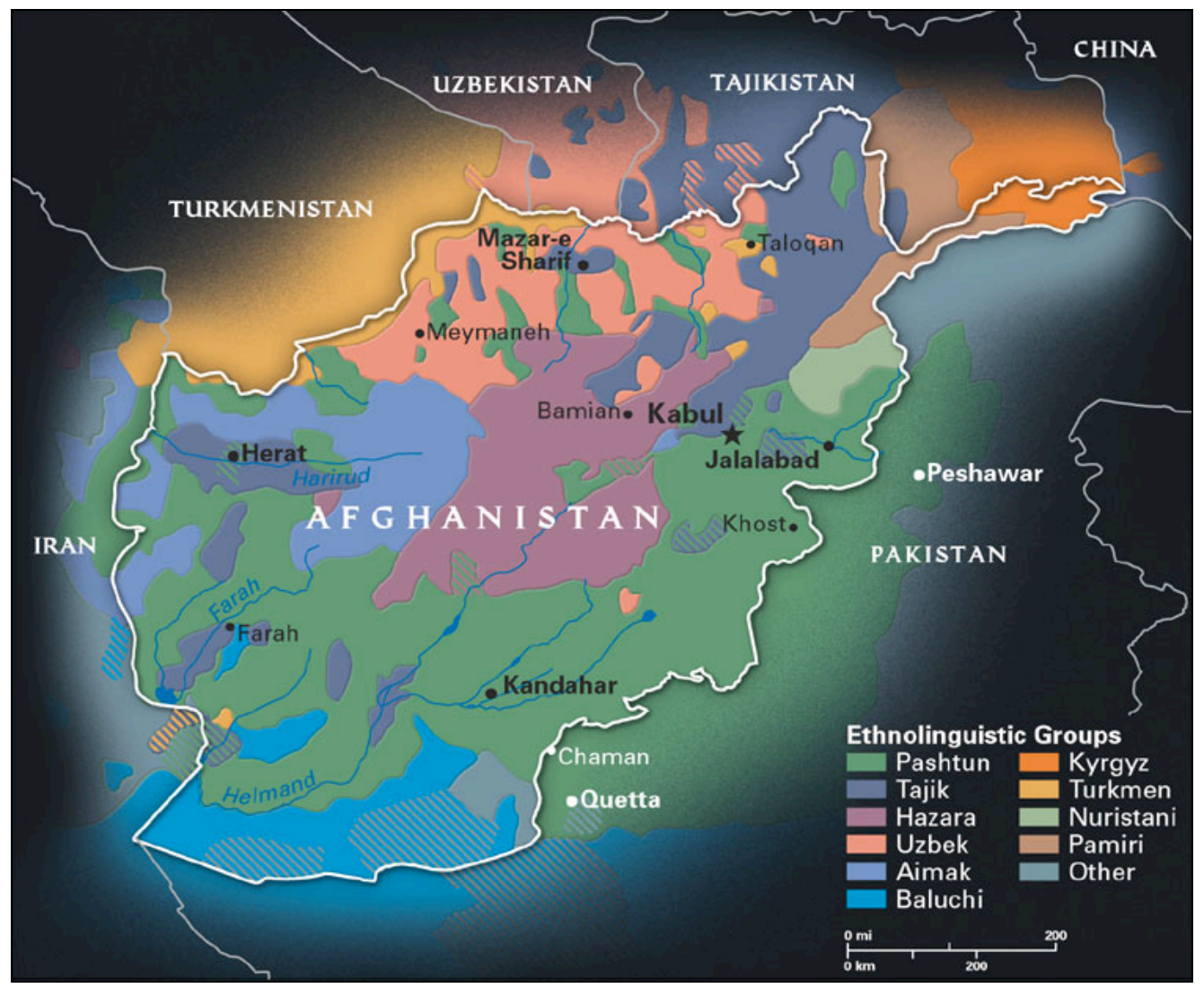

Figure 4. Ethnic Distribution Map of Afghanistan (Source: National Geographic) 
A 2009 UN estimate places the Afghan population at just over 28.1 million, with approximately 2.7 million refugees living in Pakistan and Iran. Religiously, Afghan society is $99 \%$ Islamic (with approximately $80 \%$ Sunni, 20\% Shi'a) with the other $1 \%$ representing the total Christian, Hindu, Sikh, and Jewish ${ }^{10}$ populations. According to the same UN estimate, ethnic distribution throughout the country is approximately: $40.9 \%$ Pashtun; 37.1\% Tajik; 9.2\% Hazara; 9.2\% Uzbek; 1.7\% Turkmen; and 1.9\% other (that represents the various nomadic tribes that migrate throughout the country). Afghanistan's ethnic diversity is further complicated by an underlying tribal system that works to shape people's identity and influence the lives of populations living beyond the major cities. The U.S. military's Afghanistan Field Guide (undated) describes Afghan self-identity in this way: "In many instances an Afghan will not primarily define himself as a 'Pashtun' or a 'Tajik' but as a member of the 'Zadran' tribe or an inhabitant of the 'Panjshir' valley" (U.S. Afghanistan Cultural Field Guide, undated: 3). Although the larger groups do exist, ethnic categories of analysis matter far less to the way Afghans see themselves. Identity in Afghanistan tends to be very local corresponding more to family history and the geographic dispersion of the tribes (Ibid).

Of particular importance to IRB, are the major languages spoken throughout the country. Roughly paralleling the ethnic distribution, Dari (or Persian) is the first language of almost half the national population, with Pashto being spoken by approximately $40 \%$. Uzbek is spoken or understood by $6 \%$ of the population, Turkmen by $3 \%$ (UNAMA). The languages are shared with neighbouring cross-border populations in Iran, Pakistan,

\footnotetext{
${ }^{10}$ Despite an 800-year history of residence in Afghanistan (peeking at approximately 40000 people), $\mathrm{Mr}$. Zablon Simintov, is today known as the 'last Jew in Afghanistan' who maintains the synagogue in Kabul (Hancocks 2010).
} 
Uzbekistan, and Turkmenistan respectively. Figure 5 (below) illustrates this language distribution within the Afghan state.

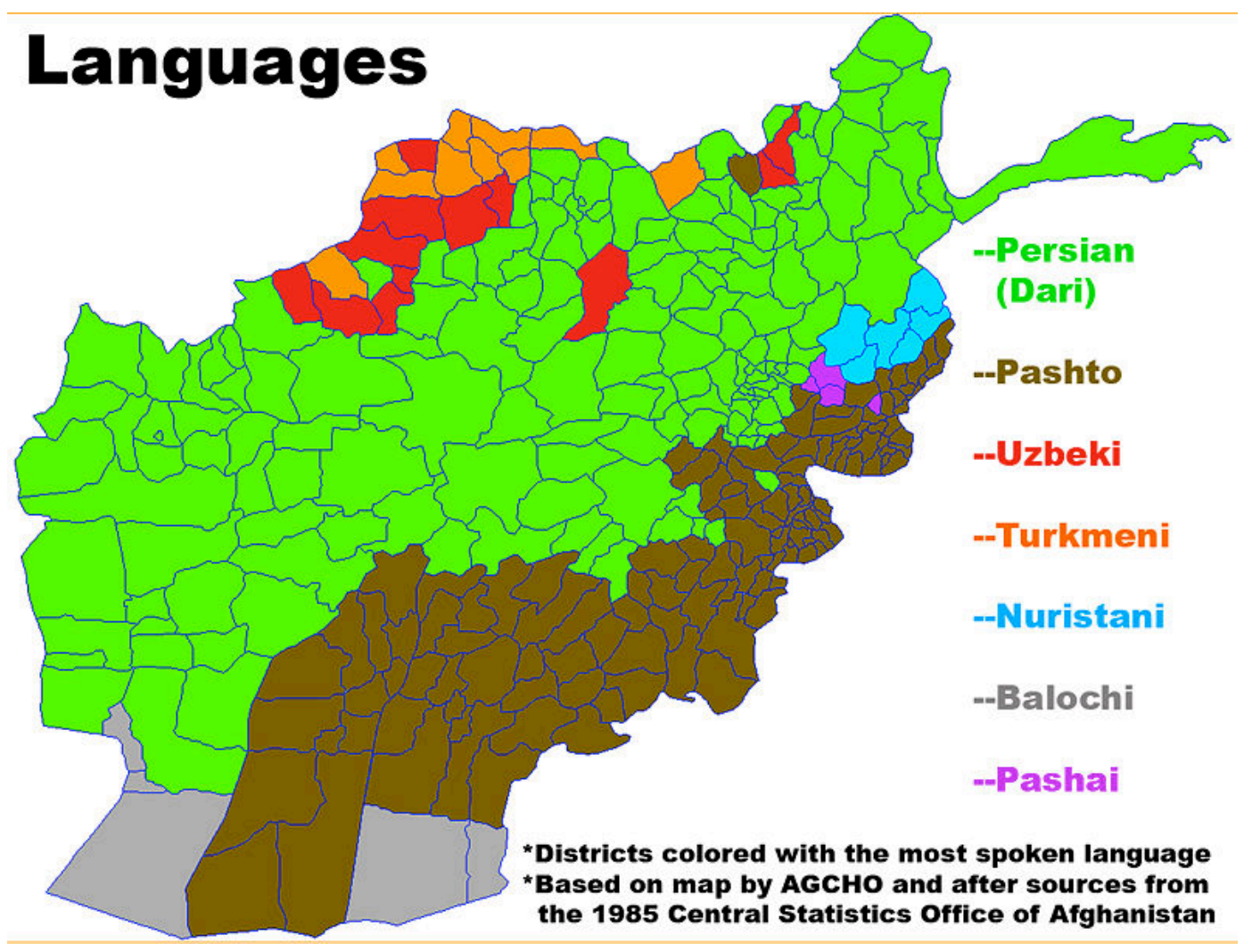

Figure 5. Language Distribution Map of Afghanistan (Source: Wikimedia Commons)

The media in Afghanistan has experienced a dramatic revival since the end of the Taliban era, with literally hundreds of newspapers, radio and television stations launching operations after the fall of the regime in 2001 (Siddiqi 2005). With low rates of literacy, and security concerns hampering the distribution of newspapers, radio is by far the main source of information for Afghans. In their 2006 Survey of the Afghan People, the Asia Foundation reported that three in five people $(60 \%)$ said that they "relied on radio as their primary source of information regarding current event and news of national importance" 
(Asia Foundation 2006: 73). Although there is a wide range of ownership models (state, private, military, and NGO), much of the content being produced is modeled on Westernstyle programs such as the British radio soap opera The Archers (New Home, New Life in Afghanistan) or the American Idol-inspired reality program Afghan Star (Brockes 2001). While such gains have been made in the number and diversity of media organizations, a recent decline in press freedoms has been observed, noting a decline in both journalistic safety and independent funding (Reporters Without Borders 2009; Sachs 2010).

In Kandahar City specifically, there is access to 13 radio stations, eight of which are local, and nine television stations (two local) as well as a large number of newspapers and magazines distributed throughout the city. In a 2010 survey of the media landscape in the province, Altai Consulting described it as follows:

As in other districts, it has seen an increase in the number of media outlets in the past few years: since 2006, at least one TV channel, three radio stations, and three new print outlets have been established. Yet the media scene is also characterized by a denser presence of religious-based, insurgent, and counterinsurgency outlets than elsewhere. The media is subject to a number of constraints, including high levels of insecurity (specifically nurtured by insurgents in Panjuai and Arghandab districts) and irregular electricity supply (electricity is generally provided every other day to government authorities and less regularly to the broader population, who are forced to rely on generators and gas). (Altai Consulting 2010: 4).

The significance of this for state-building in Kandahar province is that the information environment remains highly contested, leaving the population without a stable, credible source of news and information upon which they can rely. In such circumstances, IRBs can play a vital role in the post-conflict reconstruction process, as the institutions of the fledgling state, responsible for coordinating reconstruction and development, frequently begin without any indigenous communicative capability. 


\section{State-Building in Afghanistan}

Although the modern nation-state of Afghanistan was established in 1747, the history of democratic state-building efforts only dates back to the 1978 founding of the Democratic Republic of Afghanistan. Since this time, Afghanistan has experienced a near continuous state of civil war punctuated by two large-scale foreign occupations, including the 1979 Soviet invasion, and the 2001 U.S.-led invasion which overthrew the Taliban regime and led to the establishment of the current international state-building mission, and the focus of this study.

The international mission began on 20 December 2001 with the United Nations Security Council Resolution 1386, which authorized the formation of the International Security Assistance Force (ISAF) to stabilize the country in support of the Agreement on Provisional Arrangements in Afghanistan Pending the Re-Establishment of Permanent Government Institutions - the agreement generally referred to as the 'Bonn Agreement' (UNSCR 1386). The United Nations Assistance Mission in Afghanistan (UNAMA) was established three months later (UNSCR 1401) initiating the international civilian aspects of the reconstruction and development effort. UNAMA's current mandate is to provide political and strategic advice for the peace process; help the Government of Afghanistan with implementation of the Afghanistan Compact, the Afghanistan National Development Strategy, and the National Drugs Control Strategy (UNSCR 1662); while also promoting human rights, providing technical assistance and working to coordinate all international humanitarian relief, reconstruction and development activates (UNAMA Website).

In 2003, with the Taliban fully dislodged from power, the North Atlantic Treaty Organization (NATO) assumed command of the ISAF mission and began the three year 
expansion plan to occupy the country. From the capital region and mountain passes in the East, to the Northern provinces, then West, until occupying the Southern regions of the country in 2006. With the occupation of Kandahar City, the so-called spiritual birthplace of the Taliban movement, the conflict in Afghanistan went from sporadic fighting to a full-blown insurgency (Smith \& Koring 2008). Today, the security situation is described as 'serious', with the overall outcome still in question. Upon taking command of ISAF in mid-2009, U.S. General Stanley McChrystal wrote that:

The situation in Afghanistan is serious; neither success nor failure can be taken for granted. Although considerable effort and sacrifice have resulted in some progress, many indicators suggest the overall situation is deteriorating (ISAF 2009: 1-1).

Together, indicators such as increased insecurity, a Taliban-led shadow government, and substantial growth in opium production, threatened the viability of the state, leading the U.S. government to authorize an additional 30000 soldiers to help turn the tide (ISAF 2009).

Following the London Conference on Afghanistan in 2006, and the development of the Afghan Compact (2006), the state-building objectives in Afghanistan were divided into three lines of operation: Security; Governance, Rule of Law and Human Rights; and Economic and Social Development. Following the U.S. strategic review in 2009, a fourth 'intersecting' line of operation - Strategic Communication - was added to ISAF military plans reflecting the heightened emphasis being placed on information in combating the growing insurgency. It is described as intersecting because Strategic Communication (or StratCom) represented a 'force multiplier' for the other three lines of operation in what was increasingly being defined as a "war of ideas" (ISAF 2009: 1-2). Gen. McChrystal 
argued that: "StratCom should not be a separate Line of Operation, but rather an integral and fully embedded part of policy development, planning processes, and the execution of operations" (ISAF 2009: D2). His comments recognized the importance being placed on the informational components of all aspects of the international mission and the previous failure of ISAF to operate in the information domain - a sentiment expressed two years prior as part of the motivation for developing Canada's IRB in Afghanistan (Maple Leaf 2007). In fact, a growing number of critics (see for example: Senlis Council 2007) have expressed similar concerns, noting that ISAF may win almost every military engagement, but they have thus far failed to counter the Taliban's information campaigns, resulting in the population's declining confidence in both the Government of Afghanistan and ISAF forces (Associated Press 2010).

Following the total occupation of Afghanistan by ISAF forces in 2006, violence shifted from sporadic acts to a fully coordinated transnational insurgency. ${ }^{11}$ Civilians initially bore the brunt of the violence representing more than $75 \%$ of all fatalities. By 2007 however, the insurgency had shifted its focus from targeting international military forces alone, and began attacking humanitarian aid and development workers, elements of the fledgling Afghan National Security Forces (ANSF), as well as anyone considered to be collaborating with the Afghan government or ISAF mission (Smith \& Koring 2008: A21). In a manner similar to ISAF's doctrine of counter-insurgency (COIN), the Taliban have increasingly recognized 'winning the population' as a key factor toward achieving their long-term objectives, and have had some success at separating the people from both the government and ISAF forces (Associated Press 2010).

\footnotetext{
${ }^{11}$ Use of the term 'transnational' here refers to the Afghanistan - Pakistan international border (or Durand Line) established by the colonial Government of British India in 1893, which is not recognized by either the Government of Afghanistan or the Pashtun tribes in eastern Pakistan (Grare 2006).
} 
Against this shifting backdrop, ISAF was tasked with two basic functions: reduce the capacity of the insurgency to destabilize the country, and develop the capacity of the ANSF to provide self-sustaining security in order to set the conditions for international forces to leave. In doing so, efforts were made to "maintain and strengthen the Afghan population's positive perception of, and support for, GIRoA [Government of the Islamic Republic of Afghanistan] institutions and the constructive supporting role played by ISAF and the IC [International Community]" (ISAF 2009: D2). As described by ISAF, "The information domain is a battlespace, and it is one in which ISAF must take aggressive actions to win the important battles of perception" (ISAF 2009: D1). These 'aggressive actions' became necessary as ISAF began to understand the complexity of Taliban information activities, and realized they were they were losing the confidence of the Afghan population (Ward 2007: A3).

The five main actors in the Afghan state-building process can be understood as: GIRoA; ISAF; UNAMA; the Taliban; and importantly the civilian population. ISAF, GIRoA, and UNAMA can be understood as 'lead agencies' in the respective security, governance, and development sectors, but all can be seen to operate in an interrelated way (ANDS 2008). The term 'Taliban' is a blanket name used to describe the totality of opposition forces, rather than a complex set of loosely defined political-military actors ${ }^{12}$, and is used interchangeably with 'insurgents' and 'the insurgency'. Often overlooked in the various forms of operational planning, the civilian population is seen as the central component of counter-insurgency strategy, where the objective is not so much to defeat 'the enemy' as it is to win the support of the local populations - a distinction critical to understanding the role of IRB in state-building operations.

\footnotetext{
${ }^{12}$ See for example: Verma, S. (2011, September 14). Jalaluddin Haqqani - The Real Threat in Afghanistan.
} 
At this point, it is also important to note the dynamic nature of the state-building objectives, and the evolving strategies that have resulted from such change. When viewed as a spectrum, from open conflict to sustainable development, it becomes possible to see an evolution of the overall strategy and the subsequent role(s) of IRB therein. Discussing the role of military PSYOPS in programs of public diplomacy, former U.S. Army Captain Mark Kilbane (2009) noted that: "The situation in Iraq and Afghanistan today has moved into what the military calls Phase IV, the post-conflict stage, which shifts from tactical PSYOP into strategic communication, information operations, and PD” (Kilbane 2009: 190). During the early phases of conflict, IRBs might be expected to support the military PSYOPS objectives (such as discrediting insurgents or advising populations on areas of open conflict), whereas during the phases of reconstruction and development IRBs can be expected to perform the more traditional functions of surrogate broadcasting - providing information necessary for participation in the democratic process (McCormick Tribune Foundation 2007). In the later stages, where state-building and reconstruction activities shift to indigenous processes of national development, the popularity of IRBs could be expected to wane in favour of local media as it becomes available (Torfeh 2007).

One additional point to note about state-building in Afghanistan is that it not only goes through the different stages of a reconstruction and development process, but that these stages do not occur evenly or simultaneously throughout the country. In what ISAF describes as the "Three Block War" (Krulak 1999), one could experience the conditions of open conflict, humanitarian assistance, and development-type activities, all at the same time but in different places. Together, the dynamics of time and space work to influence the way in which IRBs will function in state-building operations. 


\section{The Battle for Hearts and Minds}

Information in state-building operations works on two distinct but related levels. There is a strategic level that can be roughly equated to the realm of international affairs, and an operational level which is similar to that of domestic operations. While both ISAF and the Taliban have strategic components to their information campaigns (such as trying to influence the cohesion of the international alliance), it is their domestic operations and the so-called 'battle for hearts and minds' that is of concern to this study of IRB. Within the Afghan domestic space, this 'battle' is for the trust and confidence of the population and is waged between the Government of Afghanistan (with ISAF and UNAMA support) on one side, and the Taliban on the other. While GIRoA and UNAMA both have critical roles to play in this struggle, ISAF is by far the biggest player on the pro-government side of the information battle. That said, the basic strategy of all parties is to build-up the trust and confidence of the population while discrediting their adversaries.

In a 2007 comparison of ISAF and Taliban information activities, Thomas Nissen of the Royal Danish Defence College identifies "major differences" in the legal, political, doctrinal, moral, and ethical aspects of the respective campaigns that together constituted a form of 'asymmetric' conflict in the information domain. "While ISAF conduct kinetic operations supported by Info Ops" he writes, "the Taliban conduct information activities supported by its kinetic operations" (Nissen 2007: 11). In doing so, both parties play to their strengths. Whereas ISAF are said to win every military confrontation, the Taliban have dominated the information domain, winning the "hearts and minds" of the Afghan population (Senlis Council 2007). Nissen suggests that this is due to the effectiveness of their relative campaigns. Whereas both ISAF and the Taliban conduct a similar range of 
information activities (such as the distribution of PSYOPS materials, radio broadcasts, and face-to-face communication) those produced by ISAF lack a "cultural creditability" and often fail to resonate with the local population (Nissen 2007). Specifically, Nissen sees the Taliban using simple rhetorical strategies where they "legitimize their actions and propaganda claims with references to The Koran and Islam in a way that ISAF is precluded from doing" (Nissen 2007: 6). In doing so, the Taliban focus their messaging around a few master themes that work to reinforce dominant cultural narratives and discredit ISAF actions. Examples of this include:

- Afghanistan is the graveyard of empires; an oft-repeated message built on the folklore of the 'Mujahidin' fighters and defeat of the British in the 1880s and Soviets in the 1980 s.

- ISAF soldiers are foreigners and GIRoA are their puppets; a message that is said to resonate in the Pashtun south where an historical resentment of both foreigners and centralized government control remains high.

- The Taliban will be here when ISAF is gone; designed to create fear and prevent people from supporting GIRoA, this theme is reinforced by ISAF's focus on exit strategies and timelines for withdrawal.

In order to try and counter the Taliban's information activities, ISAF (2009) has defined their strategic communication objectives as follows:

- Discredit and diminish insurgents and their extremist allies' capability to influence attitudes and behaviours in AFG;

- In partnership, assist GIRoA and the populace in developing a sense of ownership and responsibility for countering violent extremism in order to advance their own security, stability, and development;

- Increase effectiveness of international and GIRoA communications with the Afghan people and the IC; 
- Increase Afghan political and popular will to counter violent extremism and protect the operational center of gravity, namely the support of the Afghan people; and,

- Promote the capacity of, and confidence in, the Afghan National Security Forces as a force for good in the country.

While not a direct comparison, it is nonetheless possible to see the similarities in ISAF and Taliban strategies. As defined by ISAF: "The StratCom main effort is to maintain and strengthen the Afghan population's positive perception of, and support for, GIRoA institutions and the constructive supporting role played by ISAF and the IC" (ISAF 2009: D2). This is achieved, in part, through: the promotion of a single ISAF 'brand' to internal and external audiences; the linking of local and regional stories back to national Afghan stories; concentrating on teenagers and young adults; emphasizing 'trust and confidence'; and promoting interactive communication with the population (ISAF 2009: D6). On this last point, the plan highlights a "clear recognition that modern strategic communication is about credible dialogue, not a monologue where we design our systems and resources to deliver messages" (ISAF 2009: D3).

\section{Case Study: Rana FM}

Against the backdrop of evolving conflict in Afghanistan, the Canadian Forces launched a 24-hour Pashto-language broadcasting service to the southern Afghan city of Kandahar in January 2007. Designed as a 'commercial-style' IRB, Rana FM was developed to help inform the local population of international reconstruction activities and work to facilitate better communication with its target audience of teenagers and young adults. During the 
station's development, Brigadier-General (BGen) Tim Grant, Canadian Commander of Task Force Afghanistan (TFA), explained that:

We have not been really good at telling our story. I think (the station) will go a long way to making sure that people realize that we have made significant advances in the security situation ... of the average Afghani. It's a matter of getting the message out (Quoted in Ottawa Citizen, 02 Nov 2006).

Through the use of culturally-specific music programming, embedded with a variety of Afghan news and mission-specific information, the station began broadcasting first to the city of Kandahar before expanding out into the rural districts. By the end of the first year, an audience in excess of 30000 people could be identified in third-party opinion polling being conducted throughout the country (ACSOR 2008). Although this was considered an indicator of success (in terms of developing audience share), the effectiveness of Rana $F M$ as either a tool for getting ISAF's message out or becoming a broader communicative platform for state-society relations, was less clear.

The stated objective of Rana FM was to "provide a vehicle for communicating with the target audience" (Canadian Press 2007). While this high-level direction from the Commander of Canadian Forces in Afghanistan (Joint Task Force Afghanistan - JTF-A) is relatively straightforward, it leaves open to interpretation the way in which broadcast programming will be designed. The target audience lists an age-range and location, but no further detail as to the socio-political sub-groups being sought. What exactly is to be communicated and/or discussed? Aside from providing information on the reconstruction activities of the international mission, on what topics are opinions to be sought-out? How is this synchronized with any broader reconstruction and development activities so that public opinion can be sought in the planning stages? Who directs the editorial policy of 
the station? While the answers to some of these questions may not be apparent in such high-level direction, when synchronized with ISAF's broader Information Operations campaign (regarding the security, governance, and development lines of operation) its objectives can be seen as threefold: (1) maximize audience-share within the designated audience; (2) provide a vehicle for communicating with the designated audience; and (3) help foster a unified understanding of events concerning the security, governance, and development activities of the international state-building mission.

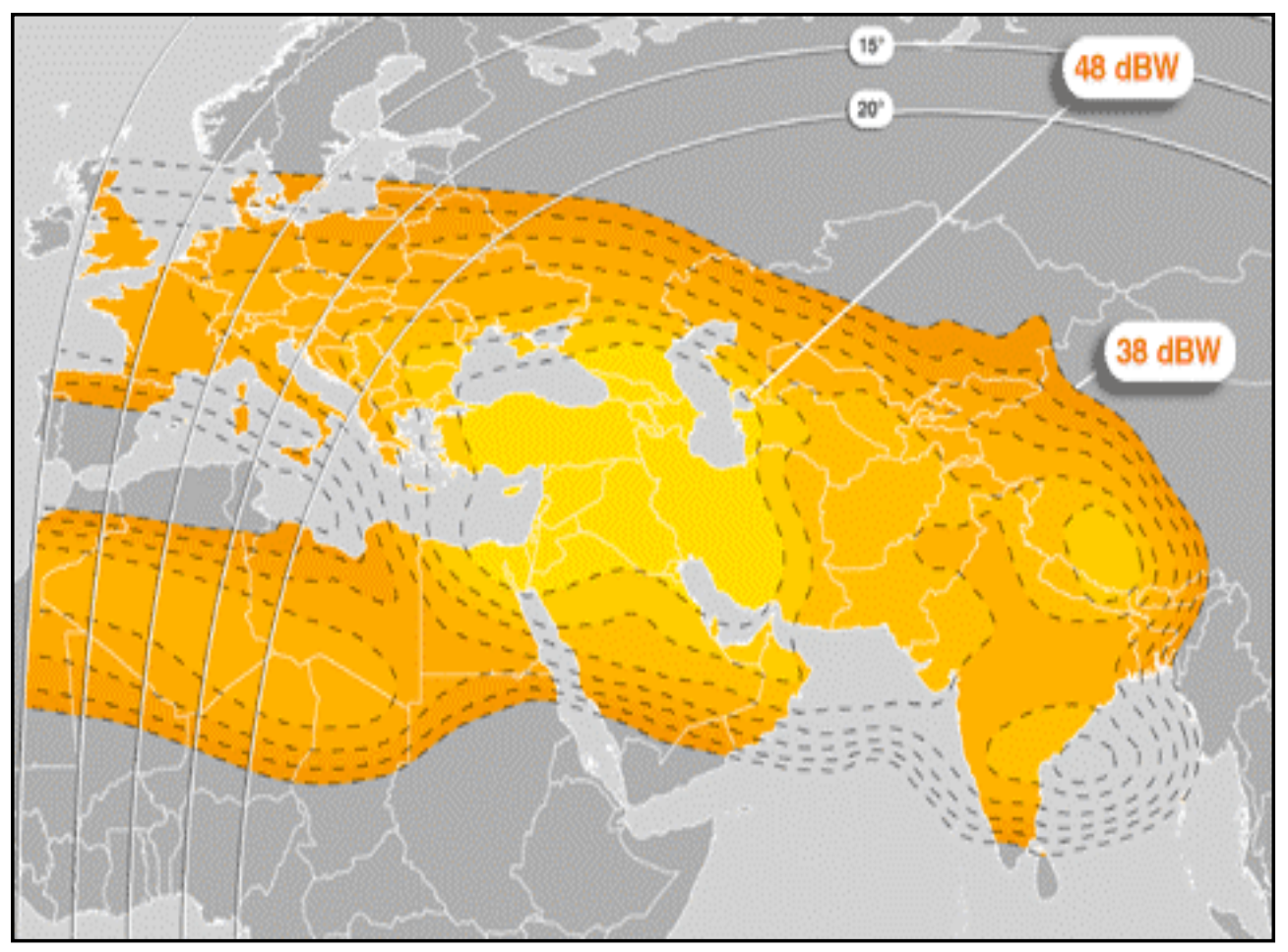

Figure 6. EuTel Satellite Coverage Map (Source: Rana FM 2009)

\section{Technical Delivery}

Rana FM programming is delivered into Kandahar, from its studios in Kingston, Ontario, via the EUTel satellite, to a series of FM transmitters within Kandahar province, 
creating a broadcast area that roughly parallels the population belt of the river valley.

Figures 6 (above) and 7 (below) show the approximate footprints of the EUTel satellite and FM broadcast areas respectively. Figure 6 shows the quality of signal (as represented from light to dark) of the EuTel Satellite service. In Figure 7, the circles in red represent the three continuous FM transmitter locations for Kandahar City (center), Panjwai District (west), and Dand District (south-east), where broadcasts have been continuous since 2007. The circles in yellow represent the two expansion districts, of Maywand (west) and Arghandab (north-east), which broadcast during 2008-09 but ceased operations since.

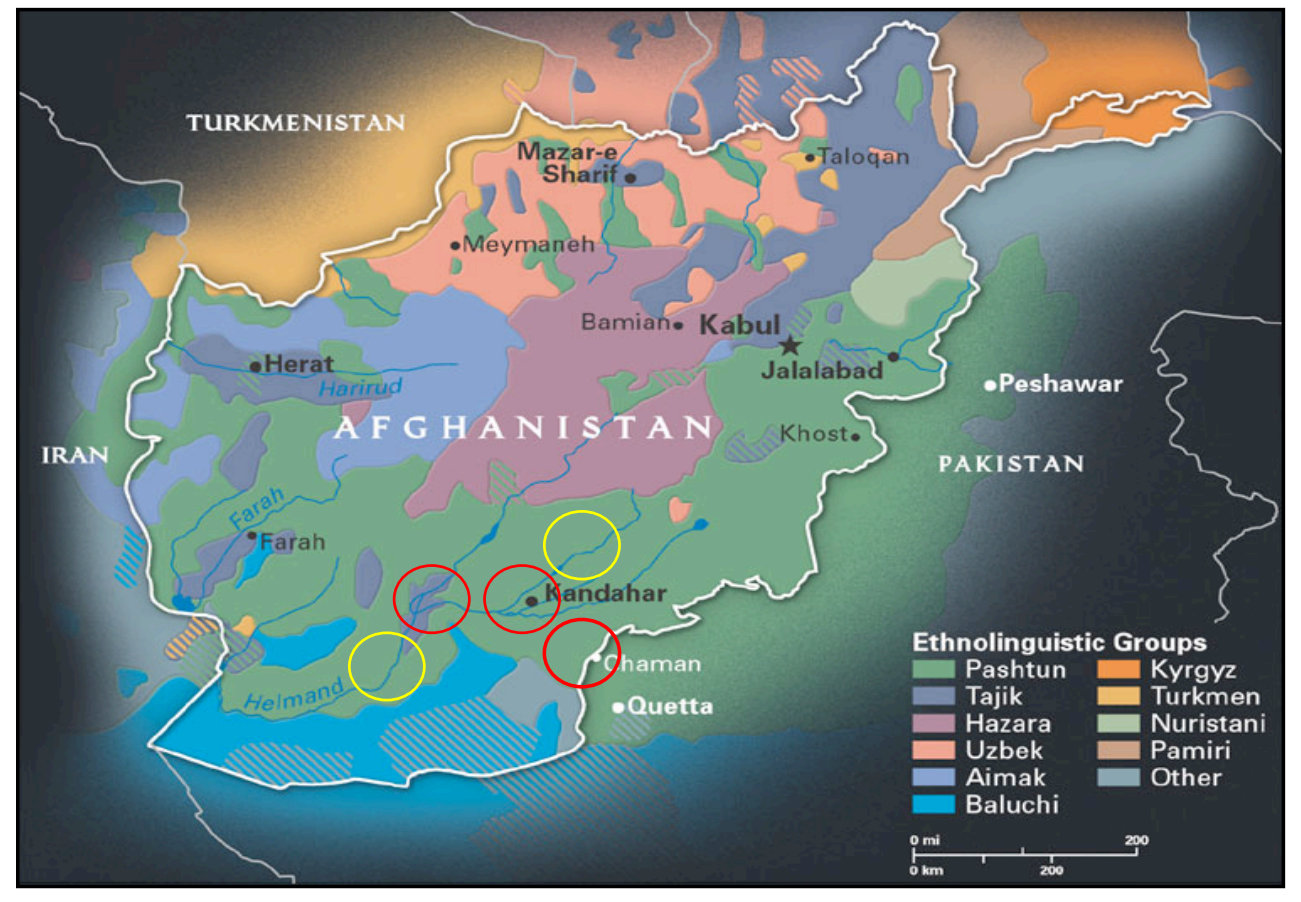

Figure 7. Rana FM Broadcast Map 2009 (Source: Rana FM 2009) 


\section{Structure and Organization}

Operating as part of Joint Task Force Afghanistan's Information Operations (IO) strategy, Rana FM was structured as part of the operational headquarters in Kandahar with oversight from a higher headquarters in Ottawa (the Canadian Expeditionary Force Command or CEFCOM). Technically, these relationships are referred to 'Operational Command' (to CEFCOM) and 'Operational Control' (to JTF-A). Operational Command describes the basic organizational structure and establishment of the general operating concept and principles. Operational Control refers to the shorter-term programming responsibility and day-to-day management of the IRB capability. A critical difference between the two headquarters is the duration for which the Command Staff remain in place. At CEFCOM in Ottawa, Command Staff are posted into set jobs for three-year periods. Whereas JTF-A is an operational theatre, Command Staff rotate into positions for durations of six-, nine-, or twelve-month periods. The military personnel and civilian broadcast staff in Kingston are generally contracted for one-year renewable contracts for the duration of operations. This is significant as the military planners responsible for the coordination of programming will change as often as every six months, whereas the broadcasting staff contracted to execute such plans remain throughout. It is the military equivalent of changing management staff every six months, while the owners and frontline workers remain the same.

One result of this was the tendency for military planners to consider broadcast operations in short-term cycles where efforts to overtly propagandize the service made tactical sense, but also failed to consider any longer-term damage to the credibility of the station. This situation led to friction between competing visions on how the broadcast 
capability was to be used in support of the ISAF mission which included short-term direct efforts in support of military objectives, versus a longer-term 'development approach' of establishing a platform for broader public participation. While the station was capable of supporting either approach, these competing visions could not be simultaneously realized, and individual personalities within the management staff began to play a significant role in the direction of broadcast programming. Throughout this period it became increasingly apparent that a divide had emerged between the shorter-term planning staff in Kandahar, who were subject to the short-term pressures of military operations, and the longer-term staff in Kingston and Ottawa, who had greater interaction with CIDA, DFAIT, and other Whole of Government (WoG) development partners. In an after action review of the first six-month military rotation, one of the early Officers Commanding noted that: "Theatre's perspective was that the reach-back [studio in Kingston] was only interested in running a radio station, and not in supporting [JTF-A's] PSYOPS plans" (Interview with author). This disconnect developed into a larger debate over the use of Rana FM in short, medium and long-term communication strategies, where conflicting perspectives advocated its use as either a reactive tool for responding to Taliban information activities, or as a proactive tool in support of ISAF's capacity building activities.

Despite these concerns, development of the station in Kingston went ahead as planned. The staff was organized into three sections: a military headquarters element, a civilian broadcast section, and a mixed military and civilian broadcast analysis section. The military headquarters element is made-up of an Officer Commanding, Second-inCommand, Operations Officer, Chief Analyst, and Administrative Clerk, who together supervise the activities of the broadcast and analysis sections, and coordinate the day-to- 
day activities and future plans with the supervising headquarters. The civilian broadcast section consists of a Broadcast Manager, Program Director, News Director, Production Supervisor, and Studio Engineer who together, plan, train, coordinate, and supervise the activities of the ten or so on-air presenters, and three 'in-country' journalists reporting for the station. The analysis section consists of a three military Analysts and three civilian Cultural Advisors who monitor, evaluate, and report on the broadcast outputs, audience feedback, and broadcaster interactions with the audience.

The staff recruitment process began with the contracting of a civilian Broadcast Manager to design the overall programming concept, which in turn helps to establish the size and organization of the station. The person selected for this position would have the most direct impact on the overall concept, program design, and orientation of the civilian staff; it was seen as necessary to select someone with a proven track record in broadcast operations, and not simply a civilian broadcast professional. That person was selected based on experience from previous NATO operations (in Bosnia-Herzegovina) setting the template for how the broadcast concept would unfold. Based on such a model, the next two positions contracted were the Programming Director and Station Engineer that would concurrently flesh-out the radio programming concept and establish the technical means for delivering the broadcast signal into Afghanistan. Given the required levels of training and experience these two positions demanded, personnel with previous experience were selected here as well.

The next stage of the staff recruitment process was the contracting and training of the on-air personnel. Pashto-language speaking presenters and journalists were required to fill such positions and become the 'voice' of the radio station. As one can imagine, the 
specificity of a persons speaking voice and particular accent become important criteria in the selection of on-air personnel. Given such unique requirements the decision was taken to find the right voices / personalities first, and deal with any job training second. It was thought to be far easier to train presenters and journalists than find experienced personnel with the desired voice / accent. Advertisements were placed in Afghan community media (in Canada) and within a short period of time a number of suitable applicants emerged. As with all Government of Canada contracting, the selection process was run by Public Works and Government Services Canada (PWGSC) creating a transparent hiring process free from any political interference. All applicants would go through an initial screening process where the suitability of their voice would be assessed. Once selected they would go through a Pashto-language proficiency test, and security clearance (both conducted by outside agencies), to determine suitability in accordance with the established criteria, and offered contracts on completion of the administrative requirements.

An in-house training program for all the on-air staff was developed and conducted by the Broadcast Manager and Program Director. It consisted of theoretical and practical radio broadcast training, followed by period of supervised 'near live' broadcasts where professional mentoring would occur. The theoretical portion consisted of a series of 40minute lectures on topics including: What is Radio? The 'One Blind Listener' concept; One Thought per Link; Clocks and Back-timing; Format Discipline; Using Your Voice; the Target Audience; and What is Rana FM? The practical training began with a number of in situ briefings on the objectives and operation of Rana FM including: What We Are Achieving: the Military's View; Studio Policy; Professionalism \& Discipline; Writing for Radio; Writing for Radio in Pashto; Afghan Media Today; ending day-one with a case 
study on the operation of a commercial music broadcaster in Toronto $(Z 103.5)^{13}$. Day

two consisted of technical training on the use of recording equipment; as well as:

Interview Techniques for Radio; Radio Bumpers, Sweeps \& Jingles; ending off with the Program Director's Vision of broadcast operations.

Following the theoretical and practical stages, presenters would begin producing full 4-hour program under the supervision of station management. The programs would begin 'near live' as a recorded broadcasts, until they were comfortable and / or proficient enough to begin low-audience shifts within the program schedule. The initial cohort of presenters had the additional stage of broadcasting over the internet while the technical means of FM signal delivery where being established ${ }^{14}$. Live broadcasting is an important component of presenter training as it allows them to get feedback from actual listeners of the station. The process from class training to live broadcasting is not fixed according to a specific timeframe, but rather is designed to progress at the learning speed of the person, helping to account for variations in previous training and experience (if any). As part of the direction given to on-air staff, the Officer Commanding cited the logic of truth and credibility explaining that: "Truth and credibility were guiding tenants. Without truth there could be no credibility. Without credibility there could be no hope of influencing the TA regardless of how much popular music was played or how clever out programs" (Interview with author). While 'truth' and 'credibility' are no doubt tenets of successful

\footnotetext{
${ }^{13}$ On a number of occasions, professional broadcasters form different private sector commercial stations in Southern Ontario would visit Rana FM and share insights on the latest trends in professional practice. It was interesting to witness the genuine interest both Canadian and Afghan broadcasters took in each other and their shared profession.

${ }^{14}$ Rana FM began live internet broadcasting approximately 90-days before the FM signal was established in Kandahar City, 7 January 2007.
} 
propaganda practice, it indicates the openness with which the objectives of the station were discussed with the civilian broadcasting staff.

Two challenges that were encountered through the staff recruitment process were differences in the cultural norms regarding the employment of Afghan youth, and labour relations with 'mission critical' staff. In terms of the cultural norms, hiring younger men and women (early 20 's) to work in Kingston away from their families was in contrast to the more common Afghan cultural practice of living at home until marriage. The Officer Commanding at the time recalled that: "Even though their families had been in Canada for several years now, there was still incredible resistance to the idea that younger family members might leave home. In the case of women, this was still unthinkable" (Interview with author). Although accommodations were eventually made, this was a limiting factor in being able to hire broadcasting staff that were reflective of the $15-25$ year-old target audience, and in the case of women, it never went beyond one. This challenge of finding additional broadcasting staff may have helped fuel the later challenge of labour relations when 'insurrections' over pay, benefits, scheduling, and 'prestige' threatened broadcast operations. Once through the arduous hiring process, it was not a great leap of logic to understand how integral to the operation the Pashto-language speaking youth became, and quite naturally, their sense of importance grew with this knowledge. Added to this was the developing 'cult of personality' surrounding the on-air presenters that, when taken together, led to a heightened sense of importance and conflict with management and administrative staff. Ultimately everything worked itself out, but in the early days with limited staff, the threat of labour disruptions became a very real concern. 
Day-to-day broadcast activities are coordinated through a weekly teleconference that includes representatives from CEFCOM, JTF-A, and Rana FM. As a rule of thumb, the division of labor between theses organization sees the broadcast team responsible for 'framework operations' such as music programming, news, and the presenter links that collectively work to attract and maintain the audience. JTF-A is responsible for all of the direct-messaging, and public service announcements, as well as all short-term planning within their current operational tour of duty. ${ }^{15} \mathrm{CEFCOM}$ is responsible for the overall planning and coordination of mid-term 'shaping operations' (such as upcoming election campaigns) as well as any long-term planning concerning the exit strategy and future missions. Direct liaison is authorized between the functional specialists (such as analysts or planners) within each organization, as well as between the news team and contracted journalists in Kandahar city.

The directed target audience was established as $15-25$ year-olds, but became generally understood as "teenagers and young adults" as the numbers do not correspond to anything specific in Afghan society. A level of cultural translation was also necessary as the life of an average 22 year-old Afghan is generally closer to that of a 32 year-old North American - that is to say, married, kids, career, property owner, and other 'adultlike' responsibilities. Nonetheless, $70 \%$ of the population is under 22 years of age making it the single largest potential category of listeners (Asia Foundation 2006). Since the beginning of broadcast operations, audience feedback has confirmed a listening audience of $8-42$ year-olds within the broadcast footprint (approximately congruent to the population belt of central Kandahar province) that crosses the political spectrum from

\footnotetext{
${ }^{15}$ Operational 'tours of duty' are generally six months in duration, but in some circumstances may run as long as twelve.
} 
those professing support for the national government, to those professing support for the insurgency. The average listener, not surprisingly, is described as a 22 year-old male from Kandahar City. The difference between the 'target audience' and the 'listening audience' is important to highlight here. While the target audience is considered a best approximation used initially to design programming and content, the listening audience is a more accurate description of who is actually listening.

\section{Programming Concept and Design}

The programming concept for broadcast operations intended to attract this audience sees Rana FM function as a 'commercial model' of IRB designed to provide Afghan-specific news and information concerning the security, governance, and development components of the state-building mission. This news and information is embedded within programs of culturally-specific music designed to attract the audience of teenagers and young adults. While broadcasting 24-hours a day, the format consists of 16-hours of live broadcasting divided into four distinct daily programs: breakfast, morning, afternoon, and evening. A standard 'programming hour' will consist of approximately 40 minutes of popular music (including: Afghan, Pakistani, Iranian and Indian music); 10 minutes of 'presenter links' where presenters discuss issues of the day and solicit audience feedback through cellular SMS text messaging and VoIP phone calls that can be re-broadcast later in the program; four to six minutes of commercial-style breaks where 'public service announcements' (PSAs), messaging from Afghan government departments, UNAMA, ISAF, and Non-Governmental Organizations 
(NGOs) occur; and four to six minutes of Afghan-centric news and information that seeks to promote the broader security, governance, and development activities of the mission.

This programming philosophy has been described as one of 'edutainment' (see p. 84) where the goal of informing or educating is done through an entertaining format that seeks to engage the audience in dialogue about issues of local significance. This took the form of presenter developed features on geography, health and education issues, poetry, and so on, that included questions to the audience inviting feedback. As one of the early Officers Commanding noted:

These were very successful in engaging audience participation as well as building 'celebrity' around the presenters. Both the edutainment format and the collateral cult of personality building around the presenters, were reinforced on a daily basis by the number of SMS text messages and phone calls received from theatre both in answer to questions proposed as well as just seeking to talk to the presenters (From interview with author).

The overall programming concept was developed by the Station Manager and Program Director who were both professionally trained civilian broadcasters. Based on the mission objectives, and a view toward the interests of a target audience of $15-25$ year olds, the programming concept was designed in relation to both the communicative behaviours of this audience, and in relation to what was already available in the listening area. In ways similar to other 'market-based' broadcasters, the overall format and content was developed according to the preferences of the desired audience. Within this general framework, music programming became the responsibility of the Program Director. The presenter links were designed by each of the individual radio presenters within thematic structures such as: 'nutritional tip of the day' or 'trivia question of the day'. The PSAs were generally selected by in-theatre military planners to coincide with specific programs 
and then produced by the Afghan-Canadian broadcasters in Kingston. Examples of these include: election registration information, immunization drives, military checkpoint procedures, etc. News selection is, in theory, the responsibility of the News Director, but in practice tended to reflect a larger process of bureaucratic negotiation and is discussed in greater detail below.

The music format is described as a 'regional echo', where popular music from the South-West Asian region is programmed in rough proportion to its proximity to Southern Afghanistan. Pashto-language music from Southern Afghanistan forms the single largest proportion, followed by Pashto-language music from Western Pakistan, and non-Pashtolanguage music from other parts of Afghanistan. Other regional music, predominantly from India and Iran, make-up the balance. Although music comprises the single largest proportion of broadcast output, it is nonetheless the least considered aspect of Rana FM's programming, suggesting its sole purpose is to attract the designated audience. While this may be an effective technique for garnering increased market share, questions remain as to the effect such music selection has on shaping youth identity and may, at times, work at cross purposes to other forms of programming. That is to say the narrative of ethnically nationalist music programming could be seen as contradicting messages of national unity and ethnic tolerance.

The 'presenter links' where on-air presenters discuss a variety of issues, take calls from listeners, and read SMS text messages and email, form the next largest proportion of broadcast content. At about 10-minutes per hour, the presenter links serve to define the overall direction of daily programming and work to portray the 'personality' of the radio station. Presenter links are used to increase listener flow by describing what's coming up, 
posing questions for audience interaction, feeding back listener comments, and generally providing the link between the music, news, and commercial-style spots. Within a typical four hour program, the presenters will introduce topics for the program, discuss cultural issues from nutritional cooking and health tips, to current movies and useful websites; as well as take calls, read letters, and try to answer listener questions. Similar to commercial broadcasters, topics are selected by the presenters with the basic guideline of "no politics, no religion". Translated examples of these links read as follows:

Greetings dear listeners, today is Tuesday evening, it is now $6 \mathrm{pm}$, and once again I am at your service. I will be with you until $10 \mathrm{pm}$ and hope that you stay with me to hear wild music and important topics. In the first hour we will hear the weather report, talk about what's new in the Indian movie world, and learn some new cooking recipes (Rana FM Broadcast, November 2009).

Let me tell you about the trivia question today, it's a very easy question and I hope that you will know the answer. Where is the Taj Mahal located? In what Indian city? If you know the answer please contact us at... (Ibid).

You are listening to Rana FM on 99.9. Dear listener, your SMSs have arrived. A lot of correct answers have come. It seems like this was too easy. Don jan, thank you for your SMS, your answer was correct. Ahmandullah jan, you answer was correct also. And so was Adel jan's. Thank you all for all your answers (Ibid).

Dear listeners, thank you all for your SMSs. Sadiq jan, got your SMS and will call you later. Qader jan, from Chaman [Pakistan], thank you again. I will also contact you later. Dear listeners, I will repeat the website again. The website we are talking about is called: www.behindthename.com (Ibid).

Other examples include listeners reading poetry, telling jokes, and asking questions of all sorts. One of note in the period sampled was a request to go over the English alphabet in greater detail. With all of the websites being promoted, a listener asked if someone could explain the basics of the English alphabet used in website URLs (Rana FM Broadcast, February 2010). While only anecdotal in nature, these examples provide a sample of the 
presenter links that readers can relate to in North American broadcasting in order to get a sense of their purpose within the broader radio format.

The third largest proportion of broadcast output is comprised of the commercialstyle 'spots' and public service announcements (PSAs). While designed to provide airtime for a variety of different groups (including GIRoA, UNAMA, ISAF, and the various NGOs operating in the region ${ }^{16}$ ), in practice this space was dominated by ISAF PSYOPS messaging. Efforts to inform the population of security threats, discredit insurgents, and convince the population to report Taliban activities accounted for most of the commercial spots during the period sampled. This type of 'direct messaging' from ISAF to the local population was highly controversial as a number of the Afghan presenters felt it echoed the propaganda techniques of the Soviet invasion and may affect the overall creditability of the station. With little opportunity for pre-testing such messages, ISAF seemed to be working more from intuition than any practical basis for communicating with the local population, and repeated this approach without trying to determine what effects (if any) these spots may have had. Translated examples of these read as follows:

It is a fact that suicide bombers and improvised explosive devices kill seven times more Afghan civilians as Afghan National Security Forces and international military personnel. ISAF reminds you not to pick up weapons or explosives, just report the location to the Afghan police (Rana FM Broadcast, July 2008).

The Government of Afghanistan, with ANSF and ISAF, are working to make a better Afghanistan. With this in mind, projects for building roads and other infrastructure are ongoing and provide work to numerous Afghans in Kandahar province. GIRoA will be looking for people to help them build these projects. Stay tuned for more information about possible reconstruction projects in your area (Ibid).

\footnotetext{
${ }^{16}$ In 2009 there were over 1600 NGOs registered with the Afghan Ministry of Planning, many of which can be found at: http://afghanistan-analyst.org/ngo.aspx
} 
Insurgents and their ways are well known to Afghans now. Even their tactics against our government, which is tainted with innocent blood and drugs, is not honourable. They continue to harm Afghans and Afghanistan by the poison of their rebellion. Report insurgent activities to your ANSF or ISAF friends (Ibid).

In order to bridge this difference of opinion, and create a separation between the ISAF messages and the IRB itself, identification credits were used to bracket such spots in the way that political advertising is identified in North America. "The preceding message was brought to you by..." This served to create enough of a partition so that the on-air presenters didn't have to answer to the listeners for ISAF policy. As this debate went on however, and ISAF personnel in Afghanistan rotated out, use of the commercial-style spots began to level-out with PSAs promoting the Afghan National Army and Police, information regarding the election registration process, and a number of public health related spots concerning sanitation, malaria, and drug use. Overall, this aspect of IRB output remains the subject of considerable debate with no definitive understanding of its role within surrogate broadcasting. Efforts to overtly propagandize the service on one side are balanced by those who advocated the 'PSA approach' to promoting the less political issues of the state-building process.

\section{News Selection Process}

The smallest and most controversial aspect of IRB output is the news. Comprised of five-minute hourly 'headline' segments, an expanded 15-minute 'drive-time' program, and a 30-minute evening news program (see timings below), the news component was the most debated aspect of the station's output. As witnessed through staff coordination meetings, discussions concerning the purpose, structure, and process for news selection / 
production became one of the recurring themes of broadcast production and editorial control.

\section{Rana FM News Program Timings (March - November)}

06:30 am Kingston, 3 pm Kandahar (main news staff begins $8 \mathrm{hr}$ shift)

07:30 am Kingston, 4 pm Kandahar (news production meeting)

08:30 am Kingston, 5 pm Kandahar (expanded hourly news, main news preview)

09:30 am Kingston, 6 pm Kandahar (Afghan news day ends)

10:30 am Kingston, 7 pm Kandahar (staff coordination meeting)

11:30 am Kingston, 8 pm Kandahar (main evening news programs)

12:30 am Kingston, 9 pm Kandahar (hourly headline news)

1:30 pm Kingston, 10 pm Kandahar (hourly headline news)

2:30 pm Kingston, 11 pm Kandahar (last live hourly news of the day; main news staff go home)

Designed to provide a balance of security, governance, and development information, the purpose of the news component was generally understood to promote the activities of the international mission, reinforce the legitimacy of the Afghan Government, and highlight the impact insurgent activities were having on the citizens and the country (Baker 2006). In doing so, the news was structured to provide a balance of the above 'mission-related' information categories, across local, national and international regions, as well as a state, market, and public spheres of domestic life in Afghanistan. Recognizing that all nine of these categories could not be fulfilled in every newscast, this normative structure for the selection of news was provided to the news team as a guide to consider during their news selection process, and reviewed for balance through the monthly assessments (discussed below). 
The news selection process itself was done by the Afghan-Canadian news team with the direction that the aim is to provide a balanced picture of the reconstruction and development activities in Afghanistan (including the related insurgency), and that all of the news ought to be related to Afghanistan (in ways similar to the national mandate of the $\mathrm{CBC}$ ). Like most other news selection processes, it begins with monitoring the other prominent news organizations both inside and outside of the country to get a sense of the 'dominant stories' of the day, followed by a more through reading of the Afghan-related wire services. These would include the Bakhtar and Pajhwok news agencies ${ }^{17}$ (to which the station subscribed), as well as the larger international services (i.e. the Associated Press, BBC, and Reuters) with Afghan coverage. The Afghan-Canadian journalists would then select $10-15$ stories for production, where the News Director would detail assignments for follow-up interviews and development, filling in any 'gaps' in coverage using locally employed journalists in Afghanistan. Two of the subject areas that were frequently under-reported were local, community-level news in Kandahar, and marketbased news in both Kandahar and Afghanistan more generally (see Figures 6 and 7 below). A sample of the daily news headlines (with original sources) reads as follows:

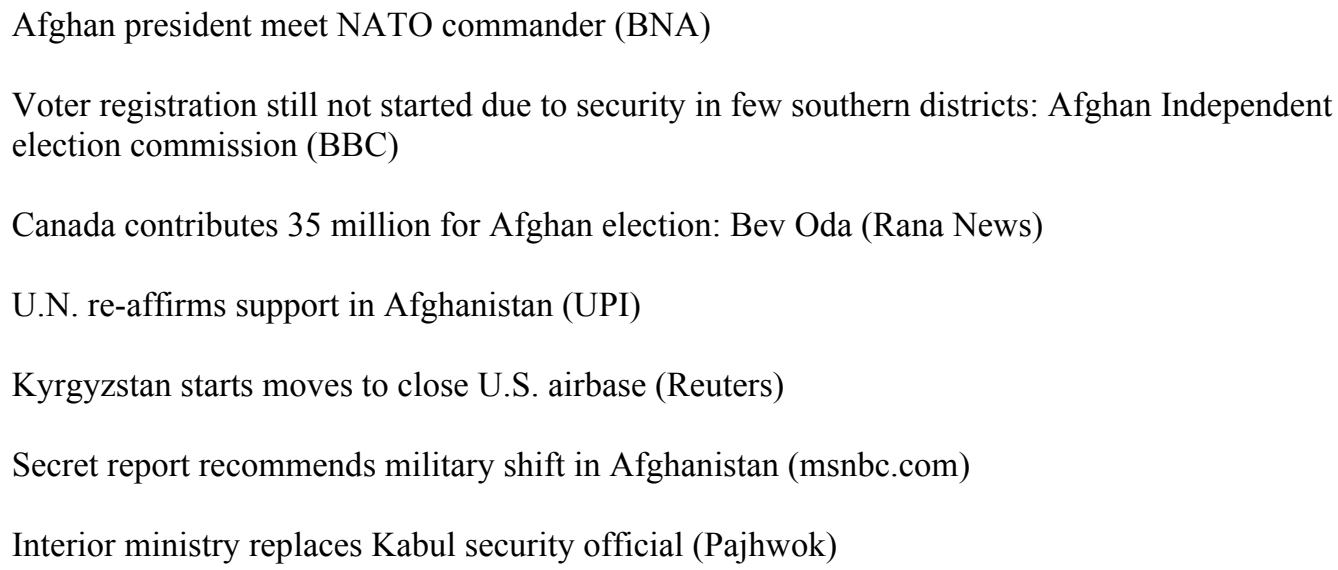

${ }^{17}$ For information on these agencies see: www.bakhtarnews.com.af and www.pajhwok.com respectively. 
U.S. special envoy Holbrooke to visit India, Pakistan, Afghanistan (Xinhua)

Russia says it wants to help US in Afghanistan (AP)

8500 students appeared in Konkor test in eastern Afghanistan (BNA)

Hope of Mother (NGO) built a clinic in Nangarhar province (BBC)

Ghazni Bank moved to newly built double story building (BNA)

Bomb blast killed six of Musa Kala District head security guards (Pajhwok)

60 percent insurgents in Helmand are foreigners: defence minister (BNA)

(Rana FM Broadcast, February 2009).

Despite this selection process, the way in which the news selection is done was perceived to have broader implications for the state-building process. Although daily news output is closely monitored to ensure both quality and balance, the independence of the news team was occasionally breached to support military operations - illustrating one of the central tensions between military planners in Canada and Afghanistan. That is to say, the people involved in day-to-day operations in Afghanistan would tend to view Rana FM as a tool of tactical-level psychological operations, similar to the way in which loud speakers are employed at a micro level; whereas the planners in Canada would tend to view it more as an independent platform for the longer-term promotion of the security, governance and development objectives of the mission. In doing so, the in-theatre personnel would place a greater emphasis on insurgent activity, following the 'if it bleeds, it leads' doctrine of many commercial broadcasters, where the in-Canada planning staff had a responsibility for the longer-term credibility of the station, emphasizing the other non-ISAF aspects of the mission, including the governance and development activities of non-military actors. While questions of editorial control would ultimately fall to the Officer Commanding, in practice contentious issues would tend to get resolved through discussion and negotiation. 

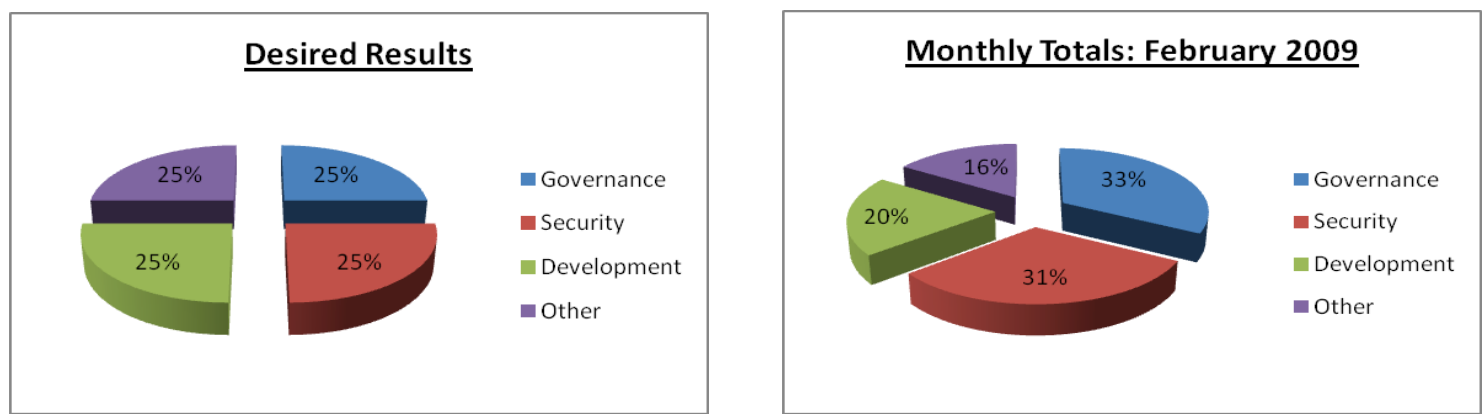

Figure 8. News Balance by Mission Framework, Normative (left) Empirical (right) February 2009 (Source: Rana FM)

Recognizing the challenges of balancing multiple issues within the short hourly newscasts, a measure of performance (MoP) is conducted to assess such 'news balance' over monthly periods. Figure 8 (above) and figure 9 (below) show the normative and empirical results for the month of February 2009. The desired results (on the left) show the normative frameworks provided to the news team as direction, whereas the monthly totals (on the right) show the actual news output, as measured by number of news items, for the month of February 2009. In additiona to the frameworks of 'mission-related' information, the news is further assessed in other ontological categogies.
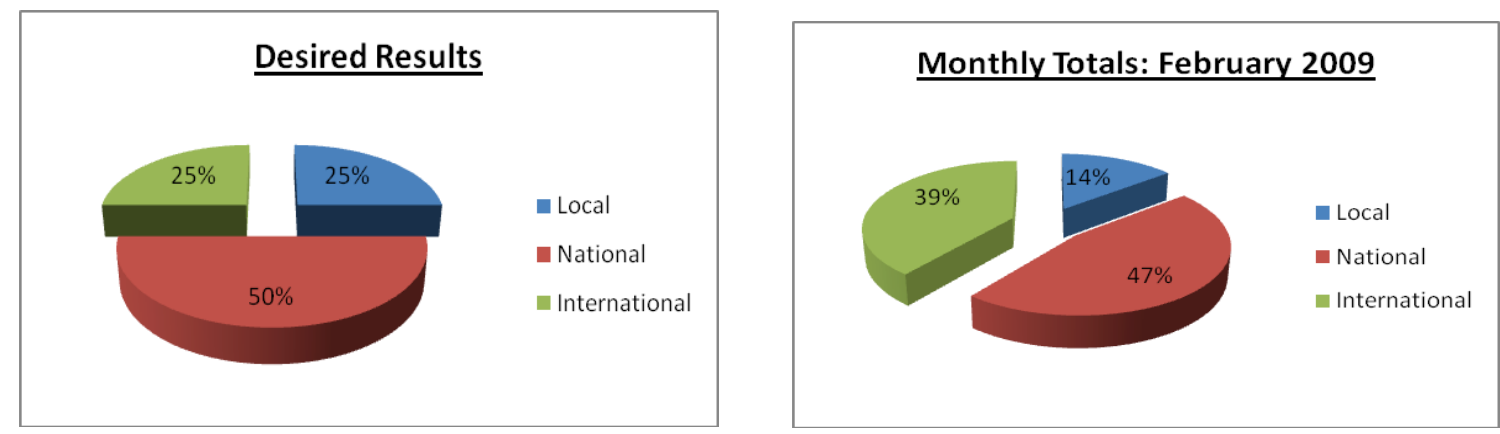

Figure 9. News Balance by Political Framework, Normative (left) Empirical (right) February 2009 (Source: Rana FM) 

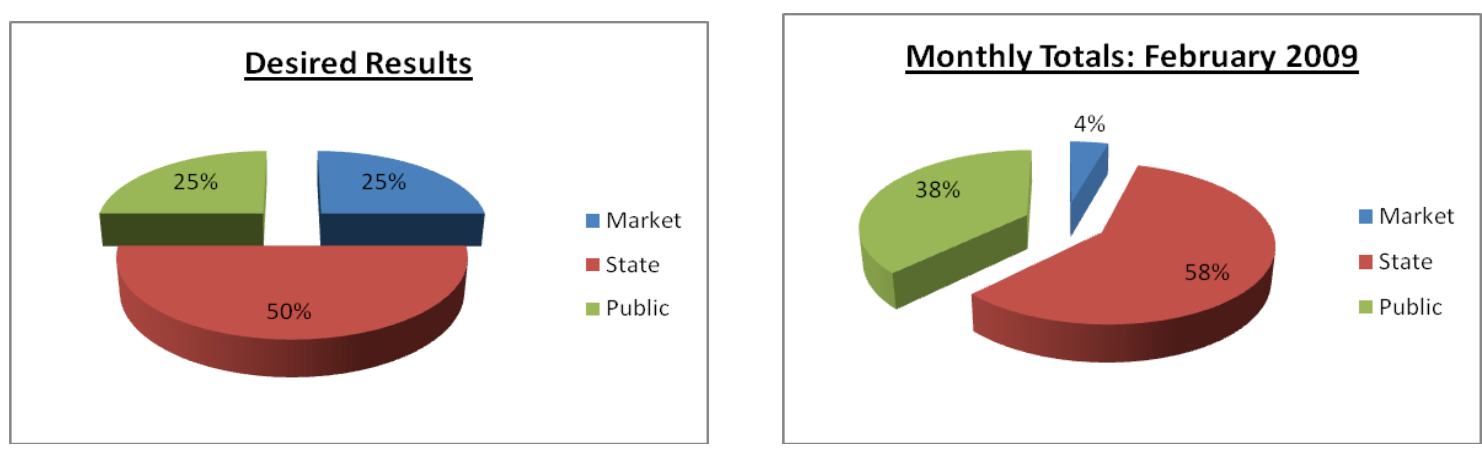

Figure 10. News Balance by Social Framework, Normative (left) Empirical (right) February 2009 (Source: Rana FM)

Figures 9 and 10 (above) show examples of news outputs through political and social frameworks of analysis. While the normative allotments for balance seen in the 'desired results' can be debated, the monthly totals represent actual news outputs for the month of February 2009. As one could infer from the desired results, national-level, state-based information, balanced across the security, governance and development components of the mission is assumed to be beneficial to the state-building project. Achieving this balance however, is far more difficult in practice. With the ongoing violence in Southern Afghanistan, and near collapse of the local economy, finding either local or market-based information can be difficult. While the majority of news items are selected from other news organizations, Rana FM does employ three journalists to help augment existing coverage. Directed from the studios in Kingston, Ontario, these journalists help to fill gaps in the coverage of local issues not covered by the commercial news organizations or wire services in Afghanistan.

Other methods of analyzing the news output have been used (Figure 11 below) but in general Rana FM can be seen to be providing a balance of predominantly nationlevel, state-based information, across the security, governance, and development aspects 
of the international mission, in accordance with their direction, to help reinforce the activities of the International Security Assistance Force.

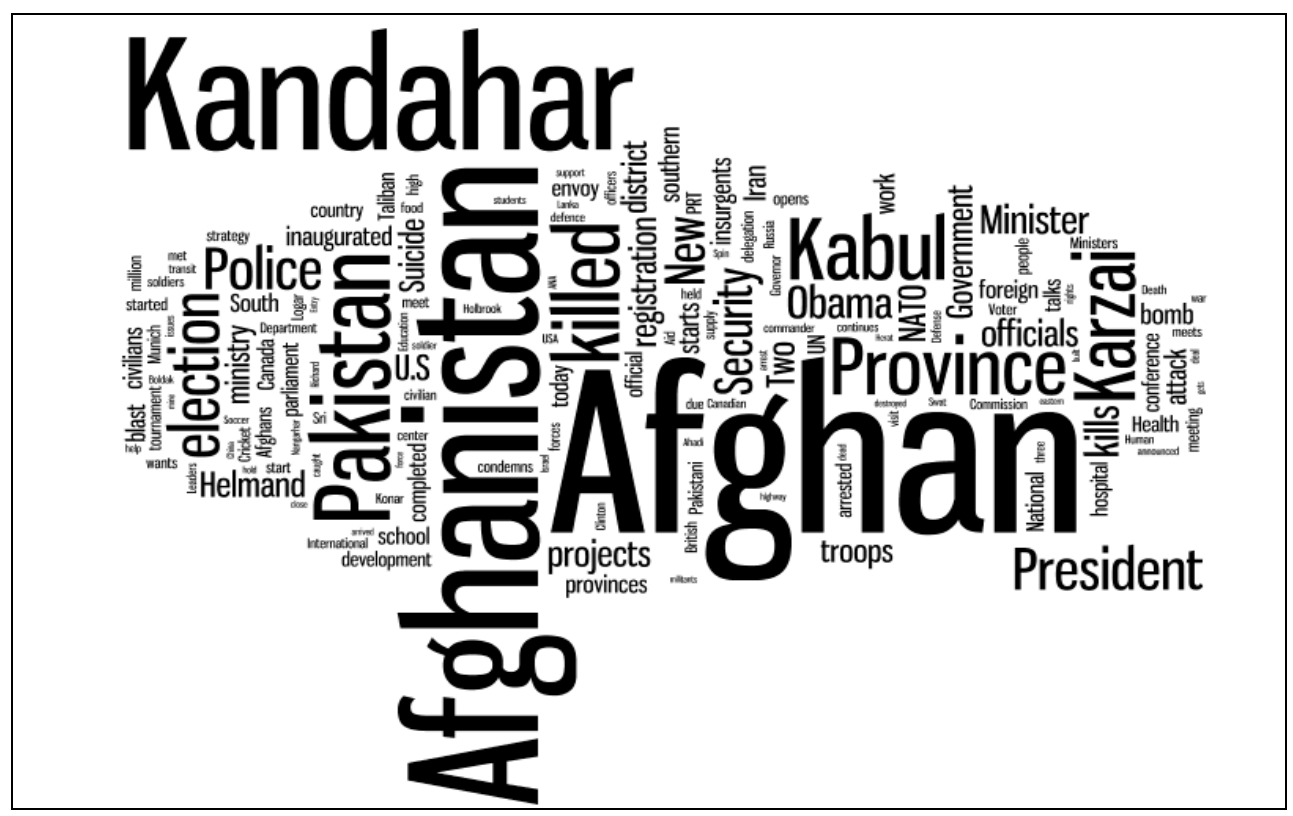

Figure 11. Word Picture of Rana FM Headlines, February 2009 (Source: Rana FM)

\section{Broadcast Analysis}

The analysis of internal analysis data is reviewed by an Analysis Planning Group (APG) to ensure that a multi-perspective approach is used to interpret any data and maximize the utility of audience feedback. The APG meets approximately four times per year to review current data, research methodologies, and future research and analysis plans. Although all such monitoring and assessment information is proprietary to the $\mathrm{CF}$ (i.e. classified by the Department of National Defence) a few observations can be made from the station's content outputs. First, is that the news component appears to achieve the desired balance of the mission related information, as established by the Afghan Compact and Afghan National Development Strategy. Second, is that participation in the 
talk shows indicates a reasonable level of awareness about such issues amongst the listening audience - and by extension, one may assume the population more generally. Third, is that there is little indication that such programming influences the perceptions, attitudes or behaviours of the target audience independently of any other material or informational conditions. And fourth, there is only limited evidence to suggest that Rana FM provides a mechanism for 'two-way' communication with the population. Audience feedback provides confirmation that broadcast content reaches the target audience, but there is little support for the notion that the audience feedback reaches any political authorities.

While there may only be limited evidence to support such communication, the desire to increase this audience interaction can be seen in the station's technological developments. In mid-2009, the Toronto Star reported that: "Canada plans to boost its propaganda reach by tapping into mobile phones in Afghanistan to send text messages, run contests and drive listeners to its military-run, Pashto-language radio station" (Woods 2009: A1). As with other channels of audience interaction, the outputs of any SMS text messaging may be designed more to encourage audience feedback, than to spread any specific type of messages. Either way, it is important to understand how this audience feedback is used internally, in determining the effectiveness of either communication technology (SMS or broadcast) as a platform for popular communication.

\section{Talk Radio and Call-in Shows}

A component of the broadcast outputs that requires additional scrutiny is the three-hour weekly talk show entitled Talks of Life. Modeled on the CBC's open-line radio 
program Cross Country Checkup (CCC), Talks of Life aims to provide a province-wide forum for the public discussion of national issues. Using a single topic per week format, the program uses the eight 'pillars' and six 'cross-cutting issues' of the Afghan National Development Strategy (see Annex A) to guide the selection of weekly topics, interwoven with fixed events of Afghan cultural life (i.e. Ramadan / Eid; Haj; Afghan Independence Day; etc.). Other dates of significance (such as: International Day for Mine Awareness, World Health Day, or Literacy Day) are used to coordinate the weekly topic selection in relation to other nationally planned events. For example, a show on the Ramadan / Eid (New Year's) celebration would ask listeners to reflect on the past year, and discuss their hopes and aspirations for the future. A show on World Health Day would reflect on the health problems affecting Afghans, and discuss current initiatives seeking to address such concerns (such as immunization programs or the development of health clinics).

Each of these programs would count against one of the ANDS issue-areas ${ }^{18}$ (Education \& Culture, and Health \& Nutrition for the examples given) to ensure that a proactive approach and balance in programming is achieved over the course of any given year. Each program is designed to inform people about the basics of the given issue, including positions within current political discourse, and solicit a range of opinions on the topic. Much like its $\mathrm{CBC}$ model, this is done through interviews with subject matter experts and the re-broadcast of political speeches concerning the topic.

Listeners are screened to help ensure geographic and editorial balance where possible. Although the open-line program format has proven to be popular amongst Rana $F M$ listeners, it is unclear who (if anyone) within the Afghan Government, ISAF,

\footnotetext{
${ }^{18}$ The 'issue-areas' of the Afghan National Development Strategy can be seen as an amplification of the 'Security, Governance, Development' issue-areas of the Afghan Compact.
} 
UNAMA, or the Taliban hear the public's concerns. The feedback is tracked according to gender and geographic area, but no attempt to summarize audience opinion has been made. Additional questions concerning the relevance of selected topics to the designated target audience of teenagers and young adults ought to be addressed as well, but no information concerning the age of talk show respondents is available. ${ }^{19}$ Despite the lack of any quantitative data, the establishment of any call-in programs represents a desire for greater two-way communication and may be considered an indicator of such motivation.

\section{Summary}

This examination of IRB in Afghanistan can be summarized by looking at the case of Rana FM as it worked to operationalize the state-building objectives of the international mission, and information strategies of the counter-insurgency struggle. As seen through its practice of commercial-style, surrogate-type broadcasting, Rana FM can be seen as a form of 'defensive propaganda' that works to reinforce the institutions of the developing state durring the process of democratic reconstruction.

The overall state-building objectives for Afghanistan were identified as: security, governance, and development; with the addition of strategic communication to the ISAF military plans in 2009. Each of these issue-areas were shown to have a number of subcategories (or enabling objectives), with the various lead agencies such as ISAF, GIRoA, and UNAMA managing their progress. Physical conditions in Afghanistan have worked to establish the priorities in the different geographic regional of the country where a lack

\footnotetext{
${ }^{19}$ Specific data on audience feedback remains classified by the Department of Nation Defence and was unavailable for this report.
} 
of physical security, the displacement of populations, food shortages, and other related humanitarian issues topped the agenda.

The information strategy was shown to be dominated by military planners with other government agencies playing a secondary role. Although a balance of information is sought for IRB programming, the planning and coordination of information strategy is predominantly a military responsibility where security concerns topped the priority list of the international mission. That said, the information strategy was described as a 'Battle for Hearts and Minds' where all parties to the conflict shared similar objectives, namely to build the 'trust and confidence' of the population while, at the same time, discrediting their adversaries. ISAF for example, described their communicative task as the ability “...to maintain and strengthen the Afghan population's positive perception of, and support for, GIRoA institutions and the constructive supporting role played by ISAF and the IC" (ISAF 2009: D2). It was shown how both ISAF and the Taliban use a series of master narratives, which are disseminated through a variety of different media, to varying degrees of effectiveness. While establishing a 'credible dialogue' with the population remains the primary objective, ISAF was shown to lack 'cultural credibility' with their target audience and often failed to resonate with the population.

Rana FM was shown to support the state-building objectives and communication strategy through the provision of mission-related information in the forms of news, talk, and directed messages; embedded in a programming format of popular music designed to maximize its audience share of teenagers and young adults. The news component can be understood as a 'force multiplier' in that it works to promote popular understanding of the mission objectives and associated activities. The talk components appear to exhibit 
the makings of a credible dialogue, but it remains less clear who (if anyone) is listening to their concerns. Although dialogue of any sort is a good first step, Afghan government officials need to be better engaged for this to reflect state-society relations. The directed messages in PSA-like formats also appear to have mixed results. Messages providing information (such as the UNHCR's 'Polio Drive' for example) have received positive feedback, whereas messages intended to discredit the Taliban tended to receive little or no feedback whatsoever. Although the ultimate effects of such messaging cannot be seen here, audience feedback on any given subject is indicative of its 'cultural resonance' and can be understood as a barometer for establishing cultural credibility.

Internal debates over the specific objectives, audiences to be targeted and overall direction of broadcast programming were seen to divide over the timeframe and types of effects that ought to be sought. Short-term military objectives competed with the longerterm development objectives resulting in divergent views over who ought to be targeted for what purpose. While programming seemed to try and accommodate both views, clear distinction between urban and rural target audiences, as well as passive verses aggressive communication strategies remain unresolved. The lack of agreement concerning the basic tenets of broadcast operations contributed to changes in both programming and strategy, resulting in oscillation between short- and long-term perspectives which dominated the programming philosophy at different times during the station's operation. 


\section{- CHAPTER FIVE -}

\section{Theorizing IRB in Afghanistan and Beyond}

The purpose of this dissertation has been to examine the nature of, and motivation for, international radio broadcasting in contemporary Afghanistan. In doing so it explored the hypothesis that the contemporary practice of IRB in Afghanistan constitutes a form of 'defensive propaganda' that works to reinforce the national institutions of the developing state during the process of democratic reconstruction. Using a case study methodology it aimed to demonstrate how this was achieved through a model of 'surrogate broadcasting' that works to engage local populations with information concerning the development of their society.

State-building operations were defined as the full range of activities conducted by the international community to help stabilize conflict areas and foster a durable peace in post-conflict states (Ottaway 2003: 314). Such operations will include a configuration of peacekeeping or peacemaking by international military forces; security sector reform that includes the disarmament of combatants and the development of a national army; as well as some form of democratic development that will generally include the drafting of a new constitution, registration of voters, and multiparty elections within a fixed period of time (Ottaway 2003: 316). Examples of this model in use included: Cambodia (1993); BosniaHerzegovina (1995); The Democratic Republic of the Congo (1997); East Timor (1998); Kosovo (1999); and Afghanistan (2002).

The dominant approach to contemporary state-building was described as the 'Democratic Reconstruction Model' (DRM) where a number of different security and 
development objectives are pursued according to a standardized model and specific timeline. The DRM is characterized by a 'top-down' centralized approach where civil society involvement is limited to participation in pre-determined democratic processes (i.e. multiparty elections). An alternate approach, described as dialectical modernization, was discussed as an active alternative where 'bottom-up' strategies are seen to build from existing socio-cultural processes up, instead of from the state-building objectives down. The emphasis here is placed on greater civic participation throughout all aspects of the reconstruction process including the establishment of objectives and local development priorities.

The significance of this for IRB in state-building suggests that the mechanisms for popular participation, designed to enhance the legitimacy of the post-conflict state, will be required from the outset of any democratic reconstruction process, and that platforms for communication ought to be established prior to any reconstruction efforts in order to help accommodate public input throughout such a process. If the development objectives are to be consensually determined, and widely articulated throughout the population, a mechanism for widespread communication will be required early in the process. While the specific role of IRB will be dependent on the overall state-building objectives, two basic communication requirements can nonetheless be observed: one is the transmission of information from state to population; and the other is transmission of information from population to state.

The case study of IRB in Afghanistan synthesized the historical context and legal framework for state-building in Afghanistan, in order to contextualize the communication strategy and provide the basis for understanding the nature of Rana FM. Using primary 
research that included interviews with IRB practitioners and personal observations made during the research period, this study examined a variety of information source including: internal content analyses, third-party opinion polls, and structured interviews with IRB directing staff, management personnel, radio producers, on-air presenters, and technical staff. As Chief Analyst for broadcast operations, I was responsible for the design and supervision of internal content analyses (ensuring a consistency of recorded data), and worked with third-party research organizations in Afghanistan to develop the research protocols and polling questionnaire. The interviews with practitioners helped to inform this study by providing the contextual information necessary to understand the different positions and organizations involved in the planning, development, programming and operation of IRB in Afghanistan.

In order to make the necessary links between the theory and practice of IRB in post-conflict state-building, this chapter begins with a brief summary of the key points regarding the theoretical frameworks, followed by a summary of findings concerning the practice of IRB in Afghanistan. It then compares the case of Rana FM with other models

of IRB in order to highlight the similarities and differences in the content and structure of IRBs used in post-conflict state-building. The dissertation concludes with an analysis of IRB in relation to the theoretical frameworks presented, including limitations to the study and any broader implications for theory and practice that may be inferred.

\section{Summary of Theoretical Frameworks}

In the broad theoretical areas of mass communication and development research, three historically related and overlapping frameworks for explaining the nature of IRB were 
discussed: propaganda, development communication, and strategic communication. In doing so, broad questions were identified for the analysis of IRB: Does the use of IRB help to promote democratic reconstruction through the dissemination accurate, reliable, and creditable information? Does IRB help to reinforce a broader sense of a national or ideological community? Does IRB work to provide a platform for public discussion and facilitate state-society relations? When it comes to identifying the nature of IRB in statebuilding, the theoretical frameworks of propaganda, development communication, and strategic communication were shown to provide a functionalist analytical structure that incorporates questions of content, structure, and effect into a comprehensive framework for the explanation of IRB in post-conflict state-building.

Throughout the relatively short history of IRB, the propaganda framework has been the dominant explanatory tool used in the study and practice of IRB. Used by the institutions of church and state, the propaganda framework has been characterized by the intentional spreading of ideas that, while generally considered truthful, may not always offer complete or competing views of the issues presented. While historically considered to be a process for the dissemination of ideas, use of the term propaganda has evolved to include the specific products of communication (i.e. films, leaflets, posters, broadcasts, etc.). Today, the term is used by critical media scholars as a process for the dissemination of ideas, whereas liberal media scholars tend to view it as an ideological activity with the connotation of being untrue. When examining the nature of IRB, it's also important to distinguish between direct propaganda (i.e. content), and indirect, structural forms that may work to reinforce a particular ideology. Strategies for the dissemination of specific 
ideas (and censoring others) need to be judged for their intent more so than any measure of effectiveness.

The theories of development communication were shown to offer an alternative framework for the use of IRB in programs of post-conflict state-building. Characterized by a structural approach to communication development, such programs have sought to 'set the conditions' for other forms of social, political, and economic development by providing the mechanisms for greater civic engagement in the development process, and the information necessary for democratic participation itself. Originally designed to help transition post-colonial societies into modern capitalist democracies, such programs have been seen to use a combination of infrastructure development and regulation to promote civic-nationalism as an alternative to other more traditional forms of social organization. When examining the motivation for IRB in state-building, development communication theory provides a normative liberal framework for assessing what IRB ought to be doing in order to achieve the broader goals of national development. Specifically, the provision information in the short-term while developing a sustainable domestic capability to help solidify the state-building process over the long-term. Such an assessment also needs to address the specific strategy (i.e. top-down vs. bottom-up) and tactics (i.e. edutainment) used in the process for engaging local populations.

A strategic communication framework was used to explain the nature of IRB in state-building as conceived by practitioners themselves. The strategic communication framework is characterised by an objectives-driven process shifting the analytical focus toward the effect of communication, while still accounting for both content and structure in the development of any directed communication strategy. While the explanatory power 
of propaganda and development communication theory is dependent on both the content and structure of directed communication programs, the strategic communication approach emphasises the 'objectives' of the initiating party, highlighting the underlying motivation for such activities.

\section{Summary of Findings}

With these frameworks in mind, this study of IRB in Afghanistan examined the case of Rana FM as it operationalized the state-building objectives of the international mission. Through an institutional analysis of its practice and procedures, Rana FM was shown to function as a commercial-style, international surrogate broadcaster. The state-building objectives for Afghanistan were identified as: security, governance, and development; with the addition of strategic communication to ISAF military plans in mid-2009. Each issue-area was shown to have a number of sub-categories (or enabling objectives) as well as a designated lead agency (such as ISAF, GIRoA, and UNAMA) to help manage their progress. The material conditions in Afghanistan (including the level of armed conflict) were shown to influence both the security and development priorities within the different regions of the country and, as a result, work to define the dominant information strategy adopted in each area.

The information strategy for the south of the country was dominated by military plans with other government agencies playing a secondary role. Although a balance of information is sought for IRB use, the planning and coordination of information strategy was shown to be primarily a military responsibility, where security concerns topped the priority list of the international mission. The information strategy adopted was described 
as a 'Battle for Hearts and Minds' where all parties to the conflict aim to build the trust and confidence of the population, while at the same time discrediting their adversaries. It was shown that both ISAF and the Taliban utilize a series of master narratives which are disseminated through multiple and different media, to varying degrees of effectiveness. While aiming to establish a 'credible dialogue' with the population remained a primary communication objective, ISAF was shown to lack 'cultural credibility' with their target audience and experienced a number of difficulties connecting with the population.

\section{Content}

The content of Rana FM can be seen to reflect the 'propaganda approach' to IRB through the dissemination of mission-related information in the forms of news, talk and directed messages, all embedded in a programming format of popular music designed to maximize its audience-share of teenagers and young adults. The news component was seen to function as a 'force multiplier' in that it aimed to promote a wider understanding of the security, governance, development and information objectives of the mission. The call-in, talk-show components of Rana FM programming are understood to exhibit the makings of a credible dialogue, both with and amongst the population, but it was less clear who, if anyone, within government circles was listening to their concerns. Although dialogue of any sort may be viewed as a good first step, Afghan government officials need to be better engaged for this to constitute a mechanism for state-society relations.

The directed messages in PSA-like formats also appeared to have mixed results. Messages that directly promoted public service-type information (such as the various health promotion campaigns) were said to receive positive feedback from the listening 
audience, whereas messages that were designed to discredit the insurgency received no feedback whatsoever, raising questions about their resonance with the population.

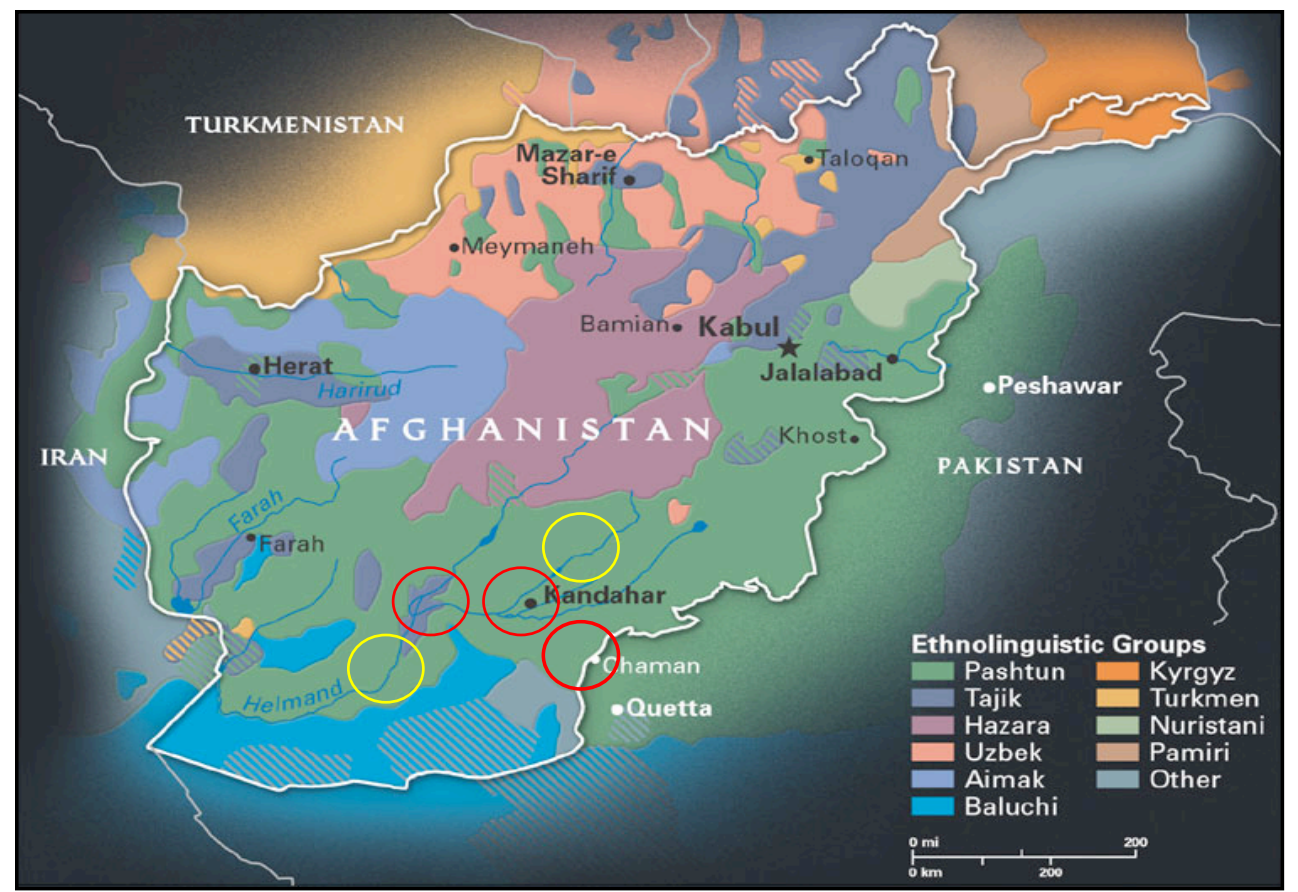

Figure 12. Rana FM Broadcast Map (Source: Rana FM 2009)

\section{Structure}

Viewed in Figure 12 (above), the structure of Rana FM's broadcast operations were shown to be 'local' in nature, broadcasting a 'national' perspective to a sub-state, unilingual region of the country. As described above, the red circles represent the three continuous FM transmitter locations for Kandahar City (center), Panjwai District (west), and Dand District (south-east). The yellow circles represent the two expansion districts, of Maywand (west) and Arghandab (north-east), which broadcast during 2008-09. The significance of this for the analysis of IRB in state-building is significant. One reason is that the top-down approach of broadcasting a national perspective may be viewed with 
suspicion by local populations long weary of centralized government control. Without a confirmation of audience participation / interaction, such one-way communication may be seen as overt government propaganda and jeopardize the credibility of the broadcaster. Another reason is that the structure of the listening community may work to reinforce the isolated nature of Afghanistan's southern provinces, and work against the broader statebuilding objective of consolidating a 'national' population. If the different regions of the country do not collectively discuss issues of national significance, then they are unlikely to develop a unified understanding of events.

\section{Comparison with other models of IRB}

How then does Rana FM compare with other models of IRB? What similarities and / or differences can be observed in relation to the structures, content, audiences, and effects? When compared with other surrogate broadcasters, such as Radio Sawa (Arabic region), Radio Free Europe, Radio Free Asia, Radio Oksigen (Bosnia), Radio K4 (Kosovo), and Radio Free Afghanistan (RFA) a number of similarities can be identified. First, is that all such stations have adopted a music-based commercial-style programming format that is designed to attract younger audiences than their public diplomacy counterparts ${ }^{20}$ (such as: Voice of America, Radio Canada International, or the BBC World Service). Such efforts to target 'youth' audiences can be seen as a departure form traditional public diplomacy broadcasting where 'elite' audiences are frequently sought for migration and diplomacy programs.

\footnotetext{
${ }^{20}$ One reason for this conformity of operating concepts may stem from the knowledge sharing and staff transfers amongst NATO countries. Although not documented here, the transfer of both military doctrine and civilian staff between such organizations is very common.
} 
Differences in these models stem from differences in the organizational structures of the missions under which they reside, and the related objectives assigned to each IRB. Broadcasters such as the United States' Radio Sawa are organized within the Department of State and reflect the diplomatic objectives of the U.S. in the Arabic-speaking regions of the Middle East and North Africa. IRBs such as Radio Oksigen (Bosnia-Herzegovina) and Radio K4 (Kosovo) are organized within the military components of such NATO-led stability operations and accordingly reflect the specific objectives of the mission. Another distinction that can be made between the different models of IRB is in the structure or shape of the broadcast areas, and their related congruence to existing political or ethnolinguistic communities. IRBs such as Radio Free Afghanistan cover the territory of the nation-state, while other models (such as Radio Sawa) stretch to the boundaries of the ethno-linguistic community - in this case broadcasting to the entire Arabic-speaking region.

Looking closer at two examples of IRB in post-conflict state-building specifically, the models of Radio Oksigen (Bosnia-Herzegovina) and Radio K4 (Kosovo) provide two examples of similarly structured IRBs, that are organized within NATO operations with comparable state-building objectives. Figure 13 (below) shows the approximate broadcast area of Radio Oksigen during its operation from 1999 - 2005. Established in support of the Dayton Peace Accord (1995), Radio Oksigen had the similar tasks of promoting the democratic reconstruction of the country to a primarily youth audience of $15-25$ year olds within the northern regions of the country (Pisani 2001). Broadcasting in a largely permissive security environment, Radio Oksigen developed a programming format of popular FM music, and sought to engage its audience through call-in shows, concert 
promotion, and celebrity dance parties. Musicians at varying levels of international fame were hosted by the broadcaster for 'peace concerts' and other public events, drawing large crowds and direct audience feedback. Gauging youth attitudes toward the Dayton Peace Accord (1995) for example, allowed the broadcaster to select the discussion topics for its weekly call-in shows where 'experts' would be invited on-air to discuss the more controversial aspects.

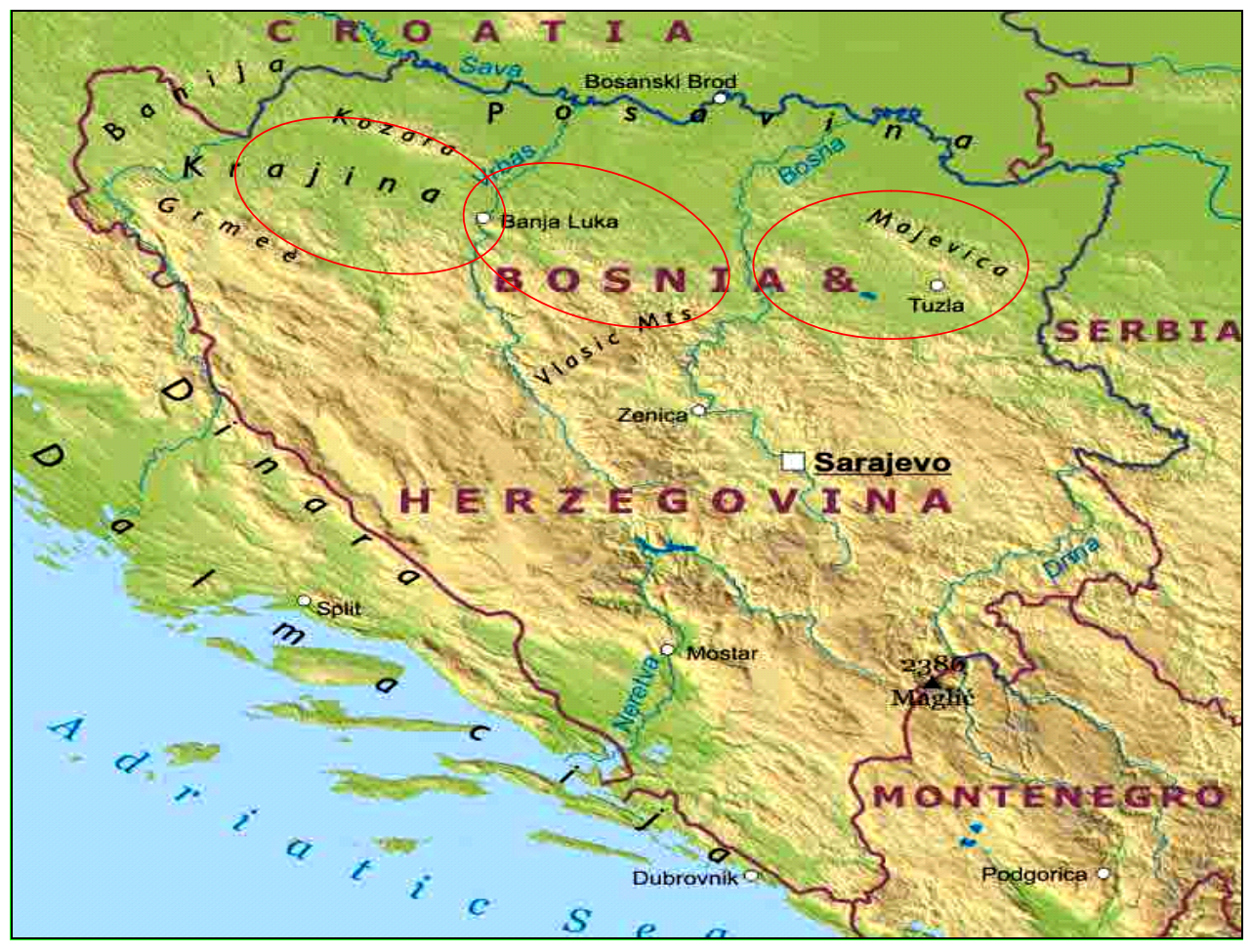

Figure 13. Radio Oksigen (Source: Radio Oksigen, NATO)

By promoting pan-ethnic discussion on the peace accord (and other topics), it aimed to solidify a sense of community beyond the ethnic divisions of the war. While anecdotally successful, its regulated broadcast area was restricted to the northern sector of the country eliminating the possibility of any broader national reconciliation. The post-conflict state 
of Bosnia-Herzegovina functions as two separate political entities (Republika Srpska and the Federation of Bosnia-Herzegovina) under a UN-supervised parliamentary republic.

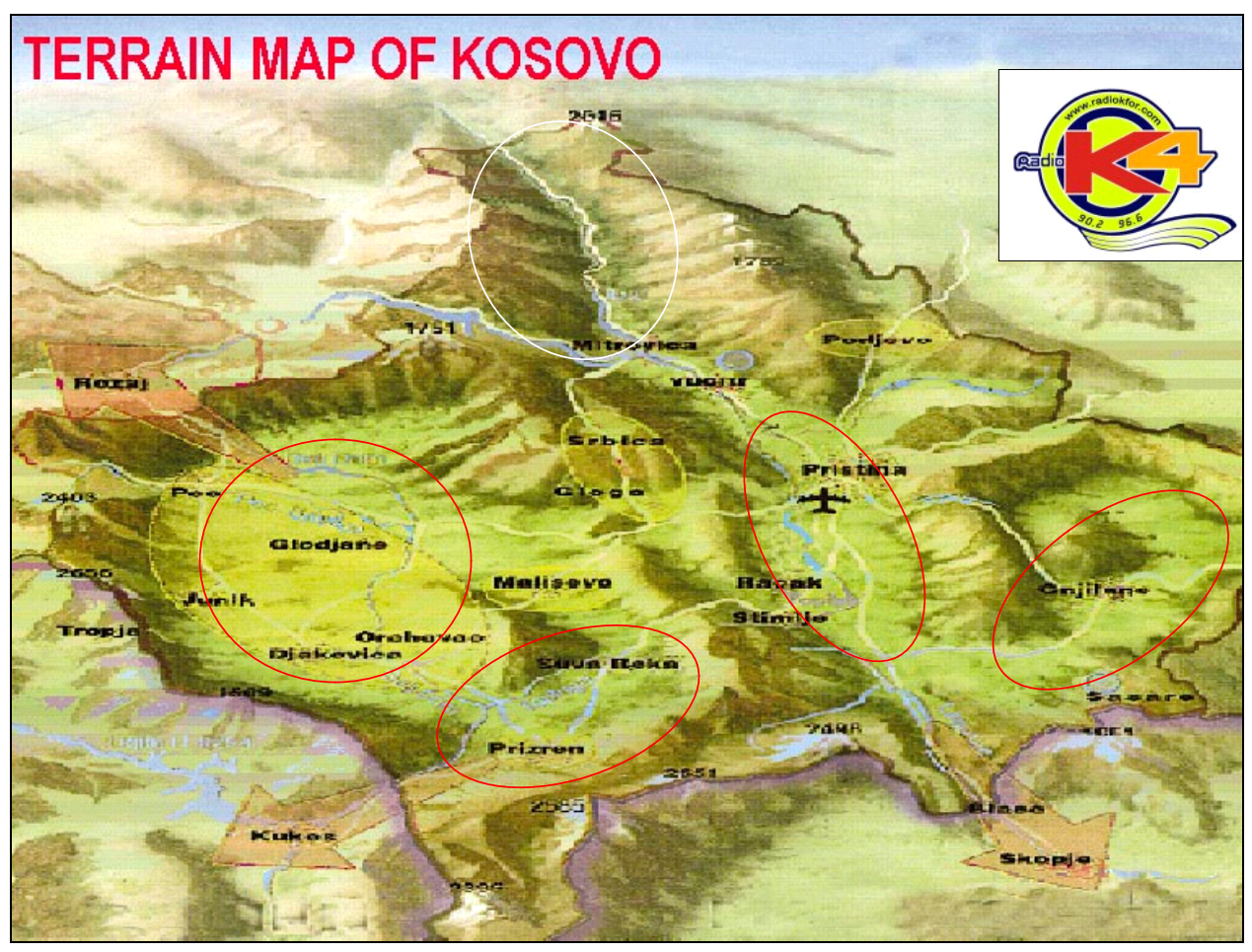

Figure 14. Radio K4 (Source: Radio K4, NATO)

Figure 14 (above) shows the FM broadcast areas of Radio $K 4$ within the UN administered political entity of Kosovo. As a component of NATO's Kosovo task force (KFOR) Radio K4 operated with a mandate to inform the population about KFOR and the state-building activities of the UN. Again targeting teenaged and young adult listeners, the broadcaster developed two distinct FM channels to reach the Albanian majority and Serbian minority enclaves in the North. Through a combination of music and talk-radio the core messages of KFOR operations were communicated to the listeners, although little effort was made to engage the audience in any deeper discussions. Despite having 'national' coverage of 
the Kosovo state boundaries, the Albanian and Serbian language distinction of the two services precluded the multi-ethnic national dialogue seen in Bosnia-Herzegovina.

In terms of the basic functions of IRB in post-conflict state-building a number of similarities can be observed. First, the basic objectives, programming concept, techniques and day-to-day procedures (including its coordination within military forces) are virtually identical. Operating to reinforce the institutions of state while engaging the population in broader discussions of political reconciliation and development, these IRBs witnessed the use of propaganda and development communication strategies (such as the promotion of national awareness) and techniques (including 'edutainment' and audience feedback) to help reinforce the institutions of state and promote democratic participation.

In terms of structure, the broadcast footprint of each IRB is somewhat different (reflecting the boundaries of the funding organizations). Rana FM broadcast uni-lingual programming to a sub-section of the transnational ethno-linguistic group (i.e. Pashtun). Radio Oksigen also broadcast uni-lingual programming but to a multi-ethnic sub-section of the Bosnian state (Republika Srpska). Radio K4, by contrast, broadcast to the political boundaries of the fledgling state in two different language versions of the same 'national' Kosovo programming. While the significance of this may not be seen for years to come, the theory of social integration suggests that some form of national dialogue is necessary to foster an integration of the population congruent to the political boundaries of the state. Although surrogate IRB is only designed to be the first step in this process, it nonetheless works to set the conditions for the growth of a domestic media sector, including the basic structure of commercial information markets. 


\section{Analysis and Conclusions}

What then is the nature of IRB in post-conflict state-building? Which framework best explains its function in the processes of post-conflict reconstruction and development? What can be concluded about the use of IRB to help reinforce the development of state institutions, facilitate state-society relations, and help to foster a culture of democratic participation within the existing framework of the nation-state? Throughout this study, IRB has been shown to function in similar ways to other forms of mass media, capable of directing public attention, conferring status on people and institutions, informing quickly, structuring perceptions of reality, and providing feedback on issues of public importance. When applied to programs of state-building, IRBs could be expected to: direct attention toward state activities, reinforce the nation-state as the dominant political actor, confer status on modernist political and cultural leadership, help keep the population informed of reconstruction and development activities, and help facilitate public participation in the reconstruction and development activities of the country.

As an IRB operating in support of state-building objectives, its activities can be seen as consistent with the media functions identified in functionalist theory. Directing attention toward state activities for example, shows a concerted effort to provide public information while indicating relations of state power, and facilitating adaptation during the process of reconstruction and development. Information provided about the security, governance, and development aspects of the international mission are described from the perspective of the Afghan state. Examples such as: the coverage of political issues and debates, enactment of legislation, and government activities in all three areas highlight this perspective. The same framework of political activities can also be seen to reinforce 
the nation-state as the dominant political actor. Coverage of various bi-lateral and multilateral international forms, may also work to stress national political leaders (such as the President and oppositional leaders in the case of Afghanistan). Regional warlords and other sub-state actors are categorically linked as 'illegally armed groups' and placed in opposition to the state only and not one another as independent political actors (recent clashes between Kochies and Hazara in Kabul provide a good example).

Conferring status on 'modernist' leaders is supported to a degree, as seen in the news and some music interviews, but does not happen consistently enough to suggest a deliberate policy of promotion. There is currently nothing like a 'player of the week' type segment to facilitate this on a regular basis. The news gathering structure further suggests that the 'informing' function is more deliberate than quick. Coverage of the pre-defined security, governance, and development categories is generally comprehensive and up-todate (including opposition perspectives on issues such as civilian casualties, government corruption, and delays in humanitarian assistance and reconstruction work) but responses to quickly developing stories are not something for which Rana FM is set-up for. In fact, a regular criticism here (of ISAF information operations) is the speed at which insurgents are able to publicly respond to (and spin) violent acts, to which ISAF has had insufficient capacity to respond. While this is something ISAF has sought to rectify (Motlagh 2010) there remains considerable debate over the wisdom of such a strategy (see for example: O'Keeffe \& Oliver 2010).

When it comes to influencing public attitudes, there is little evidence to suggest that this is occurring with any frequency. Awareness of political issues and institutions can be seen in the levels of talk show participation, but there is no evidence Rana FM 
alone is the sole contributor or has an impact on the way in which people perceive such issues. Third party opinion polling, which tracks longitudinal change in public attitudes, has documented shifts in public attitudes toward various aspects of the mission, but has not been segmented according to people's primary source of information. That is to say, there is currently no way of tracking change in the attitudes of Rana FM listeners that is independent of other information sources. There is also little discussion surrounding the role of music in these commercial-style IRBs. Outside of programming popular music to maximize audience-share, little is known about the influence of music (and other cultural products) on the attitudes of their listeners. What stories are being told? What narratives are listeners connecting with? As the dominant portion of broadcasting content, the music being played on such commercial-style IRB warrants far greater scrutiny than it currently receives.

When viewed through the propaganda framework the role of IRB in state-building can be seen as a propagandistic one that competes for the trust and confidence of the local population on behalf of the state. Operating as a surrogate for national broadcasting, IRBs that aim to reinforce state institutions and promote "national self awareness" (Ellul, 1965: ix) in opposition to other ethno-linguistic or religious forms of identity. Exclusion of the Taliban perspective on issues of public interest constitutes a deliberate form of censorship and serves as a key indicator explaining the propaganda function of IRB in state-building. As Lippmann (1922), Ellul (1965), Herman \& Chomsky (1988), Jowett \& O’Donnell (1999) and Taylor (2003) have all observed, some forms of censorship are necessary for propaganda to be effective. That said however, such communicative activities can also be seen to promote a pluralistic democratic culture where oppositional voices can be heard 
in relation to government policy (Heil 2003), including debate on issues of government corruption. In this way, such surrogate IRBs can be seen to reinforce the institutions of state while not taking any specific positions with regard to the outcomes of government decision-making. Accordingly, IRB in post-conflict state-building can be seen to function as a form of 'defensive propaganda' that works to reinforce the democratic system itself without advocating on behalf of any specific political interests.

When viewed through the frameworks of development communication IRB can be seen to have adopted elements of development communication strategy (nationalism) and tactics (edutainment) but fail to share the underlying objective of capacity building. While performing a surrogate broadcast function may be seen as a necessary component of any post-conflict reconstruction process, without a corresponding program to develop local capacity, IRBs will have a difficult time creating the enduring effects necessary for international state-building to transition into sustainable national development. Much like the process of security sector reform, international forces are understood to be necessary until a domestic capability can be developed. This suggests that any program of strategic communication ought to include 'end-state' objectives that work to replace surrogate IRB through the development of a sustainable local capability. In this way, differences can be seen in the shorter-term objectives of military IRBs, when compared with the longer-term focus of non-military agencies involved in the development process.

When viewed through the framework of strategic communication, IRBs such as Rana FM can be seen to operate as a tool of the sponsoring state, operating in support of the international state-building objectives. In doing so, it highlights the objectives of such communication processes, and helps to make the broadcast activities more explicate. Are 
surrogate IRBs designed to help support the information needs of the post-conflict state or the local populations therein? Where surrogate IRB may serve the short-term interests of the developing state during the early stages of reconstruction, without a corresponding program to develop domestic capabilities it may fail to create any enduring effects on the information environment. On the other hand, however, development communication programs designed to support the information needs of local populations may not be sufficient to support the broader state-building objectives, necessitating the consideration of a more dynamic strategy through the various stages of post-conflict development.

\section{Motivations for the use of IRB}

Where functionalist theory works to explain how IRB supports the objectives of social integration, cultural continuity, and political stability (the nature of IRB), it says little about the underlying motivation for its use. In contrast to the early centralized, statebased forms of development communication, contemporary models of IRB now tend to be local or regional in approach, privileging ethno-linguistic communities over political configurations, raising questions about the role of IRB in national social integration. In contrast to the 'national' approach of early development communication programs, much of the media development in Afghanistan has occurred on a city-by-city basis, creating a network of similarly modeled IRB stations (such as the USAID-funded network Radio Free Afghanistan shown at Figure 15 below) that suggest an effort to communicate with a broader national audience. 


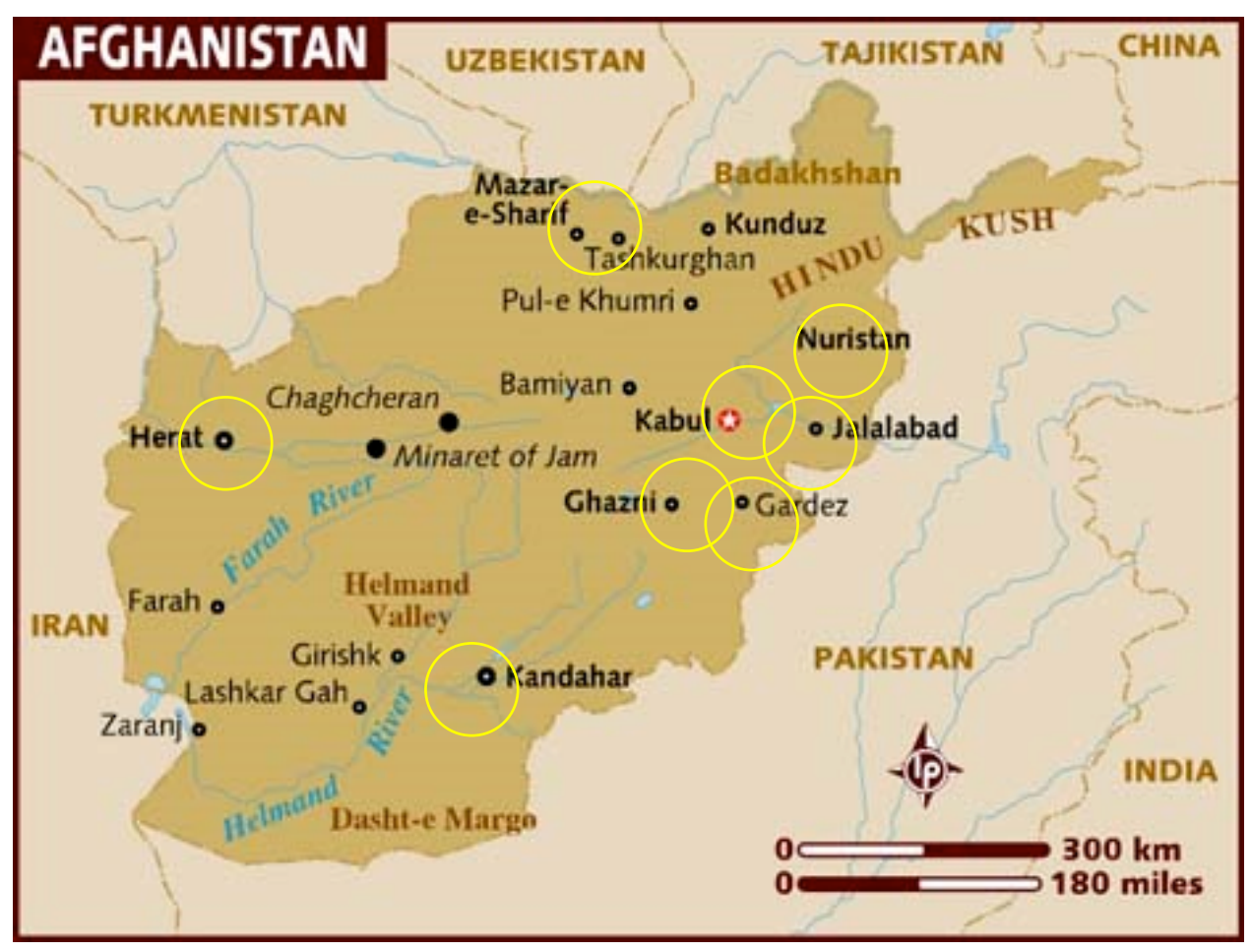

Figure 15. Radio Free Afghanistan Network 2010 (Source: Radio Free Europe)

Radio Free Afghanistan and their eight affiliate stations can be seen to form the basis of a national radio network that parallels the main transportation routes circling the country. Although not officially related, Rana FM can be understood to complement this network, helping to create a unified picture of national events, in programming formats tailored to the decentralized communities throughout the country. In this way, sub-state IRBs can be understood to meet the information needs of the local communities, while at the same time working to help reinforce the integration of the Afghan state. In doing so however, IRB operations in Afghanistan may also be seen to correlate with higher levels of conflict where the development of independent media isn't currently possible. Figure 16 (below) maps the conflict by tracking fatalities since 2006 showing the majority of armed conflict in the same areas as these recent broadcasting developments. 


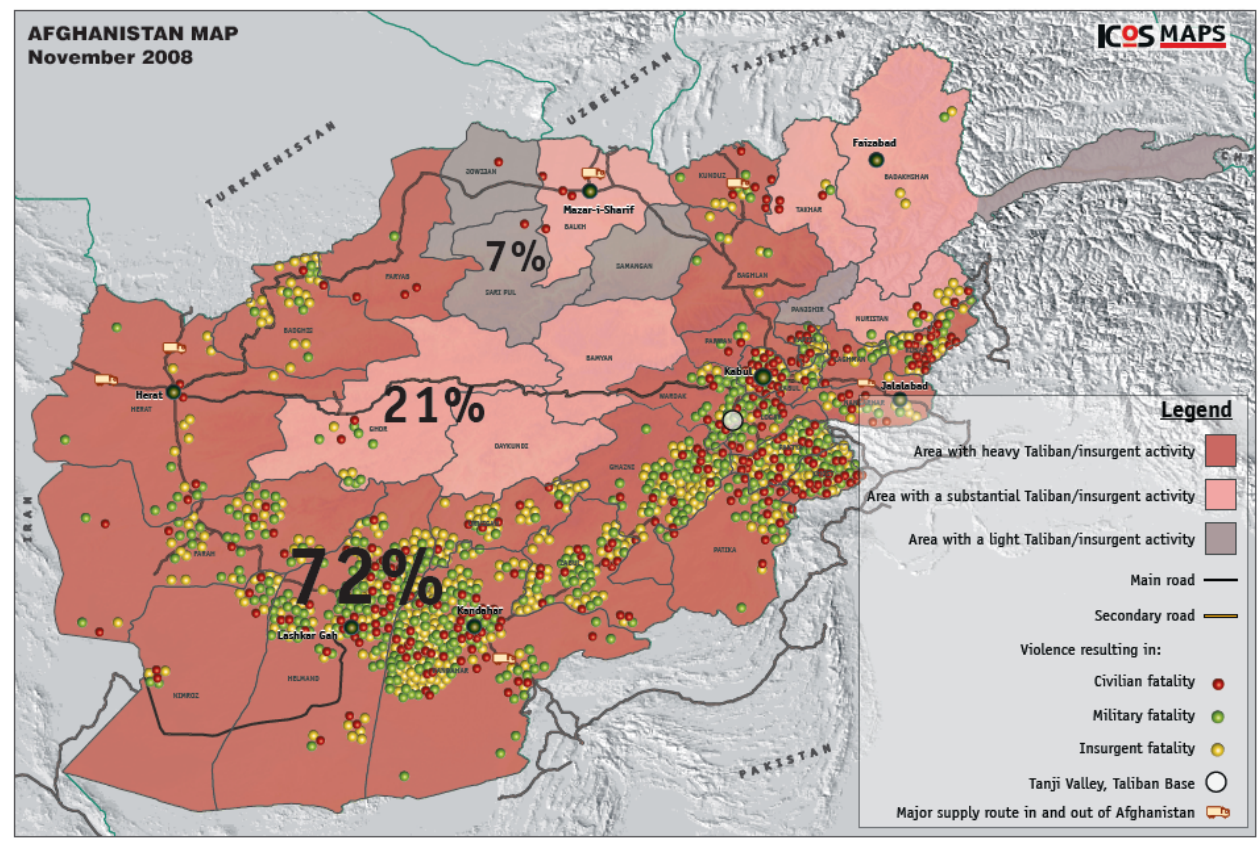

Figure 16. Afghanistan Casualty Map (Source: International Council on Security and Development)

In this way, the motivation for IRB may be considered in relation to the enduring conflict more so than any altruistic forms of democratic development. While Rana FM and other sub-state models of IRB may provide the appearance of a basic 'watchdog' function of media in the development of a democratic system, its correlation with the armed conflict in the southern and eastern parts of the country, and related censorship of an 'insurgent' perspective, suggests an adherence to the shorter-term military objectives. While the use of this 'military approach' in the short-term may help to facilitate the counter-insurgency campaign, it does not address the longer-term requirements of the state-building program. In this way, the operation of IRB by defence (verses state departments) may be at odds with the longer-term objectives of the development process. Whereas the military use of IRB seems to be addressing the short-term needs of the conflict, it does little to create the enduring effects necessary for longer-term state development. On the other hand, the use 
of IRB by development agencies (USAID for example) suggests an approach to IRB that is in-line with the democratic reconstruction of a modern state, where the structure of the information community parallels the political boundaries of the state, setting the stage for longer-term nation-building and political consolidation.

In the case of Rana FM, the broadcast area follows a geographic feature (i.e. the Arghandab river valley) within a homogenous ethno-linguistic group (i.e. Pashtuns), but operates at a sub-state political level. Although its 'edutainment' format is well-suited for

coordination within the network of eight regional IRBs currently ringing the country (that all use a similar commercial model in their respective areas of the country) it nonetheless operates independently of the U.S.-funded stations in the RFA network. However, with such similarities in both content and structure it is unlikely to demonstrate a motivation distinct from its U.S. counterparts. USAID has supported a series of media development projects that combine surrogate broadcasting with journalistic training, in order to help develop local capacity while providing a model of professional practice (Internews 2009). Canada's development agency should be encouraged to do the same.

\section{Implications of Research}

The implications of this study are twofold reflecting the theoretical and practical aspects of the research. First, is that the mass communication and development theories addressed need to better account for dynamic communication processes that change over time and space. The false 'either-or' dichotomy created between theories of propaganda and development communication need to be reconciled for mass communication theory to be able to explain the nature of IRB in state-building. In building upon the concept of 
'defensive propaganda' a model for the use of IRB that incorporates the reinforcement of state institutions within a broader program of pluralistic media development is suggested. By considering the short-term capabilities of surrogate IRB, within the longer-term plans for domestic media development, a theory for post-conflict development communication is proposed. The framework of strategic communication used here helps to illustrate such a concept by taking the 'objectives' of communication as the object of study, therefore downgrading both propaganda and development communication to the level of tactics in pursuit of the same overarching state-building objectives. Whereas the propaganda-type perspective of strategic communication can be seen to emphasize the adversarial side of the information environment, its use by development practitioners tends to shifts the focus toward a more collaborative approach, emphasizing greater audience participation, and downplaying the desire to maximize audiences. The philosophical underpinnings of public diplomacy are well suited to advance this approach.

In practice, the role of IRB in post-conflict development needs to be understood as a dynamic process where the conflicting priorities of different organizations, working in different places, at different times, will collectively work to influence the direction of broadcast operations. Although the use of surrogate IRBs may be effective in helping to promote state institutions in the short-term, it lacks the legitimacy of domestic actors to develop the media institutions necessary for longer-term state development. Conversely, the development communication models used to great effect in community development projects, lack the 'national' perspective necessary for post-conflict state-building efforts. The national network of local IRB affiliates being developed as Radio Free Afghanistan (RFA) may be an emerging model of such hybrid practice. Through combining surrogate 
IRB with local capability development, the RFA network may prove to be a model for decentralized state-building activities. In addition to providing a model for standards in journalistic practice, a clear function of surrogate IRB is to help develop (or coordinate) sustainable broadcast capability that will reduce the need for IRB as time goes on. As Baker (2008) reminds us, both IRB and media developments in Afghanistan have played key roles in promoting democracy despite the persistence of the ongoing conflict (Baker 2008).

\section{Limitations}

In drawing conclusions on the role of IRB in state-building operations, it is important to highlight limitations to the study. Although Rana FM is considered typical of such commercial-style surrogate IRB, it is one that is historically and geographically specific, and may not be equated with all forms of IRB. Differences in the institutional organization (i.e. departments of national defence, state, and international aid) may alter the priorities assigned to such broadcasters and ought to be considered in future analysis. As Kumar (2006) noted : "An additional problem facing community broadcasters is that many foreign personnel, working in provincial reconstruction teams, view US-funded radio stations as tools for their public affairs and psychological operations" (Quoted in Baker 2008: 116). While IRB practitioners are aware of this perception, it is unclear what, if anything they can do about it. Differences in the operational context (such the level of armed conflict) will have an impact on the focus and priorities of IRB, and needs to be considered when making comparisons. In the initial period following such conflict, conditions on the ground change rapidly and need to be accounted for in the assessment 
of IRB. The specific political conditions, both within and between the states involved, must be carefully considered in IRB planning, including whether IRB is an appropriate form of communication.

One of the challenges limiting comparative institutional research of this nature is getting the requisite access to the government departments and agencies responsible for IRB, and strategic communication more broadly. In active theatres of operation, justified concerns over 'operational security' have led to high levels of information classification and have worked to limit a more comprehensive assessment of broadcast operations by 'outside' agencies. Similarly, access to the full spectrum of information actors (including audiences) may be limited by the continuation of armed conflict, preventing researchers from gaining the necessary information for other such forms of analysis.

That said, an additional limitation is that this study only considers one actor in a contested information environment, which may also include: state, public, commercial, community, religious, or other non-state broadcast entities (such as the Taliban); as well as other non-broadcast forms of mass communication including: newspapers, film, video, television, and (via mobile cellular access) the internet. The context of post-conflict statebuilding, used in this study to isolate the practice of IRB, is only one type of intervention and should be critically examined as an appropriate form of international development (in comparison to 'human' or 'community' development models for example).

\section{Conclusions}

Overall, the connections between communication theory and the practice of IRB show a sub-state model that performs many of the expected functions of media in society 
structured to consolidate the political community of the nation-state. In doing so, we can conclude that IRB reflects the defensive self-interests of the coalition countries involved with the promotion of democratic reconstruction as the dominant means to realize these goals. In post-conflict state-building operations, IRB has been used for both propaganda and democratic reconstruction purposes, but generally exhibits a 'defensive propaganda' function that works to reinforce the institutions of state. In this regard, Rana FM appears to be effective in the short-term, but questions remain as to whether this is enough to set the conditions for longer-term development. Contrary to the broad goals of democratic reconstruction, the information strategy adopted by NATO forces may fail to create the conditions necessary to foster a durable peace. Without corresponding efforts in media development, surrogate IRBs are unlikely to have the sustained impact necessary for state-development.

Although current IRB practice is largely congruent with the top-down models of state-building, efforts that fail to communicate with local populations will face problems of legitimacy, and in turn efficacy. The central problem of state-society relations must be addressed early in any state-building effort in order set development goals collectively and prevent 'spoiler groups' from filling the information void encountered after conflict. The model of defensive propaganda may prove to be successful in efforts to reinforce the development of state institutions in the short-term, but lack the sustained effort required to foster a culture of democratic participation. Getting basic information from the state to the population is far less problematic than building the trust necessary for the population to engage with the post-conflict state. 
In terms of communication theory, by adopting elements of both the development communication and propaganda theory, the concept of 'defensive propaganda' provides a descriptive category for articulating the function of IRB in post-conflict state-building. In this way, we see a model of IRB that works to support the shorter-term activities of state development, but lacks the capacity building function necessary to reinforce the domestic media sector and help to solidify the political community of the nation-state.

\section{Future Research}

Additional research on the use of media by political actors is still needed in the areas of low intensity conflict and post-conflict development. Studies examining broader media ecology in competitive information environments are needed to better understand the use of media in relation to other political, military, and economic tools of protracted conflict. Understanding the operational differences in practice (such as the structure and organization of civilian, military, and quasi-governmental information actors) would help to better map the dynamics of conflict and work to direct development resources more specifically.

Other areas for future research include: examining the role of IRB at different stages of the development process. Studies on the impact of IRB following the end of international involvement are lacking in particular. Also, as mentioned in chapter four, the music component being played on commercial-style IRBs also warrants additional scrutiny. And finally, more systematic research on the medium and long-term effects of IRB is needed. Longitudinal analysis from the beginning of broadcast operations, which continue past the end of international involvement, are required in order to fully assess 
the impact such IRBs are having on the long-term development of indigenous media systems. Government institutions do some of this, but much of the data is proprietary information (i.e. classified), and none seems to continue past the end of operations. A partnership with an established research institution (such as the various university research centers) could be one way of achieving this. 


\section{- ANNEX A -}

Pillars of the Afghanistan National Development Strategy (ANDS)

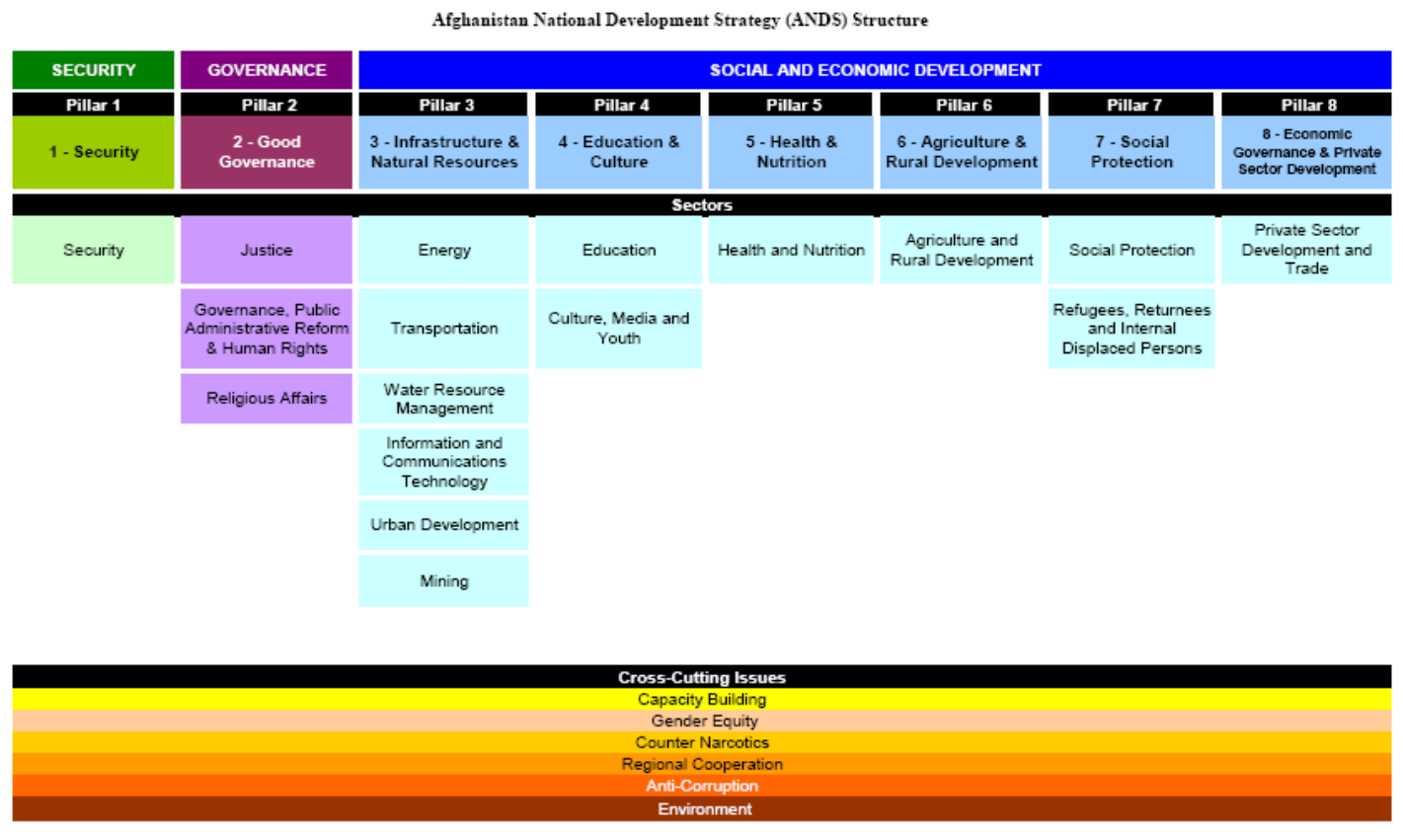




\title{
- ANNEX B - \\ United Nations Security Council Resolution 1386
}

\author{
Adopted unanimously by the Security Council at its 4443rd meeting, on 20 December 2001
}

The Security Council,

Reaffirming its previous resolutions on Afghanistan, in particular its resolutions 1378 (2001) of 14 November 2001 and 1383 (2001) of 6 December 2001,

Supporting international efforts to root out terrorism, in keeping with the Charter of the United Nations, and reaffirming also its resolutions 1368 (2001) of 12 September 2001 and 1373 (2001) of 28 September 2001 ,

Welcoming developments in Afghanistan that will allow for all Afghans to enjoy inalienable rights and freedom unfettered by oppression and terror,

Recognizing that the responsibility for providing security and law and order throughout the country resides with the Afghan themselves,

Reiterating its endorsement of the Agreement on provisional arrangements in Afghanistan pending the reestablishment of permanent government institutions, signed in Bonn on 5 December 2001 (S/2001/1154) (the Bonn Agreement),

Taking note of the request to the Security Council in Annex 1, paragraph 3, to the Bonn Agreement to consider authorizing the early deployment to Afghanistan of an international security force, as well as the briefing on 14 December 2001 by the Special Representative of the Secretary-General on his contacts with the Afghan authorities in which they welcome the deployment to Afghanistan of a United Nations authorized international security force,

Taking note of the letter dated 19 December 2001 from Dr. Abdullah Abdullah to the President of the Security Council (S/2001/1223),

Welcoming the letter from the Secretary of State for Foreign and Commonwealth Affairs of the United Kingdom of Great Britain and Northern Ireland to the Secretary-General of 19 December 2001 (S/2001/1217), and taking note of the United Kingdom offer contained therein to take the lead in organizing and commanding an International Security Assistance Force,

Stressing that all Afghan forces must adhere strictly to their obligations under human rights law, including respect for the rights of women, and under international humanitarian law,

Reaffirming its strong commitment to the sovereignty, independence, territorial integrity and national unity of Afghanistan,

Determining that the situation in Afghanistan still constitutes a threat to international peace and security,

Determined to ensure the full implementation of the mandate of the International Security Assistance Force, in consultation with the Afghan Interim Authority established by the Bonn Agreement,

Acting for these reasons under Chapter VII of the Charter of the United Nations, 
1. Authorizes, as envisaged in Annex 1 to the Bonn Agreement, the establishment for 6 months of an International Security Assistance Force to assist the Afghan Interim Authority in the maintenance of security in Kabul and its surrounding areas, so that the Afghan Interim Authority as well as the personnel of the United Nations can operate in a secure environment;

2. Calls upon Member States to contribute personnel, equipment and other resources to the International Security Assistance Force, and invites those Member States to inform the leadership of the Force and the Secretary-General;

3. Authorizes the Member States participating in the International Security Assistance Force to take all necessary measures to fulfil its mandate;

4. Calls upon the International Security Assistance Force to work in close consultation with the Afghan Interim Authority in the implementation of the force mandate, as well as with the Special Representative of the Secretary-General;

5. Calls upon all Afghans to cooperate with the International Security Assistance Force and relevant international governmental and non-governmental organizations, and welcomes the commitment of the parties to the Bonn Agreement to do all within their means and influence to ensure security, including to ensure the safety, security and freedom of movement of all United Nations personnel and all other personnel of international governmental and non-governmental organizations deployed in Afghanistan;

6. Takes note of the pledge made by the Afghan parties to the Bonn Agreement in Annex 1 to that Agreement to withdraw all military units from Kabul, and calls upon them to implement this pledge in cooperation with the International Security Assistance Force;

7. Encourages neighbouring States and other Member States to provide to the International Security Assistance Force such necessary assistance as may be requested, including the provision of overflight clearances and transit;

8. Stresses that the expenses of the International Security Assistance Force will be borne by the participating Member States concerned, requests the Secretary-General to establish a trust fund through which contributions could be channelled to the Member States or operations concerned, and encourages Member States to contribute to such a fund;

9. Requests the leadership of the International Security Assistance Force to provide periodic reports on progress towards the implementation of its mandate through the Secretary-General;

10. Calls on Member States participating in the International Security Assistance Force to provide assistance to help the Afghan Interim Authority in the establishment and training of new Afghan security and armed forces;

11. Decides to remain actively seized of the matter. 


\section{- ANNEX C -}

\section{Agreement on Provisional Arrangements in Afghanistan Pending the Re-Establishment of Permanent Government Institutions (Bonn Agreement)}

The participants in the UN Talks on Afghanistan,

In the presence of the Special Representative of the Secretary-General for Afghanistan,

Determined to end the tragic conflict in Afghanistan and promote national reconciliation, lasting peace, stability and respect for human rights in the country,

Reaffirming the independence, national sovereignty and territorial integrity of Afghanistan,

Acknowledging the right of the people of Afghanistan to freely determine their own political future in accordance with the principles of Islam, democracy, pluralism and social justice,

Expressing their appreciation to the Afghan mujahidin who, over the years, have defended the independence, territorial integrity and national unity of the country and have played a major role in the struggle against terrorism and oppression, and whose sacrifice has now made them both heroes of jihad and champions of peace, stability and reconstruction of their beloved homeland, Afghanistan,

Aware that the unstable situation in Afghanistan requires the implementation of emergency interim arrangements and expressing their deep appreciation to His Excellency Professor Burhanuddin Rabbani for his readiness to transfer power to an interim authority which is to be established pursuant to this agreement,

Recognizing the need to ensure broad representation in these interim arrangements of all segments of the Afghan population, including groups that have not been adequately represented at the UN Talks on Afghanistan,

Noting that these interim arrangements are intended as a first step toward the establishment of a broadbased, gender-sensitive, multi-ethnic and fully representative government, and are not intended to remain in place beyond the specified period of time,

Recognizing that some time may be required for a new Afghan security force to be fully constituted and functional and that therefore other security provisions detailed in Annex I to this agreement must meanwhile be put in place,

Considering that the United Nations, as the internationally recognized impartial institution, has a particularly important role to play, detailed in Annex II to this agreement, in the period prior to the establishment of permanent institutions in Afghanistan,

Have agreed as follows:

\section{THE INTERIM AUTHORITY}

\section{General provisions}

1) An Interim Authority shall be established upon the official transfer of power on 22 December 2001. 
2) The Interim Authority shall consist of an Interim Administration presided over by a Chairman, a Special Independent Commission for the Convening of the Emergency Loya Jirga, and a Supreme Court of Afghanistan, as well as such other courts as may be established by the Interim Administration. The composition, functions and governing procedures for the Interim Administration and the Special Independent Commission are set forth in this agreement.

3) Upon the official transfer of power, the Interim Authority shall be the repository of Afghan sovereignty, with immediate effect. As such, it shall, throughout the interim period, represent Afghanistan in its external relations and shall occupy the seat of Afghanistan at the United Nations and in its specialized agencies, as well as in other international institutions and conferences.

4) An Emergency Loya Jirga shall be convened within six months of the establishment of the Interim Authority. The Emergency Loya Jirga will be opened by His Majesty Mohammed Zaher, the former King of Afghanistan. The Emergency Loya Jirga shall decide on a Transitional Authority, including a broadbased transitional administration, to lead Afghanistan until such time as a fully representative government can be elected through free and fair elections to be held no later than two years from the date of the convening of the Emergency Loya Jirga.

5) The Interim Authority shall cease to exist once the Transitional Authority has been established by the Emergency Loya Jirga.

6) A Constitutional Loya Jirga shall be convened within eighteen months of the establishment of the Transitional Authority, in order to adopt a new constitution for Afghanistan. In order to assist the Constitutional Loya Jirga prepare the proposed Constitution, the Transitional Administration shall, within two months of its commencement and with the assistance of the United Nations, establish a Constitutional Commission.

\section{Legal framework and judicial system}

1) The following legal framework shall be applicable on an interim basis until the adoption of the new Constitution referred to above:

i) The Constitution of 1964, a/ to the extent that its provisions are not inconsistent with those contained in this agreement, and $b$ / with the exception of those provisions relating to the monarchy and to the executive and legislative bodies provided in the Constitution; and

ii) existing laws and regulations, to the extent that they are not inconsistent with this agreement or with international legal obligations to which Afghanistan is a party, or with those applicable provisions contained in the Constitution of 1964, provided that the Interim Authority shall have the power to repeal or amend those laws and regulations.

2) The judicial power of Afghanistan shall be independent and shall be vested in a Supreme Court of Afghanistan, and such other courts as may be established by the Interim Administration. The Interim Administration shall establish, with the assistance of the United Nations, a Judicial Commission to rebuild the domestic justice system in accordance with Islamic principles, international standards, the rule of law and Afghan legal traditions.

\section{Interim Administration}

\section{A Composition}

1) The Interim Administration shall be composed of a Chairman, five Vice Chairmen and 24 other members. Each member, except the Chairman, may head a department of the Interim Administration. 
2) The participants in the UN Talks on Afghanistan have invited His Majesty Mohammed Zaher, the former King of Afghanistan, to chair the Interim Administration. His Majesty has indicated that he would prefer that a suitable candidate acceptable to the participants be selected as the Chair of the Interim Administration.

3) The Chairman, the Vice Chairmen and other members of the Interim Administration have been selected by the participants in the UN Talks on Afghanistan, as listed in Annex IV to this agreement. The selection has been made on the basis of professional competence and personal integrity from lists submitted by the participants in the UN Talks, with due regard to the ethnic, geographic and religious composition of Afghanistan and to the importance of the participation of women.

4) No person serving as a member of the Interim Administration may simultaneously hold membership of the Special Independent Commission for the Convening of the Emergency Loya Jirga.

\section{B. Procedures}

1) The Chairman of the Interim Administration, or in his/her absence one of the Vice Chairmen, shall call and chair meetings and propose the agenda for these meetings.

2) The Interim Administration shall endeavour to reach its decisions by consensus. In order for any decision to be taken, at least 22 members must be in attendance. If a vote becomes necessary, decisions shall be taken by a majority of the members present and voting, unless otherwise stipulated in this agreement. The Chairman shall cast the deciding vote in the event that the members are divided equally.

\section{Functions}

1) The Interim Administration shall be entrusted with the day-to-day conduct of the affairs of state, and shall have the right to issue decrees for the peace, order and good government of Afghanistan.

2) The Chairman of the Interim Administration or, in his/her absence, one of the Vice Chairmen, shall represent the Interim Administration as appropriate.

3) Those members responsible for the administration of individual departments shall also be responsible for implementing the policies of the Interim Administration within their areas of responsibility.

4) Upon the official transfer of power, the Interim Administration shall have full jurisdiction over the printing and delivery of the national currency and special drawing rights from international financial institutions. The Interim Administration shall establish, with the assistance of the United Nations, a Central Bank of Afghanistan that will regulate the money supply of the country through transparent and accountable procedures.

5) The Interim Administration shall establish, with the assistance of the United Nations, an independent Civil Service Commission to provide the Interim Authority and the future Transitional Authority with shortlists of candidates for key posts in the administrative departments, as well as those of governors and uluswals, in order to ensure their competence and integrity.

6) The Interim Administration shall, with the assistance of the United Nations, establish an independent Human Rights Commission, whose responsibilities will include human rights monitoring, investigation of violations of human rights, and development of domestic human rights institutions. The Interim Administration may, with the assistance of the United Nations, also establish any other commissions to review matters not covered in this agreement. 
7) The members of the Interim Administration shall abide by a Code of Conduct elaborated in accordance with international standards.

8) Failure by a member of the Interim Administration to abide by the provisions of the Code of Conduct shall lead to his/her suspension from that body. The decision to suspend a member shall be taken by a twothirds majority of the membership of the Interim Administration on the proposal of its Chairman or any of its Vice Chairmen.

9) The functions and powers of members of the Interim Administration will be further elaborated, as appropriate, with the assistance of the United Nations.

\section{The Special Independent Commission for the Convening of the Emergency Loya Jirga}

1) The Special Independent Commission for the Convening of the Emergency Loya Jirga shall be established within one month of the establishment of the Interim Authority. The Special Independent Commission will consist of twenty-one members, a number of whom should have expertise in constitutional or customary law. The members will be selected from lists of candidates submitted by participants in the UN Talks on Afghanistan as well as Afghan professional and civil society groups. The United Nations will assist with the establishment and functioning of the commission and of a substantial secretariat.

2) The Special Independent Commission will have the final authority for determining the procedures for and the number of people who will participate in the Emergency Loya Jirga. The Special Independent Commission will draft rules and procedures specifying (i) criteria for allocation of seats to the settled and nomadic population residing in the country; (ii) criteria for allocation of seats to the Afghan refugees living in Iran, Pakistan, and elsewhere, and Afghans from the diaspora; (iii) criteria for inclusion of civil society organizations and prominent individuals, including Islamic scholars, intellectuals, and traders, both within the country and in the diaspora. The Special Independent Commission will ensure that due attention is paid to the representation in the Emergency Loya Jirga of a significant number of women as well as all other segments of the Afghan population.

3) The Special Independent Commission will publish and disseminate the rules and procedures for the convening of the Emergency Loya Jirga at least ten weeks before the Emergency Loya Jirga convenes, together with the date for its commencement and its suggested location and duration.

4) The Special Independent Commission will adopt and implement procedures for monitoring the process of nomination of individuals to the Emergency Loya Jirga to ensure that the process of indirect election or selection is transparent and fair. To pre-empt conflict over nominations, the Special Independent Commission will specify mechanisms for filing of grievances and rules for arbitration of disputes.

5) The Emergency Loya Jirga will elect a Head of the State for the Transitional Administration and will approve proposals for the structure and key personnel of the Transitional Administration.

\section{V.Final provisions}

1) Upon the official transfer of power, all mujahidin, Afghan armed forces and armed groups in the country shall come under the command and control of the Interim Authority, and be reorganized according to the requirements of the new Afghan security and armed forces. 
2) The Interim Authority and the Emergency Loya Jirga shall act in accordance with basic principles and provisions contained in international instruments on human rights and international humanitarian law to which Afghanistan is a party.

3) The Interim Authority shall cooperate with the international community in the fight against terrorism, drugs and organized crime. It shall commit itself to respect international law and maintain peaceful and friendly relations with neighbouring countries and the rest of the international community.

4) The Interim Authority and the Special Independent Commission for the Convening of the Emergency Loya Jirga will ensure the participation of women as well as the equitable representation of all ethnic and religious communities in the Interim Administration and the Emergency Loya Jirga.

5) All actions taken by the Interim Authority shall be consistent with Security Council resolution 1378 (14 November 2001) and other relevant Security Council resolutions relating to Afghanistan.

6) Rules of procedure for the organs established under the Interim Authority will be elaborated as appropriate with the assistance of the United Nations.

This agreement, of which the annexes constitute an integral part, done in Bonn on this 5th day of December 2001 in the English language, shall be the authentic text, in a single copy which shall remain deposited in the archives of the United Nations. Official texts shall be provided in Dari and Pashto, and such other languages as the Special Representative of the Secretary-General may designate. The Special Representative of the Secretary-General shall send certified copies in English, Dari and Pashto to each of the participants.

\section{For the participants in the UN Talks on Afghanistan:}

Ms. Amena Afzali

Mr. S. Hussain Anwari

Mr. Hedayat Amin Arsala

Mr. Sayed Hamed Gailani

Mr. Rahmatullah Mousa Ghazi

Eng. Abdul Hakim

Mr. Houmayoun Jareer

Mr. Abbas Karimi

Mr. Mustafa Kazimi

Dr. Azizullah Ludin

Mr. Ahmad Wali Massoud

Mr. Hafizullah Asif Mohseni

Prof. Mohammad Ishaq Nadiri

Mr. Mohammad Natiqi 
Mr. Aref Noorzay

Mr. Yunus Qanooni

Dr. Zalmai Rassoul

Mr. H. Mirwais Sadeq

Dr. Mohammad Jalil Shams

Prof. Abdul Sattar Sirat

Mr. Humayun Tandar

Mrs. Sima Wali

General Abdul Rahim Wardak

Mr. Azizullah Wasefi

Mr. Pacha Khan Zadran

Witnessed for the United Nations by:

Mr. Lakhdar Brahimi

Special Representative of the Secretary-General for Afghanistan

ANNEX I [TO THE AGREEMENT]

INTERNATIONAL SECURITY FORCE

1. The participants in the UN Talks on Afghanistan recognize that the responsibility for providing security and law and order throughout the country resides with the Afghans themselves. To this end, they pledge their commitment to do all within their means and influence to ensure such security, including for all United Nations and other personnel of international governmental and non-governmental organizations deployed in Afghanistan.

2. With this objective in mind, the participants request the assistance of the international community in helping the new Afghan authorities in the establishment and training of new Afghan security and armed forces.

3. Conscious that some time may be required for the new Afghan security and armed forces to be fully constituted and functioning, the participants in the UN Talks on Afghanistan request the United Nations Security Council to consider authorizing the early deployment to Afghanistan of a United Nations mandated force. This force will assist in the maintenance of security for Kabul and its surrounding areas. Such a force could, as appropriate, be progressively expanded to other urban centres and other areas.

4. The participants in the UN Talks on Afghanistan pledge to withdraw all military units from Kabul and other urban centers or other areas in which the UN mandated force is deployed. It would also be desirable if such a force were to assist in the rehabilitation of Afghanistan's infrastructure. 


\section{ANNEX II [TO THE AGREEMENT]}

\section{ROLE OF THE UNITED NATIONS DURING THE INTERIM PERIOD}

1. The Special Representative of the Secretary-General will be responsible for all aspects of the United Nations' work in Afghanistan.

2. The Special Representative shall monitor and assist in the implementation of all aspects of this agreement.

3. The United Nations shall advise the Interim Authority in establishing a politically neutral environment conducive to the holding of the Emergency Loya Jirga in free and fair conditions. The United Nations shall pay special attention to the conduct of those bodies and administrative departments which could directly influence the convening and outcome of the Emergency Loya Jirga.

4. The Special Representative of the Secretary-General or his/her delegate may be invited to attend the meetings of the Interim Administration and the Special Independent Commission on the Convening of the Emergency Loya Jirga.

5. If for whatever reason the Interim Administration or the Special Independent Commission were actively prevented from meeting or unable to reach a decision on a matter related to the convening of the Emergency Loya Jirga, the Special Representative of the Secretary-General shall, taking into account the views expressed in the Interim Administration or in the Special Independent Commission, use his/her good offices with a view to facilitating a resolution to the impasse or a decision.

6. The United Nations shall have the right to investigate human rights violations and, where necessary, recommend corrective action. It will also be responsible for the development and implementation of a programme of human rights education to promote respect for and understanding of human rights.

\section{ANNEX III [TO THE AGREEMENT]}

\section{REQUEST TO THE UNITED NATIONS BY THE PARTICIPANTS AT THE UN TALKS ON AFGHANISTAN}

The participants in the UN Talks on Afghanistan hereby

1. Request that the United Nations and the international community take the necessary measures to guarantee the national sovereignty, territorial integrity and unity of Afghanistan as well as the noninterference by foreign countries in Afghanistan's internal affairs;

2. Urge the United Nations, the international community, particularly donor countries and multilateral institutions, to reaffirm, strengthen and implement their commitment to assist with the rehabilitation, recovery and reconstruction of Afghanistan, in coordination with the Interim Authority;

3. Request the United Nations to conduct as soon as possible (i) a registration of voters in advance of the general elections that will be held upon the adoption of the new constitution by the constitutional Loya Jirga and (ii) a census of the population of Afghanistan. 
4. Urge the United Nations and the international community, in recognition of the heroic role played by the mujahidin in protecting the independence of Afghanistan and the dignity of its people, to take the necessary measures, in coordination with the Interim Authority, to assist in the reintegration of the mujahidin into the new Afghan security and armed forces;

5. Invite the United Nations and the international community to create a fund to assist the families and other dependents of martyrs and victims of the war, as well as the war disabled;

6. Strongly urge that the United Nations, the international community and regional organizations cooperate with the Interim Authority to combat international terrorism, cultivation and trafficking of illicit drugs and provide Afghan farmers with financial, material and technical resources for alternative crop production.

ANNEX IV[TO THE AGREEMENT]

\section{COMPOSITION OF THE INTERIM ADMINISTRATION}

Chairman: Mr. Hamid Karzai

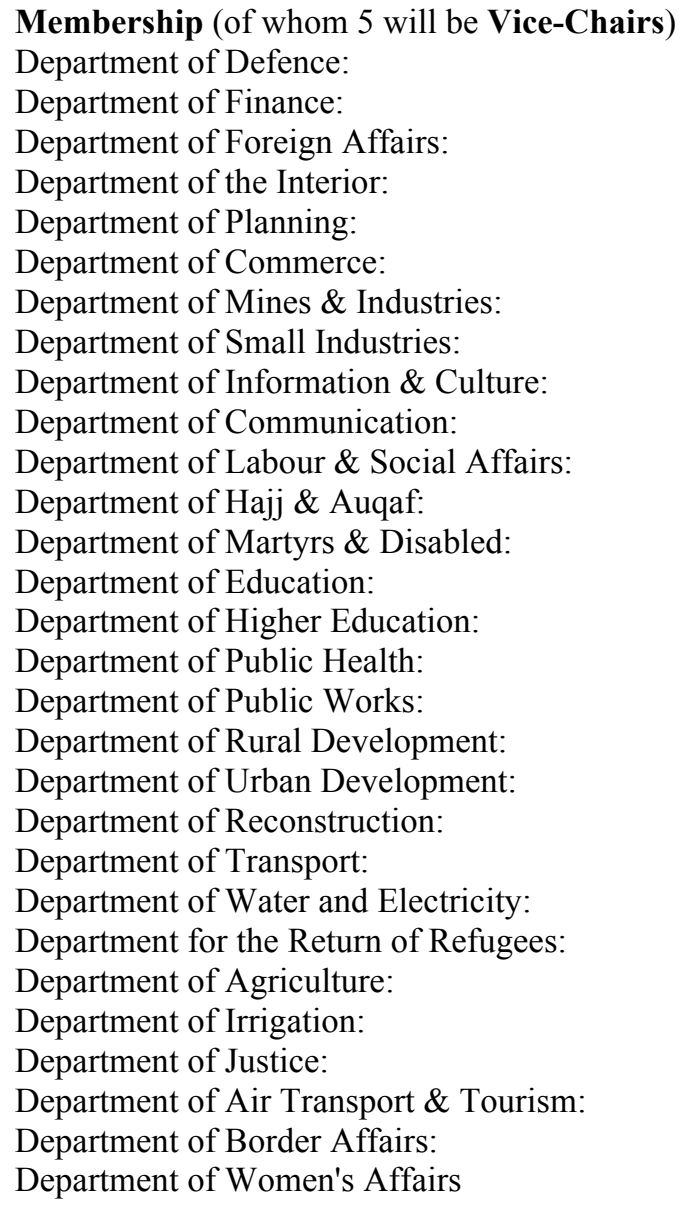




\section{- ANNEX D - \\ General Research Information}

1. Checklist Information.

a. $\quad$ Project Title. Nation-Building with Soft Power: International Radio Broadcasting and the Promotion of Democracy in Failed and Failing States

b. $\quad$ Principal Investigator. David T. Harmes, Ryerson University

c. $\quad$ Project Dates. 01 April 2009 - 31 Aug 2009

d. Type of Data. In-depth interviews.

e. Type of Subjects. Adult employees and former employees of International Radio Broadcast stations.

f. Discussion Topics: broadcast objectives; target markets; programming and/or messages; media; and metrics and/or effects.

2. Interviewee Information.
a. Name:
b. Position:
c. Organization:
d. $\quad$ Contact Information (optional):
e. Interviewee Consent:

3. Contact Information.

a. Principal Investigator: david_harmes@yahoo.com

b. $\quad$ Ryerson University Ethics Review Board: (416) 416-979-5042 
$4 \quad$ Data Management Information.

a. Date of Interview:

b. Location of Interview:

c. Name of Data File:

d. Location of Data File: 


\section{- ANNEX E - \\ Research Interview Guide}

1. General Questions. Describe your role in the organization? What do you do? How long have you being doing it? Did you have any previous training and/or experience?

2. Mission; Broadcast Objective(s). How do you understand the purpose of this radio station? Are there broadcast objectives described anywhere? Is there a formal mission statement? How are the broadcast objectives communicated? Is there a desired end-state / exit strategy in place?

3. Market; Context; Audience(s). Who is the target audience for? How would you describe the broadcast market / context / information environment into which the station is broadcasting? How would you describe the listening habits / media usage practices of the target audience?

4. Themes; Messages; Programming. Is there an overall theme of message being communicated to the audience? What message(s) do you see being communicated? How is it / are they communicated? How do you think such a message is being received? Is there any testing? Pre-testing?

5. IRB Information. Can you describe the organizational structural of the radio station? Is there a weekly routine / standard procedures that are used in its operation? What is the method of delivery $(\mathrm{AM} / \mathrm{FM} / \mathrm{SW})$ ? Audience reach? Is there any additional cross-media marketing? How is all of this funded?

6. Feedback; Metrics; Effects. Does the station receive much feedback on its programming? Is the station achieving its desired outcomes? What is the method of analysis used? Is the research / data publicly availability?

7. Summary Questions. Is there anything we haven't discussed that you feel is important to understand IRBs? Is there any documentation that could help out in this analysis (job descriptions, operating procedures, audience analysis, etc.)? 


\section{- REFERENCES -}

Achakzai, M. (2010, August 4). Don't kill civilians, Taliban code urges: Battle ramps up for Afghan 'hearts and minds'. The Toronto Star, p. A19.

Afghan Center for Socio-Economic and Opinion Research. (2008). Public Opinion in Afghanistan. Washington, DC: ACSOR Surveys.

Alexandre, L. (1987). In the Service of the State: Public Diplomacy, Government Media, and Ronald Reagan. Media, Culture, and Society. London: Sage. Vol. 9, p. 29-46.

Alhassan, A. (2005). Market valorization in broadcasting policy in Ghana: abandoning the quest for media democratization. Media, Culture \& Society. London: Sage Publications. Vol. 27(2), p. 211-228.

Almond, G. \& Verba, S. (1989). The Civic Culture: Political Attitudes and Democracy in Five Nations.

London, UK: Sage Publications, Inc.

Altai Consulting. (2010). Afghan Media in 2010: Priority District Report, Kandahar City. Altai Consulting.

Altai Consulting. (2005). Afghan Media - Three Years After: Media and Alternative Sources of Information in Afghan Society. Nationwide Media Evaluation Project, Altai Consulting.

Andreasen, A. (1995). Marketing social change: Changing behavior to promote health, social development, and the environment. Washington, DC: Jossey-Mass.

Anderson, B. (1991). Imagined Communities: Reflections on the Origin and Spread of Nationalism. New York, NY: Verso.

Ang, I. (1985). Watching Dallas: Soap Opera and the Melodramatic Imagination. Metheun \& Co. Ltd.

Appadurai, A. (2002). Here and Now. In N. Mirzoeff (Ed.), The Visual Cultural Reader (2nd ed., pp. 1739). London and New York: Routledge. (Reprinted from Modernity at Large, 1996)

Armistead, L. (2004). Information Operations: Warfare and the Hard Reality of Soft Power. Washington, DC: Brassey's Inc.

Armstrong, M. (2010). An Opportunity to Demilitarize Public Diplomacy. Atlantic Council. Retrieved from www.acus.org.

Arrighi, G. (2002). Global Capitalism and the Persistence of the North-South Divide. Science \& Society, $65,469-476$.

Asia Foundation, The. (2006). Afghanistan in 2006: A Survey of the Afghan People. San Francisco, CA: The Asia Foundation. Retrieved from www.asiafoundation.org.

Associated Press. (2006, December 8). Afghans are starting to lose hope, poll shows. The Toronto Star, p. A12.

Associated Press. (2010, July 29). Taliban stymie NATO push to bolster government. Boston Herald. Retrieved form: http://www.bostonherald.com

Ayub, F., \& Kouvo, S. (2008). Righting the Course? Humanitarian Intervention, the War on Terror, and the future of Afghanistan. International Affairs, 84(4), 641-657. 
Bagdikian, B. (1992). The Media Monopoly (4th ed.). Boston: Beacon Press.

Bah, U. (2008). Daniel Lerner, Cold War Propaganda and US Development Communication Research: An Historical Critique. Journal of Third World Studies. Vol. XXV, No 1.

Baker, R. O. (2006).The Decisive Weapon: A Brigade Combat Team Commander's Perspective in Information Operations. Military Review, May - June.

Barker, M. (2008). Democracy or polyarchy? US-funded media developments in Afghanistan and Iraq post 9/11. Media, Culture \& Society, 30(1), 109-130.

BBC News. (2010). Afghanistan Timeline. Retrieved from: http://news.bbc.co.uk/2/hi/1162108.stm

BBC News. (2010, May 26). Inter-Korean Crisis: Propaganda Fight. BBC News Online.

BBC World Service Trust. (2003). The Current State of Broadcast Media in Iraq. Report. 31 July 2003.

Bernays, E. (1928). Propaganda. New York, NY: Horace Liveright.

Boyd-Barrett, O. (1977). Media Imperialism. In Curran et al. (Eds.), Mass Communication and Society (pp. 116-35). London: Edward Arnold.

Boyd-Barrett, O. (1982). Cultural Dependency and the Mass Media. In M. Gurevitch et al. (Eds.), Culture, Society and the Media (pp. 174-95). London: Methuen.

Boyd-Barrett, O. (2003). Imperial News and the New Imperialism. Third World Resurgence. June 2003.

Brittan, S. (2002, April 11). Liberal imperialism is a dangerous temptation. Financial Times.

Broadcasting Board of Governors (2002). Marrying the Mission to the Market. Strategic Plan 2002 - 2007.

Brockes, E. (2001, October 23). A long way from Ambridge. The Guardian, p. 2 (G2). Retrieved from: www.gardian.co.uk

Burnham, P., Gilland, K., Grant, W., \& Layton-Henery, Z. (2004). Research Methods in Politics. New York, NY: Palgrave MacMillan.

Caan, C. \& Worden, S. (2007). Rebuilding Civil Society in Afghanistan: Fragile Progress and Formidable Obstacles. United States Institute of Peace. Retrieved from www.usip.org

Call, C., \& Cook, S. (2003). On Democratization and Peacebuilding. Global Governance 9, p. 233-46.

Canadian Broadcasting Corporation. (2010). Our Voice to the World: 60 Years of RCI. CBC Digital

Archives. Retrieved from http://archives.cbc.ca/arts_entertainment/media/topics/1598-10979/

Canadian Press, The. (2007, January 3). Canadian based radio station about to hit airwaves in Kandahar city. Canadian Press.

Carey, A. (1997). Taking the Risk Out of Democracy: Corporate Propaganda Versus Freedom and Liberty. Urbana: University of Illinois Press.

Carey, J. (1969). The Communication Revolution and the Professional Communicator. In P. Halmos (Ed.), The Sociology of Mass Media Communicators (pp. 23-38). Keele: University of Keele.

Chai-Anan, S. (1991). The Three-Dimensional State. Rethinking Third World Politics. London, New York: Longman. 
Chomsky, N. (1984). The Manufacture of Consent. In J. Peck (Ed.), The Chomsky Reader (pp. 121-36). New York, Toronto: Pantheon Books.

Chomsky, N. (1989). Necessary Illusions: Thought Control in Democratic Societies. Concord, Ontario: Anansi Press.

Chomsky, N. (2003). Hegemony or Survival: America's Quest for Global Dominance. Metropolitan Books.

Cmiel, K. (1996). On Cynicism, Evil, and the Discovery of Communication in the 1940s. Journal of Communication. Summer 46(3):88-107.

Cole, J. R. (2006). The Ayatollahs and Democracy in Iraq, Amsterdam: Amsterdam University Press.

Conner, W. (1972). Ethnonationalism: The Quest for Understanding. Princeton: Princeton University Press.

Cowan-Shulman, H. (1990). The Voice of America: Propaganda and Democracy, 1941-1945. Madison, Wisconsin: University of Wisconsin Press.

Cox, R. (1995). Critical Political Economy. In B. Hettne (Ed.), International Political Economy:

Understanding Global Disorder (pp. 31-45). Halifax, NS: Fernwood Publishing.

Coyne, C. J. (2005). The Institutional Prerequisites for Post-Conflict Reconstruction. George Mason University, Fairfax, VA.

Cull, N. J. (2009). Public Diplomacy before Gullion: The Evolution of a Phrase. In N. Snow \& P. Taylor (Eds.), Routledge Handbook of Public Diplomacy. New York and London: Routledge.

Djerejian, E. P. (Chair). (2003). Changing Minds, Winning Peace: A New Strategic Direction for U.S. Public Diplomacy in the Arab \& Muslim world. Report of the Advisory Group on Public Diplomacy for the Arab and Muslim World. Washington, DC (available at: http://bakerinstitute.org/programs/public-diplomacy).

Doob, L. (1950). Gobbles' Principles of Propaganda. In R. Jackall. (1995). Propaganda (pp. 190-216). New York: New York University Press.

Dos Santos, T. (1971). The Structure of Dependence, in K. T. Fann \& D. C. Hodges (Eds.), Readings in U.S. Imperialism. Boston: Porter Sargent.

Dunne, T. (2001). Liberalism. In J. Baylis, \& Smith, S. (Eds.), The Globalization of World Politics: An Introduction to International Relations (2nd ed.). Oxford University Press.

Dunne, T. \& Schmidt, B.C. (2001). Realism. In J. Baylis, \& Smith, S. (Eds.), The Globalization of World Politics: An Introduction to International Relations (2nd ed.). Oxford University Press.

Dutta-Bergman, M. J. (2006). US Public Diplomacy in the Middle East: A Critical Cultural Approach. Journal of Communication Inquiry. Vol. 30(2), p. 102-124. London: Sage.

Economist, The. (2010, August 14). International Broadcasters 'Waves in the Web': Western state-backed news outfits are struggling to keep their influence in the developing world. The Economist. Vol. 396, Number 8695.

Ellul, Jacques. (1965). Propaganda: The formation of men's attitudes. New York: Random House.

Fair, L.E. (1989). "29 Years of Theory and Research on Media and Development: The Dominant Paradigm Impact”. Gazette, 44, 129-50. 
Fanon, F. (1961). The Wretched of the Earth. New York, NY: Grove Press.

Finnie, A.K. (1996). Radio Canada International 1945-1995. Montreal, Quebec: Radio Canada International.

Fisk, J. (1990). Introduction to Communication Studies (2nd ed.). London and New York: Routledge.

Fukuyama, F. (Ed.). (2006). Nation-Building: Beyond Afghanistan and Iraq. Baltimore: Johns Hopkins University Press.

Garnham, N. (1990). Capitalism and Communication: Global Culture and the Economics of Information. London: Sage.

Gedda, G. (2002, November). Radio Sawa: Music as a Tool. Foreign Service Journal (pp. 53-6).

Gills, B. (2000). American Power, Neo-Liberal Economic Globalization, and Low-Intensity Democracy: An Unstable Trinity. In M. Cox, G. Ikenberry \& T. Inoguchi (Eds.), American Power, Neo-Liberal Economic Globalization, and Low-Intensity Democracy: An Unstable Trinity (pp. 326-44). Oxford: Oxford University Press.

Golding, P. \& Murdock, G. (1991). Culture, Communication, and Political Economy. In J. Curran \& M. Gurevitch (Eds.), Mass Media and Society (pp. 15-32). London: Edward Arnold.

Government of Canada. (2005). Canada's International Policy Statement: A Role of Pride and Influence in the World. Ottawa: Government of Canada.

Grare, F. (2006). Pakistan-Afghanistan Relations in the Post-9/11 Era (South Asia Project). Washington, DC: Carnegie Endowment for International Peace. Retrieved from www.carnegieendowment.org.

Grovogui, S. (2007). Postcolonialism. In Dunne, Kurki, \& Smith (Eds.). International Relations Theories: Discipline and Diversity (pp. 229-246). Oxford: Oxford University Press.

GTZ (2006). Strategic Communication for Sustainable Development: A Conceptual Overview. Bonn, Germany: GTZ Rioplus. Retrieved from www.gtz.de.

Hackett, R. A., \& Carroll, W. K. (2006). Remaking Media: The Struggle to Democratize Public Communication. New York; London: Routledge.

Hall, J. L. (1997). Radio Canada International: Voice of a Middle Power. East Lansing, MI: Michigan State University Press.

Hallin, D. (1994). We Keep America on Top of the World. New York: Routledge.

Hancocks, P. (2010, May 9). Afghanistan's last Jew vows to stay put. CNN World. Retrieved from http://www.cnn.com.

Hardt, H. (1992). Critical Communication Studies: Communication, History and Theory in America. London and New York: Routledge.

Hardt, M. \& Negri, A. (2000). Empire. Cambridge, MA: Harvard University Press.

Harmes, A. (2004). The Return of the State: Protesters, Power-Brokers, and New Global Compromise. Toronto: Douglas \& McIntyre. 
Harpviken, K., Strand, A., \& Ask, K. (2002). Afghanistan and Civil Society. Report commissioned by the Norwegian Ministry of Foreign Affairs.

Heiberg, M. (1994). Subduing Sovereignty: Sovereignty and the Right to Intervene. London: Printer Publishers

Heil Jr., A. L. (2003). Voice of America: A History. New York: Columbia University Press.

Herman, E. S. \& Chomsky, N. (1988) Manufacturing Consent: The Political Economy of the Mass Media. New York: Pantheon Books.

Herman, E. S. \& McChesney, R.W. (1997). The Global Media: The New Missionaries of Corporate Capitalism. London and Washington: Cassell.

Herman, E. S. (2003). The Propaganda Model: A Retrospective. Against All Reason: Propaganda, Politics, Power. Vol 1: 1-14, 09 December 2003.

Hoffmann, S. (1996). The Ethics and Politics of Humanitarian Intervention. Indiana: University of Notre Dame Press.

Hohe, T. (2005). Developing Local Governance. In Junne, G. \& Verkoren, W. (Eds.). (2005). Postconflict Development: Meeting New Challenges (pp. 59-72). London: Lynne Rienner Publishers.

Holbrooke, R. (2002, April 01). "Rebuilding Nations...”, Washington Post.

Howell, J., \& Lind, J. (2009). Manufacturing Civil Society and the Limits of Legitimacy: Aid, Security and Civil Society after 9/11 in Afghanistan. European Journal of Development Research, 21, 718-736.

Human Security Centre. (2005). Human Security Report 2005. Oxford: Oxford University Press.

Huntington, S. (1968). Political Order in Changing Societies. New Haven, CT. Yale University Press.

Ignatieff, M. (2002, July 28). Nation-Building Lite. New York Times Magazine.

Ignatieff, M. (2003). Empire Lite: Nation-Building in Bosnia, Kosovo, and Afghanistan. Toronto: Penguin Books.

Independent Panel on Canada's Future Role in Afghanistan. (2008). Final Report. Public Works and Government Services Canada.

International Commission on Intervention and State Sovereignty - ICISS (2001). The Responsibility to Protect: Report of the International Commission on Intervention and State Sovereignty. Ottawa, ON: International Development Research Centre.

Internews (2009). Afghanistan's Media Milestone: A Report by Internews Network. Arcata, CA: Internews Network Administrative Headquarters. Retrieved from www.internews.org.

ISAF (2009, August 30). Commander's Initial Assessment. Kabul, Afghanistan: International Security Assistance Force.

Joint Assistance Mission. (1999). Report of the Joint assistance Mission to East Timor. Retrieved from: http://pascal.iseg.utl.pt/ cesa/jamsummarytablefinal.pdf.

Jowett. G.S. \& O’Donnell, V. (1999). Propaganda and Persuasion (3rd ed.). London: Sage Publications.

Jowett, G. S. \& O'Donnell, V. (2005). Propaganda and Persuasion (4th ed.). Newbury Park, CA: Sage

Publications, Inc. 
Junne, G. \& Verkoren, W. (Eds.). (2005). Postconflict Development: Meeting New Challenges. London: Lynne Rienner Publishers.

Kamali, M. (2001). Civil Society and Islam: A Sociological Perspective. Archives of European Sociology, 42(3), 457-482.

Katz, E. \& Lazarsfeld, P. (1955). Personal Influence: The Part Played by People in the Flow of Mass Communication. New Jersey: Transaction Publishers.

Kilbane, M. (2009). Military Psychological Operations as Public Diplomacy. In N. Snow \& P. Taylor (Eds.), Routledge Handbook of Public Diplomacy (pp. 187-192). New York and London: Routledge.

Kolsto, P. (2000). Political construction sites: Nation-building in Russia and the post-Soviet States. Ch. 2 Nation-Building and Social Integration Theory. Boulder, Colorado: Westview Press.

Krause, K. \& Jutersonke, O. (2005). Peace, Security and Development in Post-Conflict Environments. Security Dialogue. 36(4), 447-462.

Krulak, C., C. (1999, January). The Strategic Corporal: Leadership in the Three Block War. Marines Magazine.

Lamy, S.T. (2001). Contemporary Mainstream Approaches: Neo-Realism and Neo-Liberalism. In J. Baylis, $\&$ Smith, S. (Eds.), The Globalization of World Politics: An Introduction to International Relations (2nd ed.). Oxford University Press.

Lasswell, H. D. (1934). Propaganda, in R. Jackall. (1995). Propaganda, p. 13-25. New York: New York University Press.

Laswell, H. D. (1948). The Structure and Function of Communication in Society. In L. Bryson (Ed.), The Communication of Ideas (pp. 37-51). New York: Harper.

Lee, I. (1904). Statement of Principles.

Lemay, J.M.C. (2009). The 'Operationalization' of Canadian Public Diplomacy in the $21^{\text {st }}$ Century: The Importance of Properly Understanding the Communication Strategy. Canadian Army Journal. Vol. 12.1.

Lerner, D. (1958). The Passing of Traditional Society: Modernizing the Middle East. New York, NY: Macmillan Publishing.

Lerner, D. (2001). Notes on Communication and the Nation State (pp 541-550).

Lippmann, W. (1922). Public Opinion. Free Press.

List, D. (2006). A Quick Guide to Audience Research. Wellington, New Zealand: Original Books.

LSE (2009). What is Civil Society? Centre for Civil Society, The London School of Economics and Political Science. Retrieved from www.lse.ac.uk

Lugo, L.E. (1996). Sovereignty at the Crossroads? Morality and International Politics in the Post-Cold War Era. Maryland: Rowman and Littlefield

MacBride, S. (1980). Many Voices, One World: Report of the International Study Commission on Communication Problems. Paris: UNESCO. 
Macnamara, J.R (2003). Mass Media Effects: A Review of 50 Years of Media Effects Research. Chippendale, Australia: CARMA International.

Maple Leaf, The. (2007, January 31). Rana FM hits the airwaves in Kandahar. Ottawa: Canadian Forces

Martin, L. (2007). Neoliberalism. In Dunne, Kurki, \& Smith (Eds.). International Relations Theories:

Discipline and Diversity (pp. 109-126). Oxford: Oxford University Press.

Martinussen, J. (1997). Society, State \& Market: A Guide to Competing Theories of Development. Halifax, Nova Scotia: Fernwood Publishing.

Mattelart, A. (1994). Mapping World Communication: War, Progress, Culture (S. Emanuel \& J. A. Cohen, Trans.). Minneapolis, MN: University of Minnesota Press.

Mattelart, A. \& Mattelart, M. (1992). Rethinking Media Theory: Signposts and New Directions (J. A. Cohen \& M. Urquidi, Trans.). Minneapolis, MN: University of Minnesota Press.

Mazepa, P. (2011). Direct from the Source: Canada's Integrated System of State Propaganda. In G.

Sussman (Ed.), The Propaganda Society: Promotional Culture and Politics in Global Context (pp. 297-

313). New York, NY: Peter Lang Publishing, Inc.

Mazzetti, M. \& Schmitt, E. (2008, October 9). Afghanistan in a 'Downward Spiral'. The Toronto Star, p. A4.

McCarthy, S. (2008, June 19). Pipeline opens new front in Afghan war. The Globe and Mail. Retrieved from http://www.theglobeandmail.com

McChesney, R. W. (2000). Rich media, poor democracy: Communication politics in dubious times. New York, NY: New Press.

McCormack, T. (1961). Social Theory and the Mass Media. Canadian Journal of Economics and Political Science, Vol. 4, p. 479-89.

McCormick Tribune Foundation. (2007). Understanding the Mission of US International Broadcasting. Cantigny Par, Wheaton, Illinois.

McFaul, M. (2004). Democracy Promotion as a World Value. The Washington Quarterly, p. 147-163. Vol. 28, No. 1.

McKenna, F. (2009, September 30). Let's Give Developing Countries the Tools to Help Themselves. The Globe and Mail. Retrieved from http://www.theglobeandmail.com

McNally, D. (2002). Another world is possible: globalization and anti-capitalism. Winnipeg, Arbeiter Ring Publishing

McPhail, T. L. (1987). Electronic colonialism: The future of international broadcasting and communication. Newbury Park, CA: Sage.

McPhail, T. L. (Ed.). (2009). Development Communication: Reframing the Role of the Media. West Sussex, UK: Wiley-Blackwell.

McQuail, D. (1994). Mass Communication Theory (3rd ed.). London: Sage Publications.

Mendelssohn, H. (1966). Mass Entertainment. New Haven, CT: College and University Press. 
Merrill, D. (2006). The Truman Doctrine: Containing Communism and Modernity. Presidential Studies Quarterly. 36(1): 27-37. ISSN 0360-4918 online edition.

Miller, D. (2003, December 29). Information Dominance: The Philosophy of Total Propaganda Control. Scoop. New Zealand: Scoop Media Group.

Mosco, V. (1996). The Political Economy of Communication: Rethinking and Renewal. London: Sage Publications.

Motlagh, J. (2010, Nov 28). Afghan Radio Wars: Combating the Taliban's Message Machine. Time Inc. Retrieved from: http://www.time.com

Mytton, G. \& Forrester, C. (1988). Audiences for International Radio Broadcasters. European Journal of Communication, Vol 3, p.457-81.

National Post. (2008, April 26). Rising from the Abyss? Rwanda Primer. National Post, p. A23.

Nawawy, M. (2006). US Public Diplomacy in the Arab World: The News Credibility of Radio Sawa and Television Alhurra in Five Countries. Global Media and Communication, p. 185-205.Vol 2(2).

Nicholes, J. S. (1984). When Nobody Listens: Assessing the Political Success of Radio Mardi. Communication Research, p. 281-304. Vol. 2. Sage Publications Inc.

Nissen, T. E. (2007). The Taliban's Information Warfare: A Comparative Analysis of NATO Information Operations and Taliban Information Activities. Copenhagen: Royal Danish Defence College.

Nuruzzaman, M. (2009). Revisiting the Category of Fragile and Failed States in International Relations. International Studies, 46(3), 271-294.

Nye, J. (2004). Soft Power: The Means to Success in World Politics. New York, NY: PublicAffairs.

Nye, J. (2010). The New Public Diplomacy. Project Syndicate (available at: http://www.projectsyndicate.org/commentary/nye79/English).

O'Keeffe, A. \& Oliver, A. (2010). International Broadcasting and its Contribution to Public Diplomacy. Lowy Institute for International Policy.

Olechowska, E. (2007). The Age of International Radio: Radio Canada International (1945 - 2007).

Oakville, ON: Mosaic Press.

Ottaway, M. (2002, September). Think Again: Nation Building. Foreign Policy.

Ottaway, M. (2003). Promoting Democracy After Conflict: The Difficult Choices. International Studies Perspectives, p. 314-322. Vol 4.

Park, D. \& Pooley, J. (Eds.). (2008). The History of Media and Communication Research: Contested Memories. New York: Peter Lang.

Perkel, C. (2009, June 8). Is the military misreading Afghans? Strategist says forces should take cue from Taliban to win 'trust and confidence' of local population. The Toronto Star, p. A8.

Pisani, S. (2001, February 7). Ink and radio waves contribute toward the peace. North Atlantic Treaty Organization. SFOR Informer \# 106. Retrieved from http://www.nato.int

Pithouse, R. (2005). Report back from the third world network meeting. Accra: Center for Civil Society. 
Porter, W. \& Mykleby, M. (2011). A National Strategic Narrative. Woodrow Wilson International Center for Scholars. Retrieved from www.wilsoncenter.org

Potter, E. H. (2002). Canada and the New Public Diplomacy. Discussion Papers in Diplomacy. Netherlands Institute of International Relations.

Potter, E. H. (2002). Information Technology and Canada's Public Diplomacy. In E. H. Potter (Ed.) CyberDiplomacy: Managing Foreign Policy in the Twenty-First Century. McGill-Queen's University Press.

Price, M, E. (1995). Television, the Public Sphere, and National Identity. Oxford: Clarendon Press.

Price, M, E. (2002). Media and Sovereignty: The Global Information Revolution and Its Challenge to State Power. Cambridge: MIT Press.

Putnam, Leonardi, \& Nanetti. (1994). Making Democracy Work: Civic Traditions in Modern Italy. Princeton University Press.

Pye, L. (1963). Communications and Political Development. Princeton, NJ: Princeton University Press.

Quarry, W. (2006). Decision Makers Do Want Communication - But They May Not Want Participation. Paper prepared for the World Congress on Communication for Development. 2006.

Radio Canada International. (2007). Radio Canada International: http://www.rcinet.ca/english/about-us/.

Rahman, Tariq. (1995). Pashto Language \& Identity Formation. Contemporary South Asia. July 1995, Vol 4 Issue 2, p. 151-20.

Randall, V., \& Theobald, R. (1985). Political Change and Underdevelopment: A Critical Introduction to Third World Politics. London: Macmillan.

Reporters Without Borders. (2009). Afghanistan: What gains for press freedom from Hamid Karzai's seven years as president? Paris, France: Reporters Without Borders. Retrieved from www.rsf.org

Reuters (2010, June 4). Afghan Jirga to call for peace with Taliban. Reuters.com: http://www.reuters.com/article/idUSTRE65116E20100604

Rieff, D. (2010, August 03). How NGOs Became Pawns in the War on Terror. The New Republic.

Rubin, B. (2006). Peace Building and State Building in Afghanistan: Constructing Sovereignty for whose Security? Third World Quarterly, 27(1), 175-185.

Rudolph, L., \& Rudolph, S. (1967). The Modernity of Tradition: Political Development in India. Chicago, Il: Chicago University Press.

Rogers, E. M. (1962). The Diffusion of Innovations. Glencoe, IL: Free Press.

Rogers, E. (1976). The Passing of the Dominant Paradigm - Reflections on Diffusion Research, in Schramm, D. and Lerner, D. (eds.) Communication and Change: The Last Ten Years - and the Next Ten, p. 49-51.Honolulu: University Press of Hawaii.

Romarheim, A, G. (2005). Definitions of Strategic Political Communication. Norwegian Institute of International Affairs. Oslo.

Sachs, S. (2010, December 14). Outspoken voice of Kabul is getting fainter. The Globe and Mail, p. A20.

Said, E. (1978). Orientalism. 25th Anniversary Edition, Penguin Classics (2003), ISBN 0-141-18742-5. 
Salomons, D. (2005). Security: An Absolute Prerequisite. In G. Junne \& W. Verkoren (Eds.). Postconflict Development: Meeting New Challenges. London, UK: Lynne Rienner Publishers.

Samarajiwa, R. (1987). The Murky beginnings of the communication and development field: Voice of America and The Passing of Traditional Society. In N. Jayaweera \& S. Amunugama (Eds.). Rethinking Development Communication, p. 3-19. Singapore: Asian Mass Communication Research and Information Centre.

Santucci, F. M. (2005). Strategic Communication for Rural Development. Development Communication Division, The World Bank. Retrieved from: www.radiopeaceafrica.org.

Saul, J. R. (2005). The Collapse of Globalism and the Reinvention of the World. New York, NY: Overlook Press.

Schiller, H. I. (1976). Communication and cultural domination. New York, NY: International Arts and Sciences Press.

Schiller, H. I. (1989). Culture, Inc.: The corporate takeover of public expression. New York, NY: Oxford University Press.

Schiller, H. (1991). Not yet the post-imperialist era. Critical Studies in Mass Communication, Vol. 8, p. 1328.

Schlesinger, P. (1989). From production to propaganda. Media, Culture and Society, Vol. 11.

Schramm, D. \& Lerner, D. (Eds.). (1976). Communication and Change: The Last Ten Years - and the Next Ten. Honolulu: University Press of Hawaii.

Schramm, W. (1964). Mass Media and National Development: The Role of Information in the Developing Countries. Palo Alto, CA: Stanford University Press.

Sedra, M. (2002, November 15). Afghanistan: It is time for a Change in the Nation-Building Strategy. Foreign Policy in Focus.

Sedra, M. \& Middlebrook, P. (2004). Lessons in State Building in the Post-September 11 Era. Foreign Policy In Focus. www.fpif.org.

Sen, J. (2010). Interrogating the Civil: Engaging Critically with the Concept of Civil Society. Retrieved from http://p2pfoundation.net

Shannon, C., \& Weaver, W. (1949). The Mathematical Theory of Communication. Illinois: University of Illinois Press.

Shaw, H. (2003). Communication and Nation Building: Comparing US Models of Ethnic Assimilation and Third World Modernization Gazette, Vol. 65, p. 165.

Siegel, A. (1996). Radio Canada International: History and Development. Oakville, ON: Mosaic Press.

Singhhal, A. \& Rogers, E. (1999). Entertainment Education: A Communication Strategy for Social Change. Mahwah, NJ: Lawrence Erlbaum Associates.

Singhhal, A., Cody, M., Rogers, E. \& Sabido, M. (2003). Entertainment Education and Social Change: History, Research, and Practice. Mahwah, NJ: Lawrence Erlbaum Associates. 
Smith, G., \& Koring, P. (2008, March 1). Afghanistan: Facing the Ugly Truth. The Globe and Mail, p. A20-21.

Smith, G. (2008, March 24). Air strikes, war on drugs drive Taliban. The Globe and Mail, p. A1.

Smith, G. (2008, March 28). Talking to the Taliban: Why the Taliban now embrace the concept of suicide bombing. The Globe and Mail, p. A1.

Smith, G. \& Koring, P. (2008, March 1). Afghanistan: Facing the Ugly Truth. The Globe and Mail, p. A2021.

Smythe, D.W. (1981). Dependency Road: Communications, Capitalism, Consciousness and Canada. Norwood, NJ: Ablex.

Snow, N. (2009). Rethinking Public Diplomacy. In N. Snow \& P. Taylor (Eds.), Routledge Handbook of Public Diplomacy (pp. 3-11). New York and London: Routledge.

Snow, N. \& Taylor, P. (2006). The Revival of the Propaganda State: US Propaganda at Home and Abroad since 9/11. International Communication Gazette, Vol. 68, no. 5-6, p. 389-407.

Snow, N. \& Taylor, P. (Eds.). (2009). Routledge Handbook of Public Diplomacy. New York and London: Routledge.

Stavenhagen, R. (1990). The Ethnic Question: Conflicts, Development, and Human Rights. Tokyo: United Nation University Press.

Stevenson, J. (2011, May 9). AFRICOM's Libyan Expedition: How War will change the Command's Role on the Continent. Foreign Affairs. Retrieved from www.foreignaffairs.com

Suhrke, A. (2007). Reconstruction as Modernisation: The 'Post-Conflict' Project in Afghanistan. Third World Quarterly, 28(7), 1291-1308.

Sussman, G. (2010). Branding Democracy: U.S. Regime Change in Post-Soviet Eastern Europe. New York, NY: Peter Lang.

Taylor, P. (2003). Munitions of the Mind: A History of Propaganda from the Ancient World to the Present Day (3rd ed.). Manchester and New York: Manchester University Press.

Taylor, P. (2009). Public Diplomacy and Strategic Communication. In Snow, N. \& Taylor, P. (Eds.). Routledge Handbook of Public Diplomacy. New York and London: Routledge.

Motlagh, J. (2010, Nov 28). Afghan Radio Wars: Combating the Taliban's Message Machine. Time. Retrieved from http://www.time.com/time/world/article/0,8599,2032811,00.html.

Tomlinson, J. (1991). Cultural imperialism: A critical introduction. Baltimore: John Hopkins University Press.

Tuch, H. (1990). Communicating with the World: US Public Diplomacy Overseas. Washington DC: Institute for the Study of Diplomacy, Georgetown University.

United Nations International Emergency Children's Fund (UNICEF). (2005). Strategic Communication for Behaviour and Social Change in South Asia (Working Paper). Kathmandu, Nepal: UNICEF Regional Office for South Asia.

Verma, S. (2011, September 14). Jalaluddin Haqqani - The Real Threat in Afghanistan. The Globe and Mail. Retrieved from www.theglobandmail.com. 
Ward, O. (2007, March 20). Losing Afghan hears, minds: Taliban gains as non-combat efforts fall short, poll finds. The Toronto Star, p. A3.

Wright, C.R. (1960). Functional Analysis and Mass Communication. Public Opinion Quarterly, Vol. 24, p. 606-20.

Woods, A. (2009, May 12). Afghanispam: Canadian military propagandists plan to bombard Afghans' cell phones with texts and contest offers. The Toronto Star, p. A1.

United Nations Assistance Mission to Afghanistan: http://unama.unmissions.org/Default.aspx?tabid=1742

United Nations General Assembly Resolution (UNGAR) 63/308. New York: United Nations.

United Nations Security Council Resolution (UNSCR) 1386. New York: United Nations.

United Nations Security Council Resolution (UNSCR) 1401. New York: United Nations.

United Nations Security Council Resolution (UNSCR) 1662. New York: United Nations.

United Nations Security Council Resolution (UNSCR) 1973. New York: United Nations.

United States Defense Science Board (2004). Final Report of the Task Force on Strategic Communication. United States Department of Defense. Washington, DC.

United States Department of Defense. (Undated). Afghanistan Cultural Field Guide. Cultural Intelligence for Military Operations.

United States Public Law 94-350. Washington, DC: United States of America.

Vidal, D. (2003, December). Reconstructing States: A Guide to Nation-Building. Monde Diplomatique.

Waisbord, S. (2003). State, Development, and Communication. In B. Mody (Ed.). International and

Development Communication: A $21^{\text {st }}$ Century Perspective.

Ward, O. (2007, March 20). Losing Afghan hearts, minds. The Toronto Star, p. A3.

Wesley, M. (2008). The State of the Art on the Art of State Building. Global Governance, 14(3), 369-385.

Whaites, A. (1996). Let's get civil society straight: NGOs and Political Theory. Development in Practice. Retrieved from www.oxfam.org

Whaites, A. (2008). States in Development, Working Paper. United Kingdom Department of International Development; Policy Research Division.

White, L.A. (2001). Reconsidering Cultural Imperialism. Transnational Broadcasting Studies (Archive). Vol: 6 Spring / Summer.

White, R. K. (1952). The New Resistance to International Propaganda. The Public Opinion Quarterly, p. 539-551. Vol. 16: 4. Special Issue on International Communications Research.

Wolfsfeld, G. (1997). Media and Political Conflict. Cambridge, UK: Cambridge University Press.

Wood, J., (1992). History of International Broadcasting. London, UK: P. Peregrinus Ltd. in association with the Science Museum. 
Woods, A. (2009, May 12). Afghanispam: Canadian military propagandists plan to bombard Afghans' cellphones with texts and contest offers. The Toronto Star, p. A1.

Woods, A. (2010, November 23). Canada finances TV cop show in Afghanistan. The Toronto Star. Retrieved from http://www.thestar.com

Zaleski, P. (2006). Global Non-Governmental Administrative System: Geosociology of the Third Sector. In Gawin, Dariusz, \& Glinski (Eds.). Civil Society in the Making. Warszawa: IFiS Publishers.

Zollner, O. (2006). A Quest for Dialogue in International Broadcasting: Germany's Public Diplomacy Targeting Arab Audiences. Global Media and Communication, p. 160-82. Vol. 2 (2). London: Sage Publications. 